\title{
Plant communities in organic and conventional agriculture - comparing local, landscape and regional effects
}

\author{
Dissertation \\ zur Erlangung des Doktorgrades \\ der Fakultät für Agrarwissenschaften \\ der Georg-August-Universität Göttingen
}

vorgelegt von

Doreen Gabriel

geboren in Halle/Saale

Göttingen, Februar 2006 
D 7

1. Referent: Prof. Dr. Teja Tscharntke

2. Korreferentin: Prof. Dr. Bärbel Gerowitt Tag der mündlichen Prüfungen: 03.02.2006 


\section{Contents}

1 General introduction: Plant communities in organic and conventional agriculture - comparing local, landscape and regional effects

Introduction

Study area and design

$\begin{array}{ll}\text { Main questions } & 10\end{array}$

$\begin{array}{ll}\text { Results and conclusions } & 11\end{array}$

2 Local diversity of arable weeds increases with landscape 13 complexity

$\begin{array}{lr}\text { Abstract } & 14 \\ \text { Introduction } & 15 \\ \text { Methods } & 16 \\ \text { Results } & 19 \\ \text { Discussion } & 24\end{array}$

3 Landscape context mediates inter-annual variability in arable 27 weed communities
Abstract
Introduction
29
Methods
Results 33
Discussion

4 Relative importance of beta diversity at different spatial scales - plant communities in organic and conventional agriculture.

$\begin{array}{lr}\text { Abstract } & 43 \\ \text { Introduction } & 44 \\ \text { Methods } & 45 \\ \text { Results } & 50 \\ \text { Discussion } & 54 \\ \text { Appendix } & 59\end{array}$


5 The effects of landscape complexity on arable weed species diversity in organic and conventional farming.

$\begin{array}{ll}\text { Abstract } & 63\end{array}$

Introduction $\quad 64$

$\begin{array}{ll}\text { Methods } & 65\end{array}$

$\begin{array}{ll}\text { Results } & 69\end{array}$

$\begin{array}{ll}\text { Discussion } & 74\end{array}$

$\begin{array}{ll}\text { Appendix } & 78\end{array}$

6 Insect pollinated plants benefit from organic farming. 82

$\begin{array}{lr}\text { Abstract } & 83\end{array}$

Introduction $\quad 84$

Methods $\quad 85$

Results $\quad 86$

Discussion $\quad 89$

Appendix 92

$\begin{array}{lr}\text { References } & 94\end{array}$

$\begin{array}{ll}\text { Summary } & 106\end{array}$

$\begin{array}{lr}\text { Zusammenfassung } & 108\end{array}$

$\begin{array}{lr}\text { Acknowledgements } & 110\end{array}$

$\begin{array}{ll}\text { List of publications } & 112\end{array}$

$\begin{array}{ll}\text { Curriculum vitae } & 113\end{array}$ 
Chapter

1

General introduction:

Plant communities in organic and conventional agriculture - comparing local, landscape and regional effects 


\section{Introduction}

Factors and processes that determine species richness and composition of plant communities operate at a range of different spatial scales. On the one hand, local plant communities depend on local abiotic conditions such as climate and soil properties, and local processes such as competition for light, water and nutrients, predation, adaptation and stochastic variation (Grime 1979, Tilman 1982, Ellenberg 1988). On the other hand, plant communities are also likely to be influenced by processes operating on large spatial scales (Ricklefs 1987, 1989, Turner 1989, Dunning et al. 1992, Huston 1999). According to the species-pool hypothesis, local communities are composed of a subset of the species from the surrounding species pool (Zobel 1997, Lawton 1999). The species pool should be larger in complex than in simple agricultural landscapes because complex landscapes harbour a variety of different semi-natural habitats, such as grasslands, hedges, fallows, and field margins. In addition, complex landscapes are often characterised by a heterogeneous topography containing more species due to a larger diversity of spatial niches and a larger area per se (Burnett et al. 1998, Nichols et al. 1998). The immigration of species into local sites should be enhanced in such landscapes (Ricklefs 1987) and thus, local plant species richness should be higher in complex than in simple landscapes. However, the landscape approach has received limited attention in plant ecology (de Blois et al. 2002).

Crop fields represent one of the most anthropogenically impacted systems characterised by annual soil cultivation, harvest of crops, and crop rotation. Arable weeds are well adapted to this highly dynamic system and cohabit the fields with crops. However, the term weed often has a negative connotation being associated with exotic or invasive plants that spread rapidly over large areas, but in the present study, arable weeds are understood as non-crop plants growing in crop fields, without any implication of invasive status. At present, arable weeds belong to the most endangered plant communities in Germany (Hofmeister \& Garve 1998), with roughly one third of the 250 - 300 arable weed species recorded on the German Red Data List of endangered species (Eggers 1987). The recent decline in species richness associated with a change in species composition has resulted from agricultural intensification in Europe (Albrecht 1995, Andreasen et al. 1996, Sutcliffe \& Kay 2000, Robinson \& Sutherland 2002). At the local field and farm scale, improvements in crop management techniques have taken place involving the use of herbicides and mechanical weed control, increases in fertilizer usage, simplification of crop rotations, and improvements in seed-cleaning techniques (Firbank 1988, Albrecht 1995, McLaughlin \& Mineau 1995, Sotherton 1998, Stoate et al. 2001, Benton et al. 2003). At the landscape and regional scale, farm enlargement and specialization on a narrow range of arable crops, abandonment of areas with marginal crop yields and land consolidation have led to simplified agricultural landscapes and a decrease in spatial heterogeneity over vast areas (Robinson \& Sutherland 2002, Benton et al. 2003). 
Given that arable weeds compete with the crop for space and resources, farmers regulate their densities by using herbicides, mechanical weeding and soil tillage. Communities respond differently to management methods in organic and conventional farming (Moreby et al. 1994, Hald 1999a, Menalled et al. 2001, Hyvönen et al. 2003b, Bengtsson et al. 2005), and also to different intensities in herbicide use, mechanical weed control, tillage systems, and nitrogen fertilization (Pyšek \& Lepš 1991, McCloskey et al. 1996, Andersson \& Milberg 1998, Hyvönen \& Salonen 2002). As a consequence, many plant species are confined to a narrow zone at the field edge, where management practices are less intensive (Marshall 1989, Wilson \& Aebischer 1995, Hald 1999a). Only a few species cause major crop losses and arable weeds are important components of the agroecosystem (Marshall et al. 2003). They increase floristic diversity in the agricultural landscape, constitute the base of food chains for herbivores and can serve as alternative hosts for pest and beneficial arthropods.

The aim of this study was to examine the effects of landscape complexity (i.e. simple vs. complex landscapes) and local management (i.e. organic vs. conventional farming) on local arable weed species richness in three agricultural regions. By studying this simultaneously, it was possible to test on interacting effects of landscape complexity and farming system on plant species richness. Given that arable weed communities are highly dynamic systems, focussing only on diversity at one point in time and space may lead to an incomplete understanding. Thus this thesis examines in addition the variation in species composition among years and sites (i.e. temporal and spatial species turnover $=\beta$ diversity) and among different spatial scales (i.e. plot, field, and regional scale) and its relation to landscape complexity and local management (i.e. organic vs. conventional farming).

\section{Study area and design}

The studies were conducted in three agricultural regions in Germany: Leine Bergland (Lower-Saxony), Soester Boerde (North-Rhine Westphalia), and Lahn-Dill Bergland (Hesse). The regions are characterised by intensive agricultural land use and patchily distributed fragments of semi-natural habitats such as grasslands, fallows, hedges and forests (Fig. 1.1). The regions covered $1600 \mathrm{~km}^{2}, 620 \mathrm{~km}^{2}$ and $1000 \mathrm{~km}^{2}$ with a distance of $100 \mathrm{~km}$ to $130 \mathrm{~km}$ from each other. Mean annual temperature and mean annual precipitation in the study regions were $8.7^{\circ} \mathrm{C}$ and $645 \mathrm{~mm}$ in the Leine Bergland, $9.3^{\circ} \mathrm{C}$ and $764 \mathrm{~mm}$ in the Soester Boerde, and $9.4^{\circ} \mathrm{C}$ and $745 \mathrm{~mm}$ in the Lahn-Dill Bergland. The elevation of the study sites varied between $155 \mathrm{~m}$ and $295 \mathrm{~m}$ in the Leine Bergland, $70 \mathrm{~m}$ and $320 \mathrm{~m}$ in the Soester Boerde, and $172 \mathrm{~m}$ and $496 \mathrm{~m}$ in the Lahn-Dill Bergland. 


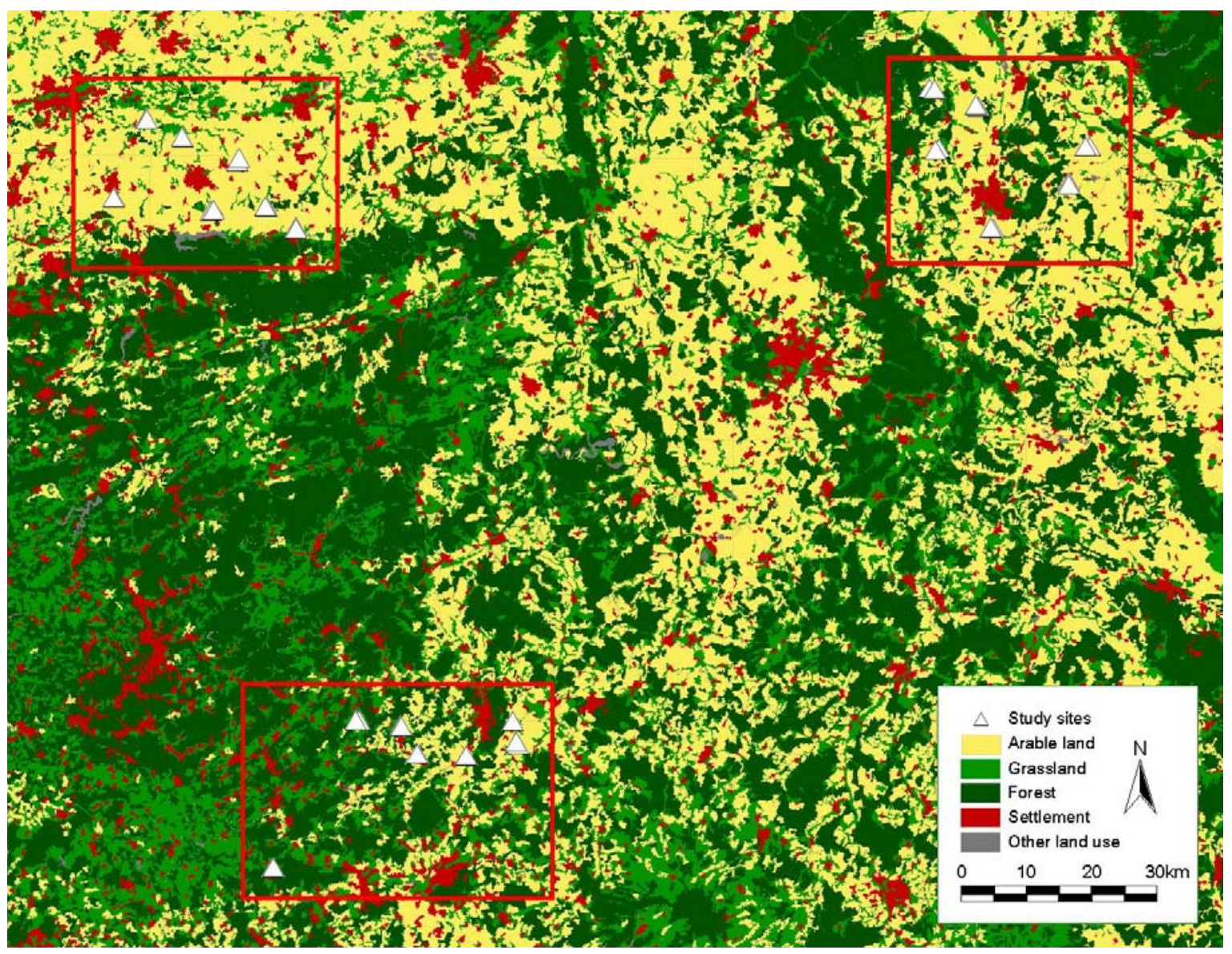

Fig. 1.1. Overview of the three agricultural regions Leine Bergland (Lower-Saxony), Soester Boerde (North-Rhine Westphalia), and Lahn-Dill Bergland (Hesse), within which the paired wheat fields were embedded (chapter 4 and 6).

To examine landscape effects, in each region circular landscape sectors were selected along a gradient of landscape complexity ranging from structurally simple landscapes with a high percentage of arable land, to structurally complex landscapes with a high percentage of semi-natural habitats, such as grasslands, hedges, fallows, and field margins (Fig. 1.2). Landscape context was characterised for each landscape using either official digital vector based maps (ATKIS - digital landscape model 25/1, Landesvermessung und Geobasisinformation, Hannover, Germany 1991-1996) (in chapters 2, 3 and 5) or field inspections and official topographical maps (DGK 5, 1:5000; in chapter 4) and GIS ArcView 3.2 (ESRI Geoinformatik Hannover, Germany). Landscape context was described using three well established landscape metrics: percentage cover of arable land, habitat-type diversity and perimeter-area ratio, which were (in chapter 2) measured at five different spatial scales, i.e. circular sectors of 1 km, 2 km, 3 km, 4 km, and 5 km diameter representing a nested set of landscape sectors.

In the centre of each landscape, arable weed species were recorded within either one focal conventional field or within a pair of one organic and one conventional field. The paired approach should ensure similar abiotic conditions within the field pairs. 
Studies were conducted in 18 conventional wheat fields (in chapter 2 and 3, see also Fig. 1.2a) and in 12 paired organic and conventional wheat fields (in chapter 5) in the Leine Bergland only, and in 20 paired organic and conventional wheat fields in the three regions Leine Bergland, Soester Boerde, and Lahn-Dill Bergland (in chapter 4 and 6, see also Fig. 1.1).
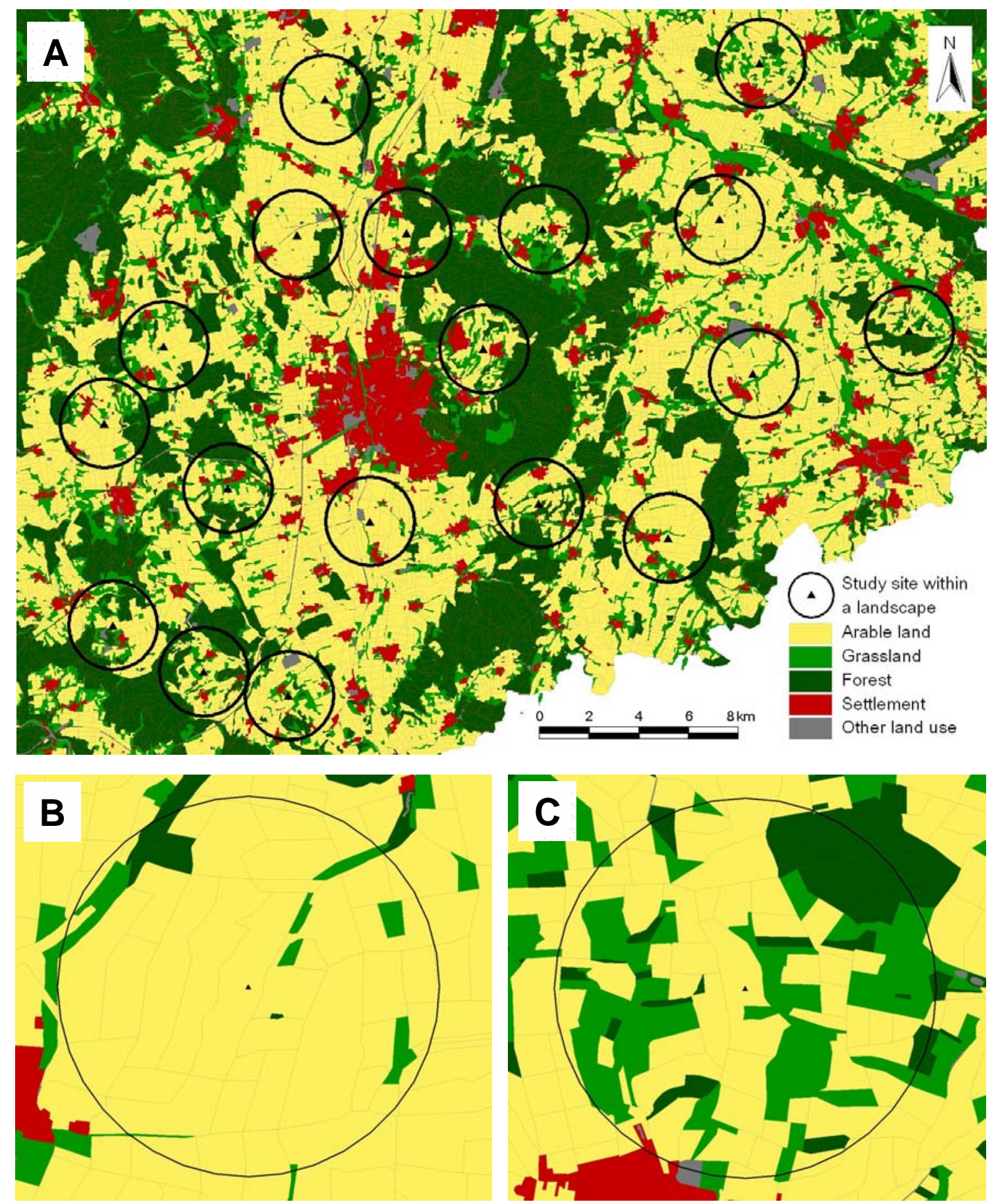

Fig. 1.2. Example of the landscape gradient approach: a) 18 non-overlapping landscapes of 5 $\mathrm{km}$ diameter in the vicinity of Göttingen (Lower-Saxony) representing a gradient in landscape complexity ranging from structurally simple landscapes (b) to complex landscapes (c). Note: $\mathrm{b}+\mathrm{c}$ illustrate landscapes of $2 \mathrm{~km}$ diameter. 


\section{Main questions}

The aim of this study was to examine the effects of landscape complexity (i.e. simple vs. complex landscapes) and local management (i.e. organic vs. conventional farming) on arable weed communities with particular focus on local species richness, spatial and temporal species turnover (i.e. $\beta$-diversity), and community composition and structure (i.e. proportion of pollination types).

Thereby the following questions were of major importance:

How are different landscape metrics related to each other and to local site characteristics? Is the local species richness of arable weeds in conventional fields related to the surrounding landscape complexity? In particular, does the predictive power of landscape complexity for local species richness differ between spatial scales, i.e. landscape sectors of different diameter? (Chapter 2)

Is the inter-annual variability (i.e. temporal species turnover) in arable weed communities related to landscape complexity? How is community similarity and composition related to landscape complexity? (Chapter 3)

Does $\alpha$-, $\beta$-, and $\gamma$-diversity of arable weeds differ between field edges and centres and between organic and conventional fields? Do patterns vary across different spatial scales, i.e. at plot, field, and regional scale? Do diversity patterns differ between rare and common species? What is the most appropriate scale for effective conservation management i.e. at which spatial scale occurs the highest species turnover? (Chapter 4)

Does the arable weed diversity in the above ground vegetation, seed rain, and the seedbank differ between organic and conventional fields? Are they related to landscape complexity? (Chapter 5)

Does the often observed positive effect of organic farming on arable weed and pollinator diversity result in a significant shift in arable weed community structure towards a higher proportion of insect pollinated species in organic crop fields? (Chapter 6) 


\section{Results and conclusions}

The percentage cover of arable land was negatively correlated with perimeter-area ratio, habitat-type diversity, and topographical heterogeneity, but landscape characteristics did not correlate with local site conditions and field management intensity. The number of plant species was mainly related to landscape characteristics and to a lesser extent to field management intensity (nitrogen fertilisation). Local soil characteristics did not contribute to the explanation of arable weed richness. Local plant species richness was best explained by the landscape context measured at $2 \mathrm{~km}$ diameter indicating a scale-dependent relationship between landscape complexity and plant species richness. This result suggests a functional scale at which the existence of potential source habitats and processes like seed dispersal interact over time. These results support the hypothesis that local plant species richness in arable fields is greatly influenced by processes operating at the landscape scale. Seed rain from ruderal source habitats and disturbed edges may be the most important underlying process. (Chapter 2)

Inter-annual variation appeared to be mediated by landscape effects, as $\beta$-diversity (i.e. temporal species turnover) increased with increasing landscape complexity, and community similarity among years was high in simple but low in complex landscapes. Community composition again was associated with year and landscape context, but also with soil properties such as soil $\mathrm{pH}$ and total soil nitrogen. The high temporal heterogeneity in arable weed communities appeared to be related to the plant's niche breadths in response to differing weather conditions since species occurring predominately in complex landscapes were generally less frequent than those in simple landscapes. Rarer species may have smaller niche breadths and increased sensitivity to changing conditions, which would explain the high inter-annual heterogeneity in plant communities observed in complex compared to simple landscapes. (Chapter 3)

$\alpha$-, $\beta$-, and $\gamma$-diversity was higher in organic than conventional fields and higher at the field edge than in the field center at all spatial scales (i.e. plot, field and regional scale). In both farming systems, $\beta$-diversity at the field and regional scale explained most of the overall species richness, indicating considerable differences in community composition among fields and regions due to environmental heterogeneity. The spatial scale at which $\beta$ diversity contributed the most to overall species richness differed between rare and common species. Total richness of rare species (present in $\leq 5 \%$ of total samples) was mainly explained by differences in community composition at the field and regional scale, but only in organic fields. Total richness of common species (present in $\geq 25 \%$ of total samples) was explained by differences in community composition at the plot and field scale, independent of farming system. These results show that organic farming made the greatest contribution to total species richness at the field and regional scale due to environmental heterogeneity. Hence, for an effective conservation management agri- 
environment schemes should exploit this large-scale contribution of $\beta$-diversity by tailoring schemes at regional scales to maximize dissimilarity between conservation areas using geographic information systems rather than focus entirely at the local field scale, which is the current practice. (Chapter 4)

Weed species diversity in the vegetation, the seed rain and the seedbank was higher in organic than in conventional fields. Increasing landscape complexity enhanced species diversity in the vegetation of conventional, but little of organic fields, resulting in nearly similar diversity in both farming systems when the landscape was complex. Species diversity of the seedbank was increased by landscape complexity irrespective of farming system. Species diversity in organic farming was clearly higher only in simple landscapes, because the vegetation in conventional fields reached similar diversity levels when the surrounding landscape was complex, providing refuges for weed populations. Consequently, agri-environment schemes to preserve and enhance biodiversity should not only consider the management of single fields, but also of the surrounding landscape. (Chapter 5)

Plant species numbers of both pollination types (i.e. insect pollinated and non-insect pollinated) were much higher in organic than in conventional fields and higher in the field edge than in the field centre. A comparison of the proportions of both pollination types to all plant species revealed that the relative number of insect pollinated species was higher in organic than in conventional fields and higher at the field edge than in the field centre, whereas the relative number of non-insect pollinated species was higher in conventional fields and in the field centre. These results show that insect pollinated plants benefit disproportionately from organic farming, which appeared to be related to higher pollinator densities in organic fields, whereas in the centres of conventional fields non-insect pollinated plants dominate presumably due to a limitation of pollinators. Hence, disruption of plant-pollinator interactions due to agricultural intensification may cause important shifts in plant community structure. (Chapter 6) 
Chapter

2

\title{
Local diversity of arable weeds increases with landscape complexity
}

\author{
Doreen Gabriel, Carsten Thies \& Teja Tscharntke
}

In: Perspectives in Plant Ecology, Evolution and Systematics (2005) 7: 85-93. 


\begin{abstract}
Patterns of plant diversity are often related to local site conditions and to competitive interactions, but landscape context may also be important for local plant species richness. This is shown here by analysing the relationship between landscape complexity and local species richness of arable weeds in wheat fields. The fields were located in 18 landscapes characterised by a gradient in landscape complexity from structurally complex to structurally simple (39 \% - $94 \%$ arable land). We quantified local site conditions, field management intensity and landscape characteristics, and used principle component analyses to ordinate the environmental variables. The percentage of arable land was negatively correlated with perimeter-area ratio, habitat-type diversity, and topographical heterogeneity, but landscape characteristics did not correlate with local site conditions and field management intensity. The number of plant species was mainly related to landscape characteristics and to a lesser extent to field management intensity (nitrogen fertilisation), whereas local soil characteristics did not contribute to the explanation of arable weed richness. In a geographic scale analysis using circular landscape sectors ranging from $1 \mathrm{~km}$ up to $5 \mathrm{~km}$ diameter, the predictive power of landscape complexity for local plant species richness was strongest at $2 \mathrm{~km}$ indicating a scale-dependent relationship between landscape context and plant species richness. Our results support the hypothesis that local plant species richness in arable fields is greatly influenced by processes operating at the landscape scale. Seed rain from ruderal source habitats and disturbed edges may be the most important underlying process.
\end{abstract}

Keywords: annual plants, landscape, local species richness, soil conditions, spatial scales 


\section{Introduction}

Patterns of plant diversity are traditionally explained by local abiotic conditions such as climate and soil properties, as well as disturbance regimes and competition for light, water and nutrients (Grime, 1979; Tilman, 1982; Ellenberg, 1988). Many arable weed studies have demonstrated the importance of local site characteristics and management practices for the occurrence of single species, community composition and species richness (Dale et al., 1992; Andersson and Milberg 1998; Kay and Gregory, 1998, 1999; Hald, 1999a; Hallgren et al., 1999; Swanton et al., 1999; Menalled et al., 2001; Hyvönen and Salonen, 2002; Walter et al., 2002; Hyvönen et al., 2003b; Gerowitt, 2003; Lososova et al., 2004). In the last decades the intensification in agricultural practices has caused major changes in the composition and species richness of weed communities in arable fields (e.g. Albrecht, 1995; Sutcliffe and Kay, 2000). Arable weeds are important components of agroecosystems (Marshall et al., 2003), as they constitute the base of food chains for herbivores and their natural enemies. Species-rich weed communities support many species of phytophagous and entomophagous insects and spiders (Mahn, 1992; Rypstra et al., 1999; Haughton et al., 2001), are pollen and nectar resources for pollinating insects, and enhance biological control (Heitzmann et al., 1992; Nentwig 1994). They possess a number of specific life-history characteristics including an enormous seed production, seed dormancy, rapid development rates, and short generation times. These traits enable populations to persist in crop fields, which are subject to high rates of disturbance such as annual soil cultivation, harvest of crops, and crop rotation (Cousens and Mortimer, 1995). Such disturbance dynamics result in the requirement for weeds to re-establish annually from the local seed and bud bank and/or via propagule immigration from surrounding landscapes.

The landscape context is central to understanding local patterns of biodiversity (Kareiva and Wennergren, 1995; Gustafson, 1998; Wiegand et al., 1999), because ecological processes operate on a range of spatial scales larger than a single patch (Turner, 1989; Dunning et al., 1992). Recent studies in agroecosystems have demonstrated a relationship between landscape complexity and local diversity patterns of carabids, butterflies, and solitary wild bees as well as on processes such as herbivory, parasitism and pollination (Thies and Tscharntke, 1999; Östman et al., 2001; Steffan-Dewenter et al., 2002; Krauss et al., 2003; Thies et al., 2003; Weibull et al., 2003). However, the potential importance of landscape context in driving local patterns has received limited attention in plant ecology (de Blois et al., 2002). A number of studies have examined regional plant diversity as a function of habitat-specific communities in a mosaic landscape (Wagner et al., 2000; Honnay et al., 2003), and thus the question arises as to whether local plant species richness may also be influenced by the landscape context.

In this study, we analysed 18 landscape sectors along a gradient from structurally simple to structurally complex. In the centre of each landscape sector a winter wheat field with homogenous local site characteristics and management intensity was selected to study 
local species richness of arable weeds in relation to landscape context at different spatial scales (landscape sectors ranging from $1 \mathrm{~km}$ to $5 \mathrm{~km}$ diameter). We hypothesise that (i) local species richness of arable weeds increases with increasing landscape complexity and that (ii) the predictive power of landscape complexity for local species richness of arable weeds differs between spatial scales.

\section{Methods}

\section{Study area and landscape context}

The study area was located around Göttingen, Germany. This region was characterised by intensive agricultural land use and patchily distributed fragments of semi-natural habitats such as grasslands, fallows, hedges and forests. We selected 18 landscape sectors, which represented a gradient of landscape complexity ranging from structurally simple landscapes with a high percentage of arable land (up to $94 \%$ ) to structurally complex landscapes with a high percentage of non-arable land (up to $61 \%$ ). There was no east-west or north-south gradient of landscape complexity, as XY-coordinates of the landscapes do not correlate with landscape context (X-coordinates vs. percentage arable land: $r=0.184, p$ $=0.464$; Y-coordinates vs. percentage arable land: $\mathrm{r}=0.120, \mathrm{p}=0.635)$. We selected a conventionally managed winter wheat field (Triticum aestivum L.) in the centre of each landscape and characterised landscape context for each of the 18 fields at five different spatial scales, i.e. circular sectors of $1 \mathrm{~km}, 2 \mathrm{~km}, 3 \mathrm{~km}, 4 \mathrm{~km}$, and $5 \mathrm{~km}$ diameter representing a nested set of landscape sectors (Fig. 2.1). We used digital vector based maps (ATKIS - digital landscape model 25/1, Landesvermessung und Geobasisinformation, Hannover, Germany 1991-1996) to measure landscape complexity. We selected three well established simple landscape metrics as indictors for landscape complexity: (i) the percentage of arable land, which is the predominant land-use type in the landscapes, (ii) the habitat-type diversity (Shannon-Wiener index $\mathrm{H}^{\prime}=-\sum \mathrm{pi} \mathrm{x} \log$ (pi), Krebs, 1989) resulting from different habitat-types (i.e. arable land, grassland, forests, hedgerows, garden land, and settlement) in the vicinity of the focal fields, which might be potential source habitat for arable weeds, and (iii) the regional perimeter-area ratio $\left(\mathrm{P} / \mathrm{A}_{\mathrm{R}}=\sum_{\mathrm{i}=1}^{\mathrm{m}} \mathrm{P}_{\mathrm{i}} / \sum_{\mathrm{i}=1}^{\mathrm{m}} \mathrm{A}_{\mathrm{i}} ; \mathrm{P}=\right.$ perimeter, $\mathrm{A}=$ area of a patch, $\mathrm{i}=$ the patch number and $\mathrm{m}=$ the number of patches in the landscape sector), which indicates the edge density and the amount of disturbed habitats along roadsides and verges that may harbour annual plant communities. In addition, we used a 20 m x 20 m grid-based Digital Elevation Model (DEM, Landesvermessungsamt und Geobasisinformationen Niedersachsen, Hannover, Germany) to characterise topographic heterogeneity by the regional slope, i.e. the average slope in the landscape sector calculated for each spatial scale (Horn, 1981). 

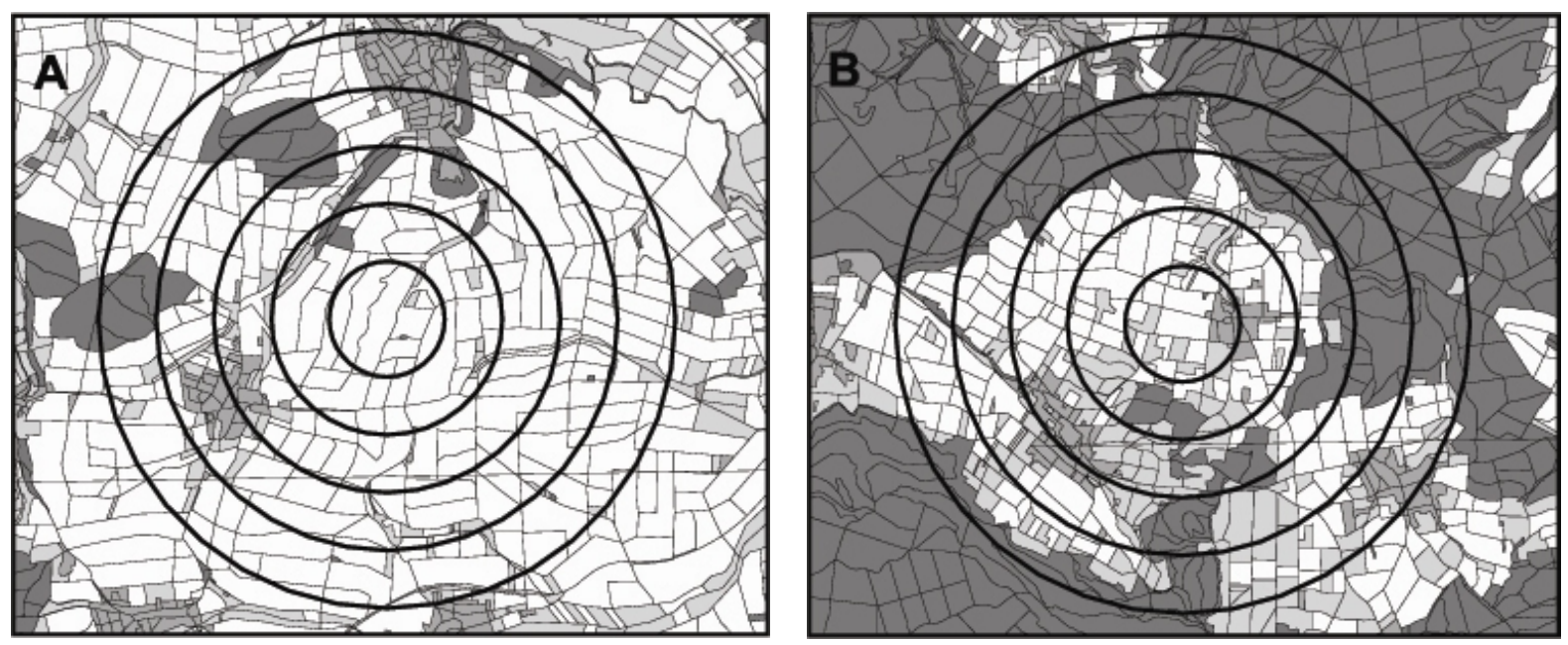

Fig. 2.1. Two landscapes illustrating the nested set of five spatial scales, i.e. $1 \mathrm{~km}, 2 \mathrm{~km}, 3 \mathrm{~km}, 4 \mathrm{~km}, 5 \mathrm{~km}$ diameter landscape sectors. (a) Structurally simple landscape with $78.9 \%$ arable land in a landscape sector of 4 $\mathrm{km}$ diameter. (b) Structurally complex landscape with $39.9 \%$ arable land in a landscape sector of $4 \mathrm{~km}$ diameter (white area: arable fields; light gray: grassland; gray: settlement; dark gray: forest).

\section{Local site characteristics and field management}

Local site characteristics were recorded for each of the 18 wheat fields. We quantified local perimeter-area ratio $\left(\mathrm{P} / \mathrm{A}_{\mathrm{L}}=\mathrm{P}_{\text {field }} / \mathrm{A}_{\text {field }}\right)$ and local slope using ATKIS and DEM. The local chemical soil properties were analysed from each site by taking 48 soil samples per field (16 samples in each subplot), at a depth of $0-30 \mathrm{~cm}$, in spring 2001. Samples were analysed for acidity measured in a $0.01 \mathrm{M} \mathrm{CaCl}_{2}$ solution. Soil content of total nitrogen and organic carbon was determined using a LECO-C/N-analyser. Fields were selected such that management was similar among the 18 study sites. Data on herbicide use and nitrogen fertilisation of the study fields obtained from questionnaires given to farmers demonstrated a relatively consistent herbicide and fertilisation management and no relation of these variables to the landscape context (spearman rank correlation: number of herbicide application vs. percentage arable land: $r=-0.021, p=0.931$; simple correlation: nitrogen fertilisation vs. percentage arable land: $r=0.257, p=0.304)$.

\section{Plant surveys}

Plant surveys were done in each of the 18 winter wheat fields in a $100 \mathrm{~m}^{2}$ area twice in May and June 2001. Arable weed species were identified in three subplots of $33 \mathrm{~m}^{2}$ (nomenclature followed Rothmaler, 2000). The percentage cover of the crop, all arable weed species together, and herb and grass species separately were estimated visually. The subplots were randomly distributed and at least $10 \mathrm{~m}$ away from the field edge. Species richness is the cumulative number of i) all plant species, ii) herb species and iii) grass species. The percentage cover is the mean of both May and June surveys. 


\section{Statistical analysis}

The statistical analysis of data was performed in three steps. In the first step, we used five principle component analyses (PCA) based on correlations (Statistica 6.1, StatSoft, 2003) to deal with the problem of multicollinearity among environmental variables by reducing the number of variables to factor complexes of independent variation (Graham, 2003). We examined how landscape variables at five spatial scales (i.e. circular landscape sectors of $1 \mathrm{~km}, 2 \mathrm{~km}, 3 \mathrm{~km}, 4 \mathrm{~km}$, and $5 \mathrm{~km}$ diameter) were related to local site and management variables. In the second step, we used five multiple linear regression analyses (ordinary least squares) to relate the extracted PCA factor scores to the species richness of arable weeds (all plant species, herb species, grass species). Thereby the standardized regression coefficient BETA equals the semi-partial regression coefficient as principle components are orthogonal to each other. In the third step, we tested how single parameters, in particular landscape parameters at different spatial scales, correlated best with the number of plant species. We did not apply Bonferroni corrections in order to avoid inflating the probability of committing type-II errors. The objective was to describe the change in the strength of the correlation with increasing diameter of the landscape sectors, and it is clear that the pattern of outcomes that fall below the value of 0.05 is not due to chance (Moran, 2003). We plotted the correlation coefficients from simple correlation analyses of regional parameters on plant species richness for each of the five spatial scales to illustrate scale-dependent changes in the predictive power of landscape context (Wiegand et al., 1999; Steffan-Dewenter et al., 2002; Thies et al., 2003). Percentage values were arcsine-square-root transformed for simple correlations to achieve normal distribution (Sokal and Rohlf, 1995). In the text, the arithmetic mean \pm one standard deviation (from original values) are given. 


\section{Results}

Local site characteristics and the landscape context at different spatial scales

Local site characteristics and the landscape context at five spatial scales are listed in Table 2.1.

Table 2.1. Local site parameters and regional parameters at five spatial scales (diameter of landscape sectors).

\begin{tabular}{|c|c|c|c|}
\hline & $\overline{\mathrm{x}} \pm \mathrm{S}_{\mathrm{D}}$ & Min & Max \\
\hline Local & & & \\
\hline $\begin{array}{l}\text { Perimeter-area ratio } \\
\text { Slope }^{1)} \\
\text { Soil pH } \\
\text { Soil total nitrogen }^{2)} \\
\text { Soil organic carbon }^{2)} \\
\text { Herbicide applications }^{3)} \\
\text { Nitrogen fertilisation }^{4} \\
\text { Crop cover }^{5)}\end{array}$ & $\begin{aligned} 0.0140 & \pm 0.0054 \\
4.2 & \pm 3.5 \\
6.8 & \pm 0.4 \\
0.13 & \pm 0.05 \\
1.33 & \pm 0.43 \\
1.94 & \pm 0.53 \\
210 & \pm 24.5 \\
78 & \pm 10.2\end{aligned}$ & $\begin{array}{c}0.0050 \\
0.1 \\
6.1 \\
0.09 \\
0.85 \\
1 \\
174 \\
58\end{array}$ & $\begin{array}{c}0.0253 \\
10.7 \\
7.5 \\
0.26 \\
2.52 \\
3 \\
252 \\
95\end{array}$ \\
\hline Regional & & & \\
\hline $\begin{array}{l}\text { Arable land } \\
\text { Scale: } 1 \mathrm{~km} \\
\text { Scale: } 2 \mathrm{~km} \\
\text { Scale: } 3 \mathrm{~km} \\
\text { Scale: } 4 \mathrm{~km} \\
\text { Scale: } 5 \mathrm{~km}\end{array}$ & $\begin{array}{l}73.9 \pm 16.9 \\
66.6 \pm 19.2 \\
64.3 \pm 15.8 \\
60.1 \pm 15.8 \\
57.0 \pm 16.0\end{array}$ & $\begin{array}{l}45.1 \\
38.6 \\
43.1 \\
39.2 \\
33.8\end{array}$ & $\begin{array}{l}97.8 \\
94.2 \\
90.2 \\
87.4 \\
83.3\end{array}$ \\
\hline $\begin{array}{l}\text { Habitat-type diversity } \\
\text { Scale: } 1 \mathrm{~km} \\
\text { Scale: } 2 \mathrm{~km} \\
\text { Scale: } 3 \mathrm{~km} \\
\text { Scale: } 4 \mathrm{~km} \\
\text { Scale: } 5 \mathrm{~km}\end{array}$ & $\begin{array}{l}0.60 \pm 0.32 \\
0.76 \pm 0.34 \\
0.85 \pm 0.29 \\
0.92 \pm 0.26 \\
0.94 \pm 0.22\end{array}$ & $\begin{array}{l}0.11 \\
0.26 \\
0.30 \\
0.32 \\
0.42\end{array}$ & $\begin{array}{l}1.06 \\
1.26 \\
1.20 \\
1.17 \\
1.16\end{array}$ \\
\hline $\begin{array}{l}\text { Perimeter-area ratio } \\
\text { Scale: } 1 \mathrm{~km} \\
\text { Scale: } 2 \mathrm{~km} \\
\text { Scale: } 3 \mathrm{~km} \\
\text { Scale: } 4 \mathrm{~km} \\
\text { Scale: } 5 \mathrm{~km}\end{array}$ & $\begin{array}{l}0.0239 \pm 0.0067 \\
0.0236 \pm 0.0054 \\
0.0233 \pm 0.0043 \\
0.0232 \pm 0.0040 \\
0.0227 \pm 0.0038\end{array}$ & $\begin{array}{l}0.0123 \\
0.0154 \\
0.0166 \\
0.0168 \\
0.0170\end{array}$ & $\begin{array}{l}0.0351 \\
0.0320 \\
0.0298 \\
0.0288 \\
0.0285\end{array}$ \\
\hline $\begin{array}{l}\text { Regional slope }{ }^{1)} \\
\text { Scale: } 1 \mathrm{~km} \\
\text { Scale: } 2 \mathrm{~km} \\
\text { Scale: } 3 \mathrm{~km} \\
\text { Scale: } 4 \mathrm{~km} \\
\text { Scale: } 5 \mathrm{~km}\end{array}$ & $\begin{array}{l}3.87 \pm 2.81 \\
3.83 \pm 2.10 \\
3.81 \pm 1.76 \\
3.83 \pm 1.57 \\
3.83 \pm 1.40\end{array}$ & $\begin{array}{l}0.31 \\
0.37 \\
0.62 \\
0.92 \\
1.11\end{array}$ & $\begin{array}{l}9.74 \\
7.22 \\
6.50 \\
6.22 \\
6.06\end{array}$ \\
\hline
\end{tabular}

Note: Means $\pm \mathrm{S}_{\mathrm{D}}$, minimum and maximum are given for the 18 study sites. ${ }^{1)}$ in degrees ${ }^{2)}$ in $\%$ in dry weight, ${ }^{3)}$ herbicide applications per year: three fields were sprayed once, thirteen fields twice, two fields threefold, ${ }^{4)}$ in $\mathrm{kg} \mathrm{N}$ ha $^{-1}$ year $\left.^{-1}, 5\right)$ in \%. 
In principle component analyses ordinating local and regional parameters simultaneously, at each spatial scale four principle components (PC) were extracted (Table 2.2a), which explained between $82.1 \%$ and $83.3 \%$ of the total variance. At the smallest spatial scale (landscape sectors of $1 \mathrm{~km}$ diameter) PC 1 was positively correlated with soil acidity (42.1\% explained variance). PC 2 was positively correlated with the local and regional perimeter-area ratio, the habitat-type diversity and the soil content of organic carbon and negatively correlated with the percentage of arable land (17.0\% explained variance). PC 3 was correlated with the percentage crop cover and the number of herbicide applications (12.3\% explained variance). PC 4 was correlated with the local and regional slope describing topographical heterogeneity (10.7 \% explained variance). At all larger spatial scales (landscape sectors of 2 to $5 \mathrm{~km}$ diameter) PC 1 was characterised by the regional parameters percentage of arable land, perimeter-area ratio, habitat-type diversity, and local and regional slope thereby describing a gradient in landscape complexity (38.7 $42.6 \%$ explained variance). PC 2 was correlated to soil content of total nitrogen and organic carbon describing a gradient in local soil properties (18.7 - $21.1 \%$ explained variance). PC 3 was correlated with the number of herbicide applications and the percentage crop cover (12.8 - $13.1 \%$ explained variance) and PC 4 with nitrogen fertilisation (8.9 - $9.2 \%$ explained variance) describing gradients in management intensity.

Hence at the smallest spatial scale (1 km diameter of landscape sector) local and regional parameters were less variable and intermingled (PC 2). But at spatial scales larger than $1 \mathrm{~km}$ diameter there were strong intercorrelations among the regional parameters, and regional parameters (PC 1), local soil characteristics (PC 2), and management practices (PC 3 and 4) were distinctly separated at four principle components. This independence was the prerequisite to separate the effects of landscape complexity from those of local site conditions and management intensity on local plant species richness of arable weeds.

\section{Species richness of arable weeds}

Altogether, 41 species from 17 families were recorded in 18 winter wheat fields, of these 30 were herb and 11 were grass species. The most common arable weed species were the herbs Viola arvensis Murray, Galium aparine L., and Veronica hederifolia L., and the grasses Elymus repens (L.) Gould, Alopecurus myosuroides Huds., and Apera spica-venti (L.) Beauv. Total number of species ( $9.1 \pm 4.7$; min: 1 , max: 20) was dominated by herbs (6.6 \pm 3.81; min: 0 , max: 14$)$, whereas grasses played a minor role $(2.5 \pm 1.62$; min: 0 , max: 6). Species number and percentage cover were positively correlated for all plant species $(\mathrm{r}=0.85, \mathrm{p}<0.001, \mathrm{n}=18)$ and for herbs $(\mathrm{r}=0.81, \mathrm{p}<0.001, \mathrm{n}=18)$ and grasses $(\mathrm{r}=0.48, \mathrm{p}=0.045, \mathrm{n}=18)$. The number of herb and grass species was not correlated $(\mathrm{r}=$ $0.40, \mathrm{p}=0.103, \mathrm{n}=18$ ).

In multiple regression analyses, the total number of species, and the number of herb and grass species were correlated with the factor scores extracted from principle components (Table 2.2b). At small spatial scales (landscape sectors of $1 \mathrm{~km}$ diameter) the total number of species was positively correlated with PC 2 and PC 4. The number of herb species was 
positively correlated with PC 4 and the number of grass species was positively correlated with PC 2. At all larger spatial scales (landscape sectors of $2-5 \mathrm{~km}$ diameter) both the total number of species and the number of herb species were positively correlated with PC 1 characterising landscape complexity. Principle components characterising local soil conditions and management practises were not related to the total number of species and herb species at any spatial scale. In contrast, at a scale of $2 \mathrm{~km}$ diameter the number of grass species was positively correlated with PC 4 describing local fertilisation intensity, but at scales larger than $2 \mathrm{~km}$ diameter it was not correlated to any principle component.

Table 2.2. (a) Significant variables characterising principle components (PC) from PCA with 12 environmental parameters at five spatial scales (diameter of landscape sectors). (b) Beta values and significance levels from multiple regression analyses of principle components on the total number of plant species, herb and grass species at five spatial scales.

\begin{tabular}{|c|c|c|c|c|c|}
\hline & \multicolumn{5}{|c|}{ Spatial scale } \\
\hline & 1 km & $2 \mathrm{~km}$ & $3 \mathbf{k m}$ & $4 \mathrm{~km}$ & $5 \mathrm{~km}$ \\
\hline (a) & & & & & \\
\hline PC1 & $\mathrm{PH}_{\mathrm{L}}$ & $\begin{array}{l}(-) \mathrm{ARAB}_{\mathrm{R}}, \mathrm{H}_{\mathrm{R}}^{\prime} \\
\mathrm{P}^{\prime} \mathrm{A}_{\mathrm{R}}, \mathrm{SL}_{\mathrm{R}}, \mathrm{SL}_{\mathrm{L}}\end{array}$ & $\begin{array}{l}(-) \mathrm{ARAB}_{\mathrm{R}}, \mathrm{H}_{\mathrm{R}}^{\prime} \\
\mathrm{P} / \mathrm{A}_{\mathrm{R}}, \mathrm{SL}_{\mathrm{R}}, \mathrm{SL}_{\mathrm{L}}\end{array}$ & $\begin{array}{l}(-) \mathrm{ARAB}_{\mathrm{R}}, \mathrm{H}_{\mathrm{R}}^{\prime} \\
\mathrm{P} / \mathrm{A}_{\mathrm{R}}, \mathrm{SL}_{\mathrm{R}}, \mathrm{SL}_{\mathrm{L}}\end{array}$ & $\begin{array}{l}(-) \mathrm{ARAB}_{\mathrm{R}}, \mathrm{H}_{\mathrm{R}}^{\prime} \\
\mathrm{P} / \mathrm{A}_{\mathrm{R}}, \mathrm{SL}_{\mathrm{R}}, \mathrm{SL}_{\mathrm{L}}\end{array}$ \\
\hline PC2 & $\begin{array}{l}(-) \mathrm{ARAB}_{\mathrm{R}}, \mathrm{H}_{\mathrm{R}}^{\prime} \\
\mathrm{P} \mathrm{A}_{\mathrm{R}}, \mathrm{C}_{\mathrm{L}}, \mathrm{P} / \mathrm{A}_{\mathrm{L}}\end{array}$ & $\mathrm{N}_{\mathrm{L}}, \mathrm{C}_{\mathrm{L}}$ & $\mathrm{N}_{\mathrm{L}}, \mathrm{C}_{\mathrm{L}}$ & $\mathrm{N}_{\mathrm{L}}, \mathrm{C}_{\mathrm{L}}$ & $\mathrm{N}_{\mathrm{L}}, \mathrm{C}_{\mathrm{L}}$ \\
\hline PC3 & $\mathrm{HA}_{\mathrm{L}}, \mathrm{CC}_{\mathrm{L}}$ & $\mathrm{HA}_{\mathrm{L}}, \mathrm{CC}_{\mathrm{L}}$ & $\mathrm{HA}_{\mathrm{L}}, \mathrm{CC}_{\mathrm{L}}$ & $\mathrm{HA}_{\mathrm{L}}, \mathrm{CC}_{\mathrm{L}}$ & $\mathrm{CC}_{\mathrm{L}}$ \\
\hline PC4 & $\mathrm{SL}_{\mathrm{R}}, \mathrm{SL}_{\mathrm{L}}$ & $\mathrm{NF}_{\mathrm{L}}$ & $\mathrm{NF}_{\mathrm{L}}$ & $\mathrm{NF}_{\mathrm{L}}$ & $\mathrm{NF}_{\mathrm{L}}$ \\
\hline
\end{tabular}

(b)

All plants

$\begin{array}{llllll}\text { PC1 } & 0.00 & 0.61 * * & 0.59 * & 0.58 * & 0.58 * \\ \text { PC2 } & 0.49 * & 0.22 & 0.19 & 0.20 & 0.21 \\ \text { PC3 } & -0.22 & -0.16 & -0.17 & -0.15 & -0.12 \\ \text { PC4 } & 0.44 * & -0.25 & -0.20 & -0.22 & -0.25\end{array}$

Herbs

PC1

0.09

$0.63 * *$

$0.60 * *$

0.57 *

0.56 *

PC2

0.38

0.20

0.18

0.20

0.22

PC3 -0.14

$-0.15$

$-0.14$

$-0.13$

$-0.11$

PC4 0.55 *

$-0.10$

$-0.10$

$-0.12$

$-0.17$

Grasses

$\begin{array}{lllrrr}\text { PC1 } & -0.23 & 0.29 & 0.30 & 0.33 & 0.37 \\ \text { PC2 } & 0.52 * & 0.17 & 0.12 & 0.12 & 0.11 \\ \text { PC3 } & -0.31 & -0.10 & -0.17 & -0.13 & -0.10 \\ \text { PC4 } & -0.01 & -0.48 * & -0.37 & -0.34 & -0.34\end{array}$

Note: (a) Principle components were retained with eigenvalues greater than 1.0. Factors with loadings higher than 0.7 after varimax normalised factor rotation were accepted to be significant for principle components. Factors marked with (-) correlate negatively with PC. Regional parameters: percentage of arable land ( $\left.A R A B_{R}\right)$, habitat-type diversity $\left(H_{R}{ }_{R}\right)$, regional perimeter-area ratio $\left(P / A_{R}\right)$, regional slope $\left(S_{R}\right)$. Local parameters: perimeter-area ratio $\left(P / A_{L}\right)$, local slope $\left(\mathrm{SL}_{\mathrm{L}}\right)$, soil acidity $\left(\mathrm{PH}_{\mathrm{L}}\right)$, soil total nitrogen $\left(\mathrm{N}_{\mathrm{L}}\right)$, soil organic carbon $\left(\mathrm{C}_{\mathrm{L}}\right)$, number of herbicide applications $\left(\mathrm{HA}_{\mathrm{L}}\right)$, nitrogen fertilisation $\left(\mathrm{NF}_{\mathrm{L}}\right)$ and percentage crop cover $\left(\mathrm{CC}_{\mathrm{L}}\right)(\mathrm{b}){ }^{(*)} \mathrm{P}<0.1 ; * \mathrm{P}<0.05$; ** $\mathrm{P}<0.01$. 
Simple correlation analyses testing the relationship between each single parameter and the number of plant species support the finding that landscape context was important in explaining species richness of arable weeds while local soil properties and management practises (which did not vary greatly) were of minor importance. The local perimeter-area ratio was positively correlated to the total number of plant species, herb species, and grass species, and local slope was positively correlated with the total number of species and the number of herb species (Table 2.3). Nitrogen fertilisation was negatively correlated with the total number of species. Neither soil acidity, total soil nitrogen and organic carbon content nor the number of herbicide applications and the percentage crop cover were related to the total number of species, and to the number of herb and grass species. The best predictor variable for the total number of species and the number of herb species was the regional perimeter-area ratio (Fig. 2.2a), followed by habitat-type diversity and percentage of arable land. The first two variables correlated positively with the total number of species and herb species, and the percentage of arable land was negatively correlated (Table 2.4).

Table 2.3. Correlation coefficients and significance levels from simple correlations or Spearman rank correlations ${ }^{1)}$ between local site parameters and the total number of plant species, herb, and grass species.

\begin{tabular}{lccc}
\hline & All plants & Herbs & Grasses \\
\hline Perimeter-area ratio & $0.64^{* *}$ & $0.54^{*}$ & $0.60^{* *}$ \\
Slope & $0.55^{*}$ & $0.63^{* *}$ & 0.10 \\
Soil pH & 0.19 & 0.29 & -0.13 \\
Soil total nitrogen & 0.09 & 0.12 & -0.02 \\
Soil organic carbon & 0.17 & 0.18 & 0.07 \\
Herbicide applications & 0.10 & 0.11 & -0.06 \\
Nitrogen fertilisation & $-0.47^{*}$ & $-0.40^{(*)}$ & $-0.42^{(*)}$ \\
Crop cover & -0.17 & -0.10 & -0.27 \\
\hline
\end{tabular}

Note: ${ }^{(*)} \mathrm{P}<0.1 ; * \mathrm{P}<0.05 ; * * \mathrm{P}<0.01$.

In a geographic scale analysis the predictive power of perimeter-area ratio and habitattype diversity differed depending on the spatial scale considered, thereby suggesting a scale-dependent relationship between landscape context and the number of plant species. Correlation coefficients of perimeter-area ratio and habitat-type diversity on the total number of species and herb species, respectively, were highest at landscape sectors of $2 \mathrm{~km}$ diameter explaining up to $62 \%$ of the variance, and decreased at smaller and larger scales (Fig. 2.2b). In contrast, the predictive power for the number of grass species decreased as spatial scale increased. 
Table 2.4. Correlation coefficients and significance levels from simple correlations between regional parameters and the total number of plant species, herb, and grass species at five spatial scales.

\begin{tabular}{|c|c|c|c|c|c|}
\hline & \multicolumn{5}{|c|}{ Spatial scale } \\
\hline & 1 km & $2 \mathrm{~km}$ & 3 km & 4 km & $5 \mathrm{~km}$ \\
\hline \multicolumn{6}{|l|}{ All plants } \\
\hline Arable land & $-0.49 *$ & $-0.55 *$ & $-0.51 *$ & $-0.51 *$ & $-0.54 *$ \\
\hline Habitat-type diversity & $0.43^{(*)}$ & $0.55 *$ & $0.50 *$ & $0.45^{(*)}$ & 0.40 \\
\hline Perimeter-area ratio & $0.75 * * *$ & $0.79 * * *$ & $0.74^{* * *}$ & $0.68 * *$ & $0.64 * *$ \\
\hline Slope & $0.46^{(*)}$ & $0.44^{(*)}$ & $0.42^{(*)}$ & $0.45^{(*)}$ & $0.48 *$ \\
\hline \multicolumn{6}{|l|}{ Herbs } \\
\hline Arable land & -0.37 & $-0.50 *$ & $-0.48 *$ & $-0.48 *$ & $-0.51 *$ \\
\hline Habitat-type diversity & 0.38 & $0.55 *$ & $0.51 *$ & $0.44^{(*)}$ & 0.38 \\
\hline Perimeter-area ratio & $0.67 * *$ & $0.73 * * *$ & $0.70^{* *}$ & $0.64 * *$ & $0.60 * *$ \\
\hline Slope & $0.54 *$ & $0.51 *$ & $0.46^{(*)}$ & $0.45^{(*)}$ & $0.45^{(*)}$ \\
\hline \multicolumn{6}{|l|}{ Grasses } \\
\hline Arable land & $-0.56 *$ & $-0.44^{(*)}$ & -0.35 & -0.33 & -0.36 \\
\hline Habitat-type diversity & 0.37 & 0.32 & 0.25 & 0.26 & 0.27 \\
\hline Perimeter-area ratio & $0.59 *$ & $0.57 *$ & $0.50 *$ & $0.45^{(*)}$ & $0.45^{(*)}$ \\
\hline Slope & 0.05 & 0.09 & 0.14 & 0.24 & 0.34 \\
\hline
\end{tabular}

Note: ${ }^{(*)} \mathrm{P}<0.1 ; * \mathrm{P}<0.05 ; * * \mathrm{P}<0.01 ; * * * \mathrm{P}<0.001$
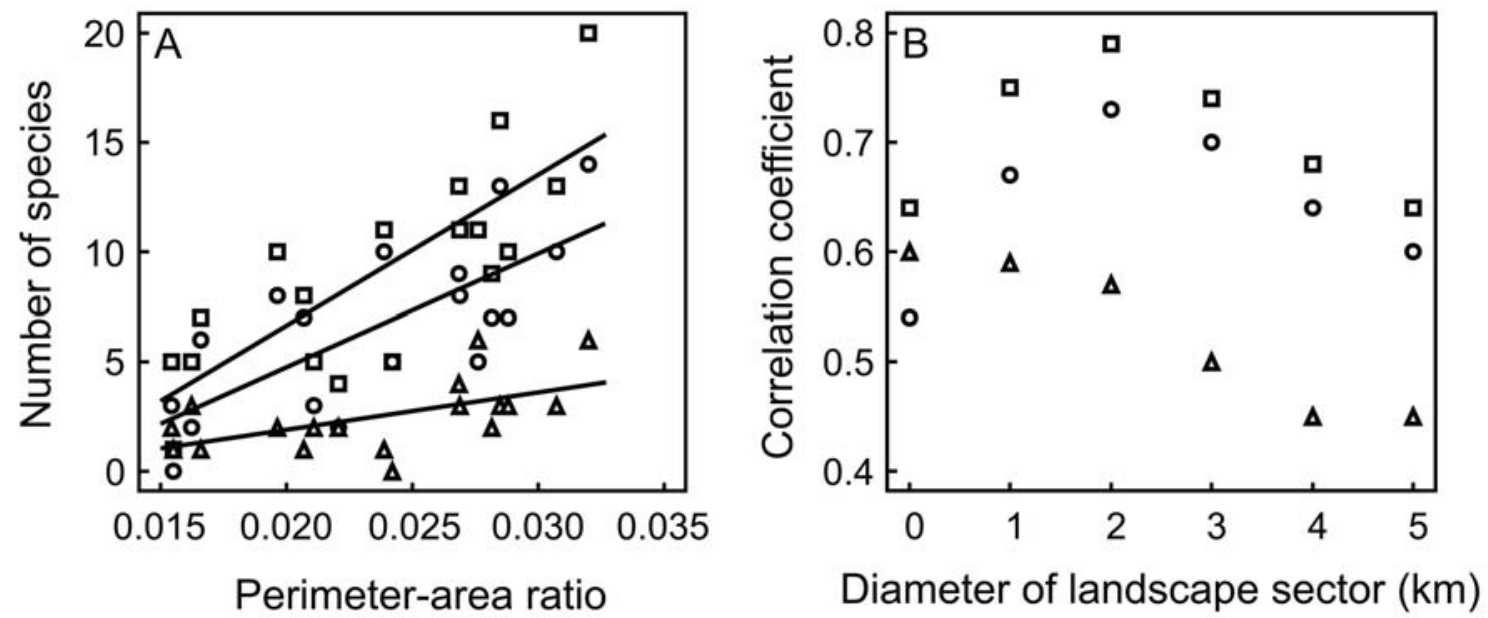

Fig. 2.2. The relationship between landscape context and species richness of arable weeds. (a) Simple regressions of perimeter-area ratio at a spatial scale of $2 \mathrm{~km}$, i.e. diameter of landscape sectors on the total number of plant species, herb and grass species. $\left(Y_{\text {all plants }}=-7.09+686 \mathrm{X}, \mathrm{F}=\right.$ 27.42, $\mathrm{P}=0.0001, \mathrm{R}=0.7947, \mathrm{~N}=18$; $\mathrm{Y}_{\text {herbs }}=-5.55+515 \mathrm{X}, \mathrm{F}=18.77, \mathrm{P}=0.0005, \mathrm{R}=0.7347, \mathrm{~N}$ $=18 ; \mathrm{Y}_{\text {grasses }}=-1.54+171 \mathrm{X}, \mathrm{F}=7.89, \mathrm{P}=0.0126 ; \mathrm{R}=0.5747, \mathrm{~N}=18$ ). (b) Scale-dependent changes in the correlation coefficients from simple correlations between perimeter-area ratio and the total number of plant species, herb, and grass species (spatial scales: $0=$ local, $1 \mathrm{~km}, 2 \mathrm{~km}, 3$ $\mathrm{km}, 4 \mathrm{~km}, 5 \mathrm{~km}$ diameter of landscape sectors, Quadrates = all species, dots = herbs, triangles = grasses). 


\section{Discussion}

Our analyses showed that the number of arable weed species, and particularly the number of herb species, was mainly related to a factor complex characterising landscape complexity. Species richness increased with increasing perimeter-area ratio, habitat-type diversity and decreasing percentage of arable land in a landscape. These landscape characteristics were intercorrelated and indicated a higher diversity of arable weeds in structurally complex landscapes.

Our results suggest that diversity of arable weeds may have benefited from both local and regional processes, but regional processes appeared to be more important. On a local scale, field edges contributed to the explanation of plant species richness. Diversity of arable weeds is known to be higher in field edges than in the field centre (Marshall, 1989; Wilson and Aebischer, 1995), thereby contributing significantly to local diversity (Simmering et al., 2001). This can be related to source-sink relationships due to a reduced intensity of agricultural management at the field edge (Wagner and Edwards, 2001) and/or to neighbourhood effects due to immigrating species from adjacent field margins, which provide disturbed habitats for annual and ruderal plant populations (Dunning et al., 1992; Marshall and Arnold, 1995). In our study these hypotheses are supported by strong correlations between species richness of arable weeds and local perimeter-area ratio which indicate the importance of field edges for local plant diversity in arable fields. However, the correlations of the total number of plant species, and particularly of herb species, with perimeter-area ratio were stronger at a landscape scale. Plant species were more affected by the entirety of edge elements in a landscape than by the adjacent field edge only. Arable weeds do not only occur in agricultural fields, but also in ruderal patches like road verges, fallow land, dry grassland and vegetation gaps in managed fertilised grasslands. Therefore a high diversity of habitat-types in a landscape might be expected to enhance colonisation probability. This was confirmed by a positive correlation between the number of plant species and the habitat-type diversity. Both landscape metrics, perimeter-area ratio and habitat-type diversity, which represent the amount of potential source habitats for arable weeds, explained most variation (up to $62 \%$ ) in plant species richness of arable weeds when characterising the landscape context in sectors of $2 \mathrm{~km}$ diameter. This scaledependent response of arable weed species richness to landscape complexity might point to a functional scale at which the existence of potential source habitats and processes like seed dispersal interact over time. However, since our study is based on a correlative approach, causalities have to be proven with other experiments.

The local and the regional slope were also positively related to the number of weed species. A topographically heterogeneous site may contain more species due to a larger diversity of spatial niches and a larger area per se. A topographically heterogeneous landscape may contain a larger species pool than a homogeneous landscape (Burnett et al., 1998; Nichols et al., 1998), thereby enhancing immigration of plant species into local sites (Ricklefs, 1987). Therefore, our results suggest that local species richness may be 
influenced by the number of species present at a larger scale according to the "species pool hypothesis” (Zobel, 1997), but little is known on such processes for arable weeds. The importance of regional processes in structuring local plant communities has been suggested by Caley and Schluter (1997), Collins et al., (2002), and Valone and Hoffman (2002) who have shown positive correlations between local and regional plant species richness.

In contrast to herbs, the species richness of grasses was best explained by the local perimeter-area ratio and the regional perimeter-area ratio at small spatial scales, suggesting that spreading from adjacent habitats is important in this group. However, variability in the number of grass species was very low, affecting statistical analysis and data interpretation. Plant family-specific differences between herbs and grasses may become prominent, as pollinators such as bees and butterflies also respond to landscape context in our study region (Steffan-Dewenter et al., 2002; Krauss et al., 2003). This may affect the reproductive success of insect pollinated herbs but not of grasses, which are mainly wind pollinated.

Study site selection aimed to homogenise local site characteristics and management intensity. Nevertheless, the amount of nitrogen application, which showed the highest variability ranging from $174 \mathrm{~kg} \mathrm{~N}^{-1}$ year $^{-1}$ to $252 \mathrm{~kg} \mathrm{~N}^{-1}$ year ${ }^{-1}$, had a significantly negative effect on the number of all plant species. This was similarly found by Pyšek and Lepš (1991), Kleijn and Vandervoort (1997) and Andersson and Milberg (1998). However, since the amount of nitrogen application was not related to landscape context, interpretation of the relationship between landscape complexity and arable weed species richness was not interfered.

We conclude that local species richness of arable weeds, in particular of herbs, was related to landscape context and topographical heterogeneity. The findings are compatible with source-sink models (Wagner and Edwards, 2001), neighbourhood effects (Dunning et al., 1992), and the species pool hypothesis (Zobel, 1997). Hence understanding the local diversity of arable weeds requires a large scale perspective at distinct different spatial scales. In this study, the landscape complexity in sectors of $2 \mathrm{~km}$ diameter explained most of the local weed diversity suggesting that local patterns were determined by surprisingly large landscape areas. Seed rain from a high diversity of source habitats and disturbed edges may be the most likely underlying process, but mechanisms are largely unknown. More field experiments as well as spatially explicit modelling should help to elucidate how local patterns in plant species richness connect to processes operating at different spatial scales.

\section{Acknowledgements}

We are grateful to Jan Bakker, Thomas Valone, Helene Wagner, Kerstin Wiegand, Joachim Saborowski, Martin Schmidt, Tatyana Rand and two anonymous reviewers for helpful comments on the manuscript. We thank Indra Roschewitz for advice and assistance 
in the field and Christof Bürger for GIS support. This study is part of the BIOPLEXproject (Biodiversity and spatial complexity in agricultural landscapes under global change) supported by the German Federal Ministry of Education and Research (BMBF). 
Chapter

3

\section{Landscape context mediates inter-annual variability in arable weed communities}

Doreen Gabriel, Tatyana A Rand \& Teja Tscharntke

Submitted to Journal of Biogeography 


\section{Abstract}

Aim Arable weed communities are exposed to a frequently changing environment, which is in turn likely to generate great community variability in space and time. Here, we examined inter-annual variability in arable weed communities and the potential role of landscape context in mediating such variability.

Location The study was conducted in an agricultural region in the vicinity of Göttingen, Lower Saxony (Germany).

Methods 18 non-overlapping circular landscape sectors were selected along a gradient of landscape complexity ranging from structurally simple to structurally complex. Arable weed species were recorded within a focal, conventionally managed, winter wheat field in the centre of each landscape in three consecutive years. The influence of year, landscape context and other local environmental variables on species richness, $\beta$-diversity (i.e. annual turnover), community similarity and composition were analysed.

Results The number of species per field did not vary among years but increased with increasing landscape complexity suggesting that the species pool is an important determinant of overall diversity patterns. Inter-annual variation appeared to be mediated by landscape effects, as $\beta$-diversity (i.e. temporal species turnover) increased with increasing landscape complexity, and community similarity among years was high in simple but low in complex landscapes. Community composition again was associated with year and landscape context, but also with soil properties such as soil $\mathrm{pH}$ and total soil nitrogen.

Main conclusions Inter-annual changes in arable weed communities were observed at the level of community similarity and composition rather than at the level of aggregate species numbers. The high temporal variability in arable weed communities appeared to be related to the plant's niche breadths in response to differing weather conditions since species occurring predominately in complex landscapes were generally less frequent than those in simple landscapes. Rarer species may have smaller niche breadths and increased sensitivity to changing climatic conditions, which would explain the high inter-annual heterogeneity in plant communities observed in complex compared to simple landscapes.

Keywords: Agroecosystem, ANOSIM, annual plants, CCA, landscape context, plant community, temporal variability 


\section{Introduction}

Determinants of plant species richness and community composition vary in time and space (Harper 1977). On the one hand, within a given location, climatic conditions such as temperature, precipitation and solar radiation vary through time thereby influencing plant germination, subsequent growth and plant fitness. On the other hand, within a given time period spatial variation in environmental factors such as nutrient and water availability, predation intensity, or elevation can influence distribution, composition and species richness of plant communities (Townsend et al. 2000). However, spatial determinants of plant community structure also vary through time and temporal determinants vary from place to place. Therefore, in order to fully understand the influence of temporal and spatial variability on plant communities it is critical to consider the interactions between them.

According to assembly theory and the species-pool hypothesis, local communities are composed of a subset of the species from the surrounding species pool, which have successfully passed through a series of environmental filters based on their traits (Zobel 1997, Lawton 1999, Booth \& Swanton 2002). Each species present within a community must have been able to germinate and grow under the predominating conditions, compete with other species and adapt to disturbances. In addition, in order to successfully establish a species must reach maturity, reproduce and deposit propagules in the seed bank. Thus in general, community composition and variability depend on both local environmental conditions and factors determining the regional species pool (Ricklefs 1987, 1989, Turner 1989, Huston 1999).

Annual plant populations occurring within disturbed habitats, such as arable weeds in crop fields, are exposed to a frequently changing environment. Such environmental heterogeneity is in turn likely to generate great variability in community structure in space and time (Firbank 1993, Gou \& Brown 1996, Milberg et al. 2000). The influences of local management, abiotic site conditions, climate and historical changes on arable weed communities and its variability are broadly studied (Pyšek \& Lepš 1991, Dale et al. 1992, McCloskey et al. 1996, Bàrberi et al. 1997, Andersson \& Milberg 1998, Hallgren et al. 1999, Menalled et al. 2001, Milberg et al. 2001, Hyvönen \& Salonen 2002, Hyvönen et al. 2003a, Lososova et al. 2004). In contrast the importance of the surrounding landscape context in influencing arable weed communities has been little addressed. Complex landscapes provide many alternative disturbed habitats for arable weeds such as fallows, road verges and field margins, thereby enhancing the probability of propagule immigration into local fields. Positive effects of landscape complexity on local species richness and/or spatial turnover (i.e. $\beta$-diversity) of arable weeds have been reported (Gabriel et al. 2005, Gabriel et al. unpublished manuscript, Roschewitz et al. 2005a) suggesting that a larger species pool in complex landscapes is the major driver of community patterns. However, the role of landscape context in mediating community variability through time has not been previously addressed. 
In this three year study, we examined how inter-annual variability in arable weed communities is mediated by landscape context. Community variability can be differentiated into two types, the aggregate variability, which describes changes in variables concerning the entire community (e.g. species richness), and the compositional variability, which describes changes in the relative abundance of component species (Micheli et al. 1999). Here, we examined both types of variability by analysing changes in species richness, similarity and composition of arable weed communities in 54 conventionally managed wheat fields among three consecutive years. We first examined year-to-year variation in species richness per field and its relation to landscape context. We expected strong variation in species richness among years and a positive relationship between species richness and landscape context. Next, we related $\beta$-diversity (i.e. annual species turnover) of arable weeds to landscape context and tested whether community similarity differs among years and between simple and complex landscapes. In this case, we hypothesised that species turnover would increase with increasing landscape complexity and community similarity among years would be high in simple but low in complex landscapes. Finally, we elucidated the relative importance of year, landscape context and environmental variables describing local site conditions for arable weed communities using multivariate ordination methods.

\section{Methods}

\section{Study area and landscape context}

The three-year study was conducted in conventionally managed winter wheat fields in the vicinity of Göttingen, Lower Saxony (Germany). This region is characterised by intensive agricultural land use and patchily distributed fragments of semi-natural habitats such as grasslands, fallows, hedges and forests. The average temperature $\left({ }^{\circ} \mathrm{C}\right)$ and total rainfall (mm) during the active growing season form March to June was $10.9{ }^{\circ} \mathrm{C}$ and 205 $\mathrm{mm}$ in 2001, $11.3^{\circ} \mathrm{C}$ and $259 \mathrm{~mm}$ in 2002, and $11.7^{\circ} \mathrm{C}$ and $176 \mathrm{~mm}$ in 2003 (data from the meteorological station in Göttingen).

In each year, 18 non-overlapping circular landscape sectors along a gradient of landscape complexity ranging from structurally simple landscapes to structurally complex landscapes were selected. Landscape complexity was characterised in each landscape circle of $2 \mathrm{~km}$ diameter by quantifying the regional perimeter-area ratio PAR $\left(\mathrm{P} / \mathrm{A}_{\mathrm{R}}=\sum_{\mathrm{i}=1}^{\mathrm{m}} \mathrm{P}_{\mathrm{i}} / \sum_{\mathrm{i}=1}^{\mathrm{m}} \mathrm{A}_{\mathrm{i}} ; \mathrm{P}=\right.$ perimeter, $\mathrm{A}=$ area of a patch, $\mathrm{i}=$ the patch number and $\mathrm{m}=$ the number of patches in the landscape sector) using ArcView 3.2 and digital vector maps (ATKIS - digital landscape model 25/1, Landesvermessung und Geobasisinformation, Hannover, Germany 1991-1996). The PAR is highly correlated with other landscape metrics such as the habitat-type diversity and topographical heterogeneity and indicates the edge density and the amount of disturbed habitats along roadsides and verges that may 
harbour annual plant communities (Gabriel et al. 2005). Analyses at different spatial scales (i.e. landscape sectors varying in diameter from $1 \mathrm{~km}$ to $5 \mathrm{~km}$ ) have shown that the PAR describing landscape sectors of $2 \mathrm{~km}$ diameter size had the best predictive power for arable weed diversity (Gabriel et al. 2005).

In the centre of each landscape a conventionally managed winter wheat field (Triticum aestivum L.) was selected. Fields changed during the three years as necessary due to crop rotation. In year 2003, in three landscapes we were unable to find fields that met our a priori selection criteria and therefore we replaced the landscapes with three new landscapes of similar complexity.

\section{Environmental variables}

Local site characteristics were recorded for each of the 18 wheat fields in each year. Soil types (cambisol, stagnic cambisol, entric regosol, haplic luvisol, fluvisol) were determined using the official map (1:50000) of the Niedersächsisches Landesamt für Bodenforschung (www.nlfb.de). Local chemical soil properties were analysed by taking soil samples from each site at a depth of $0-30 \mathrm{~cm}$. In 2001, 3 x 16 samples were taken in spring. In both 2002 and 2003, 16 samples were taken in September after harvest. Soil samples were analysed for soil $\mathrm{pH}$ measured in a $0.01 \mathrm{M} \mathrm{CaCl}_{2}$ solution and for total soil nitrogen $(\mathrm{N})$ using a LECO-C/N-analyser.

Fields were selected such that management was similar among the study fields. Previous analyses have shown that herbicide application rate is relatively consistent within the study region and independent from the surrounding landscape context (Gabriel et al. 2005, Roschewitz et al. 2005b). Data on nitrogen fertilisation (NF) were obtained from questionnaires given to farmers and were available for 42 of the 54 fields. Soil $\mathrm{pH}$, soil total nitrogen, and nitrogen fertilisation did not vary significantly between years (ANOVA $_{\mathrm{pH}} \mathrm{P}=0.174, \mathrm{ANOVA}_{\mathrm{N}} \mathrm{P}=0.807$, ANOVA $_{\mathrm{NF}} \mathrm{P}=0.115$ ) and were not related to landscape context; simple regressions $\mathrm{pH}(\mathrm{P}=0.307, \mathrm{R}=-0.14), \mathrm{N}(\mathrm{P}=0.227, \mathrm{R}=0.18)$, $\mathrm{NF}(\mathrm{P}=0.368, \mathrm{R}=-0.14)$.

\section{Plant surveys and diversity measures}

In each year, arable weed species were identified and the percentage cover of each species and of the crop were estimated. Surveys were done in the interior of the wheat fields on three subplots totalling $100 \mathrm{~m}^{2}$ in area in 2001 and 2002; and on two subplots totalling $50 \mathrm{~m}^{2}$ in area in 2003. Diversity of arable weeds was characterised by the species richness defined as the total number plant species per field. Annual species turnover was quantified (i.e. $\beta$-diversity) using the additive partitioning approach, where $\alpha+\beta=\gamma$ (Lande 1996). There, $\beta$-diversity is defined as the difference between the total number of species found in a landscape during the three years ( $\gamma$-diversity) and the average species richness found in a landscape per year ( $\alpha$-diversity). In addition, frequencies of each species were defined as the percentage of fields occupied by the species. 


\section{Statistical analysis}

To test whether species numbers of arable weeds vary among years and respond to landscape context, a mixed effect model (Pinheiro \& Bates 2000) was performed. The effects of year and landscape context and other measured environmental variables (soil type, soil acidity, total soil nitrogen, crop cover) and first-order interactions of year and landscape context with each other as well as with environmental variables were tested on species richness of arable weeds. Additionally, a block-factor was included as a random factor in the model to account for the variance that may be explained by fields positioned in the same landscapes over the three years. The model was simplified by removing first non-significant interactions $(\mathrm{P}>0.05)$ and then non-significant factors. A Mantel test (Legendre \& Legendre 1998) was performed to test for spatial autocorrelation by relating residuals from the statistical model with xy-coordinates of the study fields, but no spatial autocorellation was found ( $\mathrm{P}=0.321, \mathrm{R}=0.02)$.

In order to test for inter-annual changes in arable weed communities, first the relationship between annual species turnover and landscape context (PAR) was analysed by regressing $\beta$-diversity on the PAR (averaged across the years). Subsequently, analyses of similarity (ANOSIM, Clarke 1993) were performed to test whether the species composition of arable weed communities differs between simple and complex landscapes and among years. For ANOSIM, landscapes had to be classified into either simple or complex. Therefore sites were divided into the 9 simplest and 9 most complex landscapes in each year. The complement of the Jaccard index (Southwood \& Henderson 2000) was used as a measure of floristic distance in arable weed communities. A first ANOSIM was performed to test for the differences in community composition between simple and complex landscapes in general. In a further ANOSIM, we tested for differences in community composition among years in all landscapes and subsequently for simple and complex landscapes only.

Canonical correspondence analysis (CCA; ter Braak 1996, Legendre \& Legendre 1998), a direct ordination technique, was performed to evaluate the relationship between the measured environmental variables and the arable weed community. A forward stepwise procedure was used to find a best subset of all measured environmental variables (year, landscape context, soil type, soil acidity, soil total nitrogen, and crop cover) that represents the relation among species and environment. Subsequently, several partial canonical correspondence analyses (pCCA) with one explanatory variable and other best subset variables as covariables were performed to estimate the community variability attributable to the specific environmental variable after factoring out the effects of other variables (Legendre \& Legendre 1998). The ratio of constrained components to total inertia was used as a measure of the amount of explained variation. Significance of models were tested using ANOVA like permutation tests for pCCA (Legendre \& Legendre 1998), with 1000 or 10000 permutations depending on the critical $\mathrm{P}$ value. Community and environmental data were standardized to a range between 0 and 1 before ordination. Only species that were present in at least 5 fields out of 54 were used in the ordinations. 
In order to test whether species-specific responses to environmental gradients, as detected by pCCA, are related to their frequency (i.e. percentage of fields occupied), simple regression analyses were performed using axis scores of pCCAs. Percentage frequencies of species were log transformed to achieve adequate error distribution and only species with a fit to pCCA-axis greater than or equal to 0.15 were used for analyses.

Statistical analysis was carried out using R (R Development Core Team, 2004) in particular the nlme package for mixed models and the vegan package for community analysis. In the text, the arithmetic mean \pm standard deviation (from original values) are given.

Due to missing values for the nitrogen fertilisation, both a mixed effect model and a CCA were performed again for a sample size of 42. In the mixed model, the effects of year, landscape context, soil acidity, soil total nitrogen, crop cover, nitrogen fertilisation and first-order interactions between nitrogen fertilisation and the factors were tested. CCA was performed in the same way as described above. These analyses showed that nitrogen fertilisation had no significant effect on species numbers and species composition of arable weeds.

\section{Results}

The studied arable weed communities in 54 wheat fields had a species pool of 58 arable weed species, of which 42 were dicotyledons, 15 monocotyledons and one pteridophyte (Equisetum arvense L.). Forty-one species were found in 2001, 37 species in 2002 and 44 in 2003. The average number of arable weeds per field (8.9 \pm 4.2 , min: 1 , max: 20$)$ was composed of $6.6 \pm 3.6$ herbaceous species (min: 0, max: 14) and $2.3 \pm 1.4$ gramineous species (min: 0, max: 6). The average percentage cover of arable weeds per field (3.6 \% \pm $4.5 \%$, min: $0.01 \%$, max: $19 \%$ ) was composed of $2.2 \% \pm 3.2 \%$ cover of herbaceous species (min: $0 \%$, max: $14 \%$ ) and $1.4 \% \pm 2.6 \%$ cover of gramineous species (min: $0 \%$, max: $15 \%)$. Species number and percentage cover of arable weeds were highly correlated $(\mathrm{P}<0.001, \mathrm{R}=0.77, \mathrm{~N}=56)$.

\section{Effects on species richness}

Results of the mixed effect model revealed no differences in the number of arable weed species per field among years $(\mathrm{F}=1.0$, n.s., Fig. 3.1a) and a strong positive effect of landscape complexity on the number of species per field $\left(\mathrm{F}=21.8^{* * *}\right)$. However, landscape effects varied between years as indicated by an interaction $\left(\mathrm{F}=3.6^{*}\right)$ and were strongly pronounced in 2001 and 2003, but not observed in 2002 (Fig. 3.1b). No significant effects of soil type, soil $\mathrm{pH}$, total soil nitrogen, and crop cover were found on species numbers of arable weeds. 

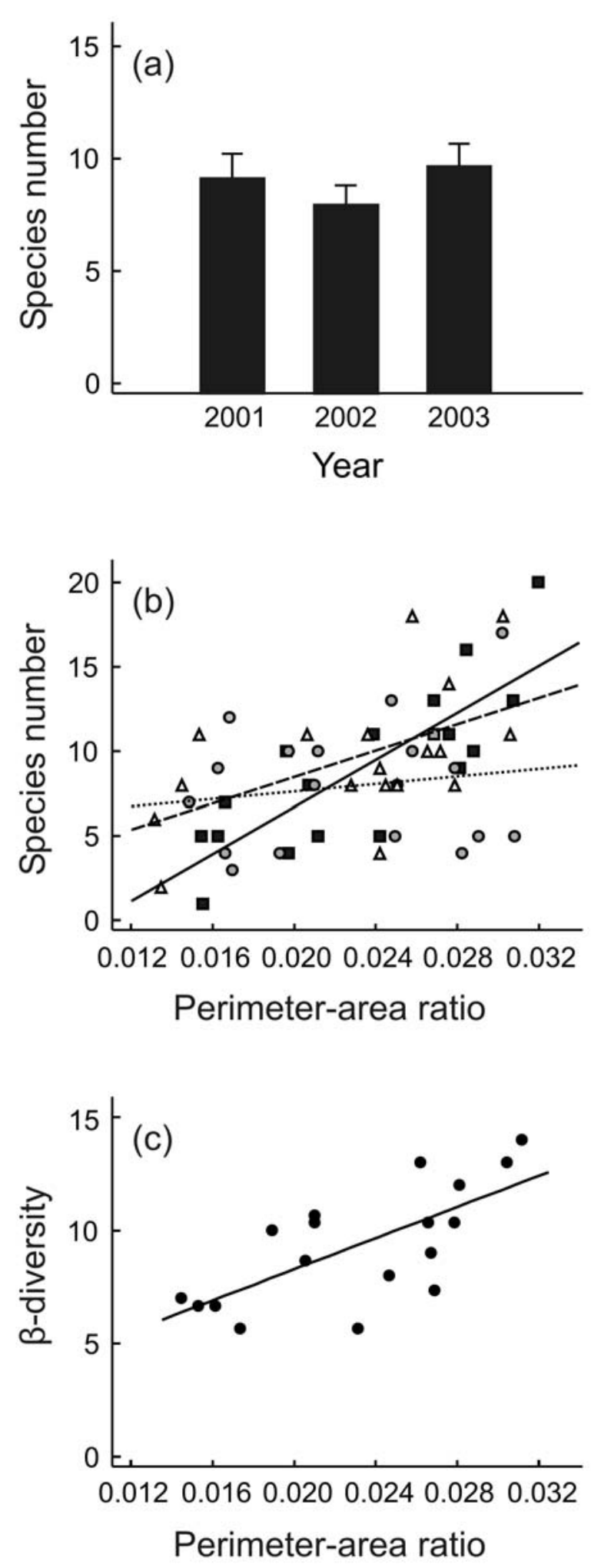

Fig. 3.1. Species numbers of arable weeds per field in relation to (a) the year of record and (b) the perimeter-area ratio of landscape sectors of $2 \mathrm{~km}$ diameter size. Legend: black quadrates and line year 2001, grey dots and dotted line year 2002, dark grey triangles and dashed line year 2003. Results of mixed effect models see text. $N=54$. (c) Temporal turnover ( $\beta$-diversity) of arable weeds in relation to the perimeter-area ratio of landscape sectors of $2 \mathrm{~km}$ diameter size (averaged over years) $\mathrm{N}=18$. 
$\beta$-diversity and community similarity

Annual species turnover responded to the landscape context (Fig. 3.1c), as indicated by a positive relationship between $\beta$-diversity and landscape complexity (simple regression: $\mathrm{R}$ $=0.70, \mathrm{P}=0.001, \mathrm{~N}=18$ ).

ANOSIM testing for differences in community similarity between simple and complex landscapes and among years revealed differences in community similarity between simple and complex landscapes $\left(\mathrm{R}=0.08^{* *}, \mathrm{~N}=54\right)$ and among years $\left(\mathrm{R}=0.08^{* *}, \mathrm{~N}=54\right)$. Interestingly, inter-annual changes in community similarity were not observed in simple $(\mathrm{R}$ $=0.05$ n.s., $\mathrm{N}=27)$, but only in complex landscapes $\left(\mathrm{R}=0.14^{* *}, \mathrm{~N}=27\right)$.

\section{Effects on community composition}

Out of 58 arable weed species found in the 54 fields, 25 occurred in at least 5 fields, and thus were suitable for ordination. Fig. 3.2a and b show the relationship between variation in species distribution and measured environmental factors as detected by CCA. A best subset model resulted in the following explanatory variables: soil $\mathrm{pH}$, year, landscape context, and total soil nitrogen (in the order they entered into the model) and explained $21.3 \%$ of species variance. The first axis (Fig. 3.2a) was negatively correlated with soil $\mathrm{pH}$ and low scores (i.e. response to high $\mathrm{pH}$ ) were found for Papaver rhoeas, Taraxacum officinale, Cirsium arvense, while high scores (i.e. response to low $\mathrm{pH}$ ) were found for Apera spica-venti, Agrostis stolonifera. The second axis was positively correlated with soil total nitrogen and negatively correlated with landscape complexity. High scores (i.e. high total nitrogen, simple landscapes) were found for Chenopodium album, Polygonum convolvulus, Veronica hederifolia and low scores (i.e. low total nitrogen, complex landscapes) were found for Papaver rhoeas, Taraxacum officinale, Aphanes arvensis (Fig. 3.2a). The third and fourth axis mainly described effects of the different years, with high occurrences of Stellaria media, Agrostis stolonifera, and Thlaspi arvense and low occurrences of Cirsium arvense and Papaver rhoeas in year 2002 (axis 3). High occurrences were observed for Aphanes arvensis, Lolium perenne, Galium aparine in year 2001 (axis 4) and Viola arvensis, Polygonum aviculare in 2003 (axis 4, Fig. 3.2b). Partial CCAs revealed highly significant effects of each best subset variable and similar species responses as detected in CCA (Tab. 3.1). Year and soil $\mathrm{pH}$ explained the most variance of species variation, $7.30 \%$ and $5.33 \%$, respectively, followed by landscape complexity and total soil nitrogen, $4.36 \%$ and $4.30 \%$.

Species-specific frequencies were not related to pCCA axes describing $\mathrm{pH}$ and year effects (P-values $>0.10$ ). A negative correlation between axis scores of pCCA describing landscape context and species-specific frequency (Fig. 3.3) indicated that species occurring in simple landscapes had a higher frequency of occurrence, than species occurring in complex landscapes. Similarly, the frequency of occurrence of species that responded to high total soil nitrogen was generally higher, than that for species responding to low total soil nitrogen $(\mathrm{P}=0.084, \mathrm{R}=0.46, \mathrm{~N}=15)$. 

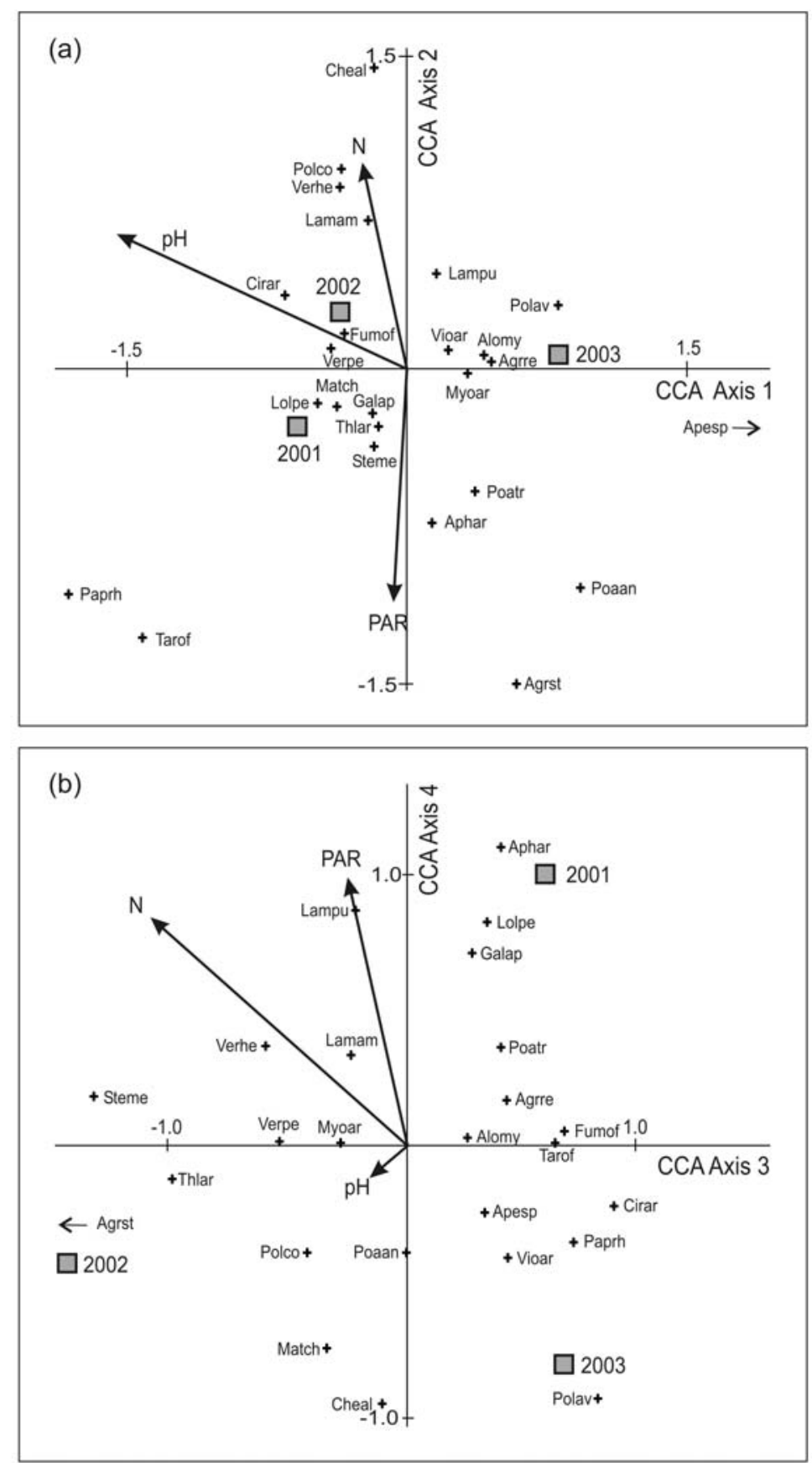

Fig. 3.2. Canonical correspondence analysis showing species distribution and relation to the best subset environmental variables. (b) Axis 1 and 2 with Eigenvalues of 0.44 and 0.36 and (c) Axis 3 and 4 with Eigenvalues of 0.31 and 0.23 . Axis 5 with Eigenvalue of 0.19 not shown. Variance inflation factors of each variable in the CCA model were for soil $\mathrm{pH}: 1.6$, year 2002: 1.4, year 2003: 1.5, landscape context: 1.2 and total soil nitrogen: 1.5. Abbreviations: Agrre $=$ Agropyron repens L., Agrst $=$ Agrostis stolonifera L., Alomy $=$ Alopecurus myosuroides Huds., Apesp $=$ Apera spica-venti (L.) P. Beauv., Aphar = Aphanes arvensis L., Cheal = Chenopodium album L., Cirar = Cirsium arvense (L.) Scop., Fumof $=$ Fumaria officinalis L. s. l., Galap = Galium aparine L., Lamam = Lamium amplexicaule L., Lampu $=$ Lamium purpureum L. s. l. p. p., Lolpe $=$ Lolium perenne L., Match = Matricaria chamomilla L., Myoar = Myosotis arvensis (L.) Hill, Paprh = Papaver rhoeas L., Poaan = Poa annua L., Poatr $=$ Poa trivialis L. s. l., Polav $=$ Polygonum aviculare L. (s. l.), Polco = Polygonum convolvulus L., Steme = Stellaria media (L.) Vill. s. str., Tarof $=$ Taraxacum officinale Weber, Thlar $=$ Thlaspi arvense L., Verhe $=$ Veronica hederifolia L. s. l., Verpe $=$ Veronica persica Poir., Vioar $=$ Viola arvensis Murray. 
Table 3.1. Summary of four separate partial canonical correspondence analyses with best subset variables explaining variation in species data. High values of axis scores of pCCAs are associated with low soil $\mathrm{pH}$, high landscape complexity, high total soil nitrogen. Low values of axis 1 in pCCA describing year effects represents high abundance in year 2002, axis 2 high values represents high abundance in year 2003 and low abundance in 2001. \% F: Percentage frequency that species occurred in 54 wheat fields.

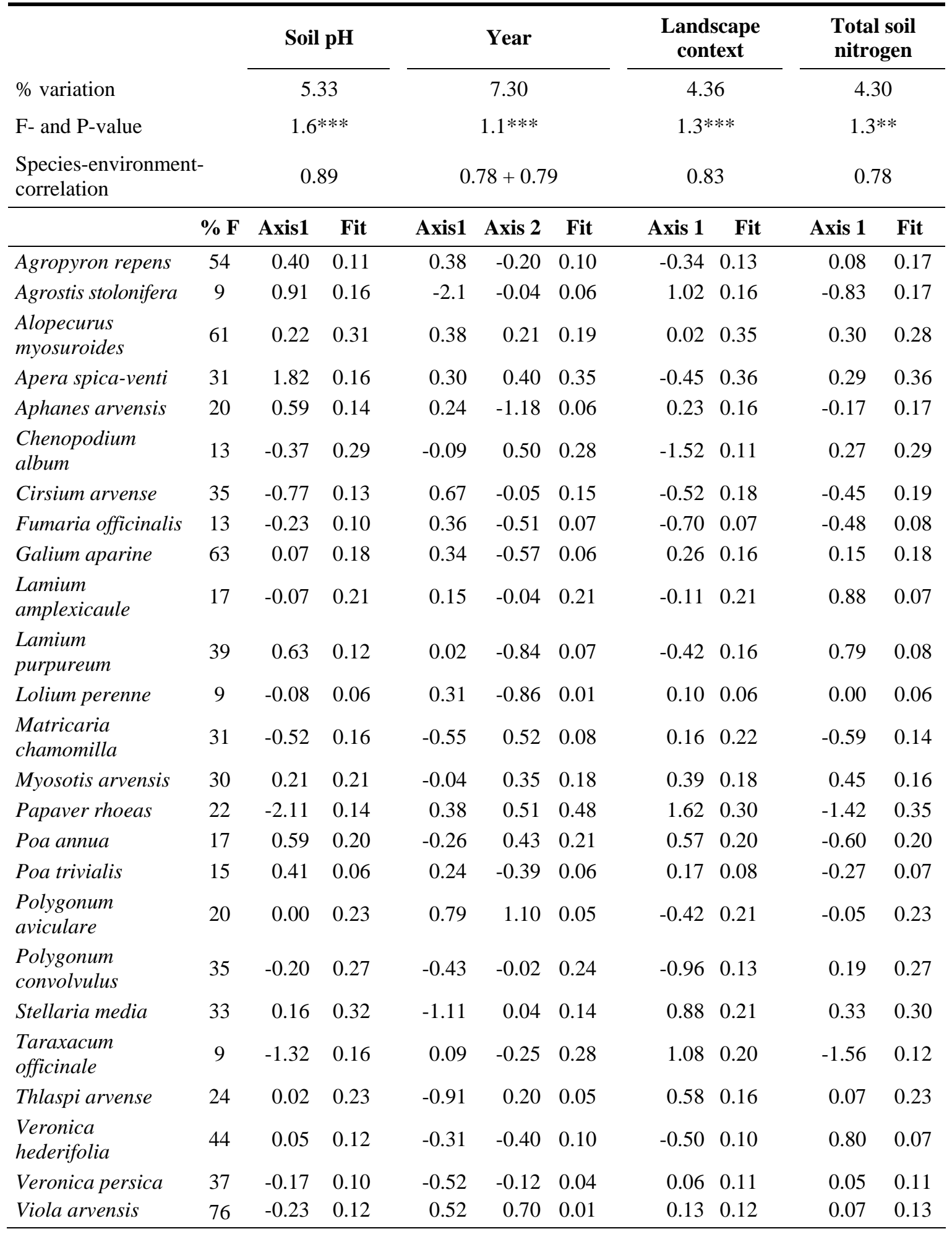




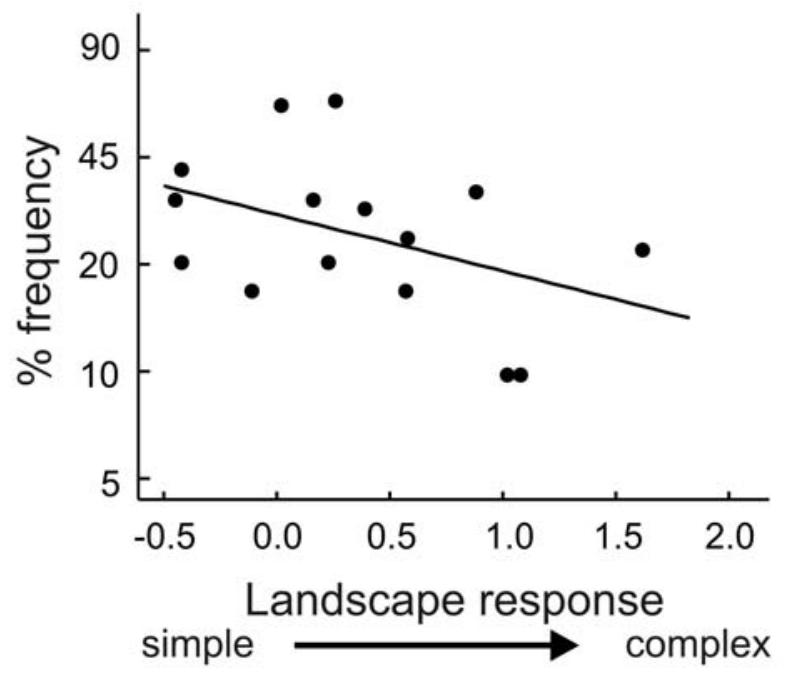

Fig. 3.3. Relationship between species-specific frequency (percentage occurrence out of 54 fields) and species response to landscape context described by pCCA axis scores $(\mathrm{P}=0.079, \mathrm{R}=-0.45, \mathrm{~N}$ =16). See also Table 3.1.

\section{Discussion}

Patterns of arable weed community structure were strongly influenced by year and landscape context. Interactions between time (year) and space (landscape context) showed that inter-annual changes in arable weed communities are mediated by landscape complexity. Plant communities differed between simple and complex landscapes and among years. However, inter-annual variability in plant communities was low in simple landscapes, but high in complex landscapes. Similarly, $\beta$-diversity (i.e. temporal species turnover among years) increased with increasing landscape complexity. Cumulatively these results indicate higher heterogeneity in plant communities among years in complex compared to simple landscapes.

The aboveground plant community, which was measured in our study, results from germinating seeds originating either from the persistent seed bank, from seed rain resulting from local plant community and/or from seeds immigrating from the surrounding landscape. The importance of these processes was shown by Roschewitz et al. (2005a), who found that the species pool in the seed bank was strongly related to landscape context, with complex landscapes harbouring more species. Furthermore, in arable weed communities the aboveground vegetation resembles species in the soil seedbank (Albrecht \& Pilgram 1997, Legere et al. 2004, Roschewitz et al. 2005a). Thus, our finding that local species richness is higher in complex than in simple landscapes is in accordance with the previous work. Although community similarity and composition varied considerably 
among years, species richness per field - a measure of aggregate variability - did not differ among years, indicating compensation effects (Micheli et al. 1999).

Plant communities were similar among years in simple landscapes, but quite dissimilar in complex landscapes suggesting a strong role of landscape context in mediating interannual variability. While a high heterogeneity in plant communities in complex landscapes may be attributed to a higher heterogeneity in environmental conditions among fields, our analysis did not support this hypothesis. Environmental variables (e.g. soil $\mathrm{pH}$ or $\mathrm{N}$ content) were not related to landscape context and did not differ in their coefficients of variation between simple and complex landscapes (simple vs. complex: $\mathrm{pH}_{\mathrm{CV}}: 6.0 \%$ vs. $6.7 \%, \mathrm{~N}_{\mathrm{CV}}: 30.0 \%$ vs. $\left.30.8 \%\right)$. We suggest that inter-annual variability more likely results from an interaction between landscape context and temporal effects such as differing weather conditions among years (Silverton \& Lovett Doust 1993). Arable weed communities have to re-establish each year after ploughing and weed control methods. Which species germinate within a field depends on their specific traits, and response to environmental conditions, e.g. temperature and humidity, time of cultivation, and dormancy patterns (Harper 1977, Baskin \& Baskin 1985, Bazzaz 1996, Baskin \& Baskin 2000, Milberg et al. 2001). Inter-annual differences in environmental conditions may thus favour different subsets of species, creating heterogeneity in plant communities among years, but why should this differ among simple and complex landscapes? We suggest that this is likely due to the fact that landscape types generally differ in the traits of their component species. Our correlation analysis between species-specific frequency of occurrence and axis scores of pCCA describing the landscape response (Fig. 3.3), indicate that plant communities in simple landscapes were dominated by the very frequent, widespread and robust arable weed species such as Agropyron repens, Apera spica-venti, and Polygonum convolvulus, while species in complex landscapes generally had a lower frequency of occurrence e.g. Papaver rhoeas, Taraxacum officinale, Thlaspi arvense (Table 3.1). Species that are widely distributed generally have broader niche breadths, and thus may be more tolerant to environmental changes e.g. in weather conditions (Brown 1984, but see Thompson et al. 1999 and Thompson \& Ceriani 2003). This might explain our finding that communities in simple landscapes were similar among years, whereas communities in complex landscapes were more sensitive to changes thereby creating heterogeneity, i.e. temporal turnover among years. Furthermore, our results are in accordance with the idea that in a given system the number of rare, i.e. less frequent, species is positively related with overall species richness (Gaston 1994 and citations therein). In our study, complex landscapes had overall more species and a greater proportion of rare species occurred in species rich plots (Fig. 3.4). This would additionally explain why complex landscapes, which had more diverse communities, exhibited greater temporal heterogeneity in community composition.

While local soil properties had no significant effect on arable weed species richness per field, soil $\mathrm{pH}$ and total soil nitrogen were important determinants of plant community composition. This result is in accordance with other studies of plant community 
composition (Salonen 1993, Ervio et al 1994, Lososova et al. 2004, Hyvönen et al. 2005). Interestingly, species that were positively affected by landscape complexity also responded negatively to total soil nitrogen, although these two factors were independent from one another. Our results demonstrate that areas with low soil nitrogen levels harbor rarer species and therefore, conservation strategies should aim to protect areas with low soil nitrogen levels. At the same time our results suggest that the maintenance and enhancement of diverse arable weed communities requires a multi-scale perspective, incorporating both local and regional aspects (Tscharntke et al. 2005). The landscape-wide agricultural intensification threatens the continuity of complex landscapes. But landscapes with high densities of field edges and semi-natural habitats can act as refuges for many arable weed species and should therefore be preserved.

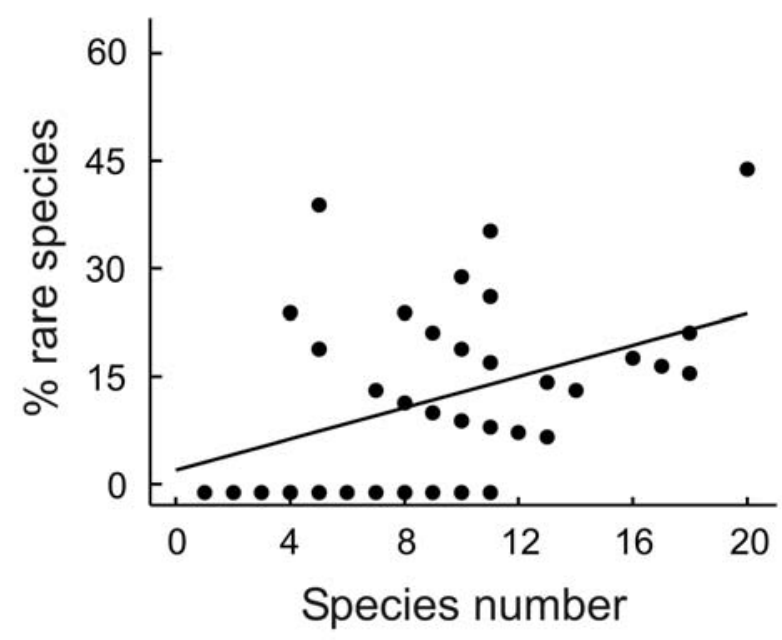

Fig. 3.4. The percentage of rare species per field increased with increasing total species number per field $(\mathrm{F}=62.0, \mathrm{P}<0.0001, \mathrm{~N}=54)$. Rare species were defined as species occurring in less than 5 fields out of 54 fields (i.e. percentage frequency $<10 \%$ ). Statistics: Mixed effect model was performed with quasipoisson errors and random factor (see also Methods).

Although we found interpretable patterns detected by CCA and pCCAs, our study also has limitations, which should be taken into account. First, while the four best subset variables in the ordination explained $21 \%$ of variation in species composition, a larger amount of the variance remained unexplained suggesting that additional unmeasured factors such as local weather and management conditions may be important. Second, ordinations were done for less than half of the total species pool found during the study. Thus our ordination results are valid only for the prevalent arable weeds. Despite these limitations, our careful study site selection made it possible to differentiate between local and landscape effects because covariation among explanatory variables was low as indicated by the very low variance inflation factors. 
In summary, inter-annual changes in arable weed communities were observed at the level of community similarity and composition but not at the level of aggregate species numbers. Community similarity was high in simple but low in complex landscapes suggesting that inter-annual variation was mediated by landscape effects. We suggest that differing weather conditions acting on the seed pool determined by the surrounding landscape may drive inter-annual changes in community structure. We found that species occurring in complex landscapes were less common (lower frequency of occurrence) than those in simple landscapes. Rarer species may have smaller niche breadths and increased sensitivity to changing conditions, which would explain the high inter-annual heterogeneity in plant communities observed in complex compared to simple landscapes.

\section{Acknowledgements}

This work was embedded in the BIOPLEX project (Biodiversity and spatial complexity in agricultural landscapes under global change) supported by the German Federal Ministry of Education and Research (BMBF). We thank all the people who were involved in the project and made good collaborations possible, in particular Jens Dauber, Tobias Purtauf, Martin Schmidt and Carsten Thies. Many thanks also to the farmers for their willingness to participate. 
Chapter

4

Relative importance of beta diversity at different spatial scales plant communities in organic and conventional agriculture

Doreen Gabriel, Indra Roschewitz, Teja Tscharntke \& Carsten Thies

Submitted to Ecological Applications 


\begin{abstract}
Biodiversity studies that guide agricultural subsidy policy have generally compared farming systems at a single spatial scale - the field. However, diversity patterns vary across spatial scales. Here, we examined the effects of farming system (organic vs. conventional) and position in the field (edge vs. center) on plant species richness in wheat fields at three spatial scales. We quantified $\alpha$-, $\beta$-, and $\gamma$-diversity at the micro scale in 800 plots, at the meso scale in 40 fields, and at the macro scale in three regions using the additive partitioning approach, and evaluated the relative contribution of $\beta$-diversity at each spatial scale to total observed species richness. $\alpha$-, $\beta$-, and $\gamma$-diversity was higher in organic than conventional fields and higher at the field edge than in the field center at all spatial scales. In both farming systems $\beta$-diversity at the meso and macro scale explained most of the overall species richness (up to $37 \%$ and $25 \%$, respectively), indicating considerable differences in community composition among fields and regions due to environmental heterogeneity. The spatial scale at which $\beta$-diversity contributed the most to overall species richness differed between rare and common species. Total richness of rare species (present in $\leq 5 \%$ of total samples) was mainly explained by differences in community composition at the meso and macro scale (up to $27 \%$ and $48 \%$, respectively), but only in organic fields. Total richness of common species (present in $\geq 25 \%$ of total samples) was explained by differences in community composition at the micro and meso scale (up to $29 \%$ and $47 \%$, respectively), i.e. among plots and fields, independent of farming system. Our results show that organic farming made the greatest contribution to total species richness at the meso (among fields) and macro (among regions) scale due to environmental heterogeneity. Hence, agri-environment schemes should exploit this largescale contribution of $\beta$-diversity by tailoring schemes at regional scales to maximize dissimilarity between conservation areas using geographic information systems rather than focus entirely at the classical local field scale, which is the current practice.
\end{abstract}

Keywords: arable weeds, field edge, gamma diversity, landscape, mass effect, mixed effect models, organic farming, spatial scale, species richness 


\section{Introduction}

During the last decades increasing agricultural intensification has led to a decrease in species richness and a change in species composition of arable weeds (i.e. non-cultivated wild plants cohabiting the fields with crops; Albrecht 1995, Andreasen et al. 1996, Sutcliffe and Kay 2000, Robinson and Sutherland 2002). At the field and farm scale, improvements in crop management techniques involving the use of herbicides and mechanical weed control, increases in fertilizer usage, simplification of crop rotations, and improvements in seed-cleaning techniques have been responsible for the loss of annual wildflowers and other taxa in agroecosystems (Firbank 1988, Albrecht 1995, McLaughlin and Mineau 1995, Sotherton 1998, Stoate et al. 2001, Benton et al. 2003). At the landscape scale, farm enlargement and specialization on a narrow range of arable crops, abandonment of areas with marginal crop yields and land consolidation has led to large uniformly cropped areas and a decrease in spatial heterogeneity (Robinson and Sutherland 2002, Benton et al. 2003). Arable weeds as important components of biodiversity in agroecosystems (Marshall et al. 2003) belong to the most endangered plant communities in Germany (Hofmeister and Garve 1998), with roughly one third of the 250 - 300 arable weed species recorded on the German Red Data List of endangered species (Eggers 1987).

To counteract the decline of biodiversity in agro ecosystems, strategies on agrienvironmental schemes classically focus on the improvement of local habitat conditions by implementing conservation headlands i.e. flowering plant strips in the field margin or in the field edge without nitrogen fertilization and herbicide applications (Kleijn and Vandervoort 1997), reducing agrochemical applications or promoting organic farming (Kleijn and Sutherland 2003). It has been suggested that organic farming enhances biodiversity in agroecosystems (van Elsen 2000, Hole et al. 2005). Positive effects on species richness and composition of arable weeds from organic farming relative to conventional farming have been reported in several studies (Moreby et al. 1994, Hald 1999a, Menalled et al. 2001, Hyvönen et al. 2003b, Bengtsson et al. 2005). However, most of this research has focused on only one spatial scale, i.e. plots or fields (see Hole et al. 2005). Such single-scale studies identify only a subset of diversity that may lead to fragmentary results. For example, several high-diversity fields all harboring similar species may collectively be less diverse than comparatively low-diversity fields harboring different species. A multi-scale approach makes it possible to identify the spatial scale at which each farming system contributes most to overall arable weed diversity, i.e. where the highest turnover occurs, and therefore the appropriate scale at which the management for conservation (e.g. agri-environment schemes) should be designed.

The additive partitioning approach is a useful tool for quantifying diversity components across multiple spatial scales (Allan 1975, Lande 1996, Wagner et al. 2000, Gering et al. 2003). Total species richness ( $\gamma$-diversity) found in a given location can be partitioned into $\alpha$-diversity (the average number of species that occur in a sampling unit $=$ withincommunity diversity) and $\beta$-diversity (between community diversity; $\beta=\gamma-\alpha$ ). $\alpha$ - and $\beta$ - 
diversity can be compared because their units of measurement are the same. Therefore partitioning can be applied at any spatial scale (Veech et al. 2002). Additive partitioning of diversity was applied in a spatial context by Wagner et al. (2000) and Fournier and Loreau (2001) for plants and carabid beetles of different habitat types in agricultural landscapes. It has also been used for arboreal beetles and forest Lepidoptera (Gering et al. 2003, Summerville et al. 2003), and for butterfly and bird diversity in canyons and mountain ranges (Fleishman et al. 2003).

In general, species richness and composition of arable weeds are related to local abiotic conditions like soil properties (Dale et al. 1992) and farming practices differing in herbicide use, mechanical weed control, tillage systems, and nitrogen fertilizer input (Pyšek and Lepš 1991, McCloskey et al. 1996, Andersson and Milberg 1998, Hyvönen and Salonen 2002). As a consequence, many plant species occur predominantly at the field edge, where management practices are less intensive (Marshall 1989, Wilson and Aebischer 1995, Hald 1999a). The structural complexity of the surrounding landscape, e.g. the amount of ruderal land cover, and the regional species pool is regarded to influence local diversity (Ricklefs 1987, Zobel 1997, Booth and Swanton 2002, Gabriel et al. 2005) and effects of landscape complexity might interfere with effects of farming system (Bengtsson et al. 2005, Hole et al. 2005, Roschewitz et al. 2005a). However, the impacts of spatial variability have received little attention in weed ecology as yet.

Here, we analyze the contribution of farming system (organic vs. conventional) and position in the field (edge vs. center) to plant species richness in wheat fields at three spatial scales. We quantified species richness at a micro scale from 800 plots within 40 fields, at a meso scale from 40 fields within three regions, and at a macro scale from three regions by partitioning the number of species into the additive components $\alpha-$-, $\beta$-, and $\gamma$ diversity. We examined whether (1) $\alpha$-, $\beta$-, and $\gamma$-diversity of arable weeds is higher in field edges, organic fields and structurally complex landscapes, and whether (2) any patterns differ between rare and common species. In addition, we evaluated the relative contribution of $\beta$-diversity at the micro, meso, and macro scale to overall species richness and to the richness of rare and common species to identify the most appropriate scale for effective conservation management.

\section{Methods}

\section{Study sites and sampling design}

The study was conducted in three agricultural regions in Germany: Soester Boerde (51 ${ }^{\circ}$

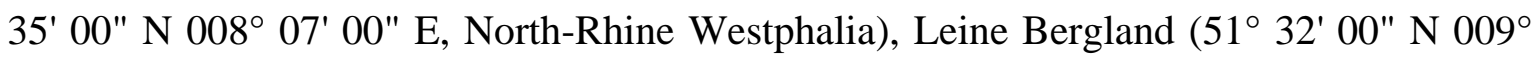
56' 00" E, Lower-Saxony), and Lahn-Dill Bergland (5049' 00" N 008 46' 00" E, Hesse) (Fig. 4.1a). The regions covered $620 \mathrm{~km}^{2}, 670 \mathrm{~km}^{2}$ and $1000 \mathrm{~km}^{2}$ with a distance of 100 $\mathrm{km}$ to $130 \mathrm{~km}$ from each other. Mean annual temperature and mean annual precipitation in the study regions were $9.3^{\circ} \mathrm{C}$ and $764 \mathrm{~mm}$ in the Soester Boerde, $8.7^{\circ} \mathrm{C}$ and $645 \mathrm{~mm}$ in the 
Leine Bergland, and $9.4^{\circ} \mathrm{C}$ and $745 \mathrm{~mm}$ in the Lahn-Dill Bergland. The average elevation of study sites within each region was as follows: Soester Boerde: $170 \mathrm{~m}$ (min: $70 \mathrm{~m}$, max: 320 m), Leine Bergland: 214 m (min: 155 m, max: 295 m), Lahn-Dill Bergland: 273 m (min: 172 m, max: $496 \mathrm{~m}$ ). We selected seven circular landscape sectors (2 km diameter) in the regions Soester Boerde and Lahn-Dill Bergland and six landscape sectors in the region Leine Bergland. These landscape sectors differed in their structural complexity, varying from structurally simple landscapes with a high percentage of arable land, to complex landscapes with a low percentage of arable land and a large proportion of seminatural land cover and land use types, such as grasslands, hedges, fallows, and margins (Fig. 4.1b). In the center of each landscape a pair of one organic and one conventional winter wheat field (Triticum aestivum L.) was selected. The matched fields were in close proximity to ensure similar abiotic conditions. Around each focal field, habitat and land use types were surveyed within a radius of $1 \mathrm{~km}$ and mapped by field inspections on the basis of official topographical maps (DGK 5, 1:5000) using the GIS ArcView 3.2 (ESRI Geoinformatik Hannover, Germany). We used the percentage of arable land surrounding each study site as a simple measure of landscape complexity because of its close correlation with other landscape metrics such as habitat type diversity (Shannon diversity; $P<0.001 ; \mathrm{R}=-0.95 ; \mathrm{N}=40)$ and the perimeter-area ratio $(P<0.001 ; \mathrm{R}=-0.64 ; \mathrm{N}=40)$ (see also Gabriel et al. 2005). The average percentage of arable land \pm SD within $1 \mathrm{~km}$ around the study sites was: Soester Boerde: 64\% $\pm 12.1 \%$, (min: 42\%, max: 86\%), Leine Bergland: $68 \% \pm 15.8 \%$, (min: 40\%, max: 85\%), Lahn-Dill Bergland: $47 \% \pm 21.5 \%$, (min: 17\%, max: 85\%).

Organic fields were managed according to European Union Regulation 2092/91/EEC, which prohibits the use of synthetic fertilizers and pesticides. The average time since conversion to organic farming was 11.6 years \pm 5.9 years and varied between 2 years and 24 years. Species richness of arable weeds was not related to the time since conversion ( $P$ $=1 ; \mathrm{R}=0.0 ; \mathrm{N}=20$ ).

Local soil chemistry was analyzed from each field by taking 16 soil samples at a depth of $0-30 \mathrm{~cm}$. Sampling was carried out after wheat harvest in September 2003 to ensure representativeness that might have been lacking during vegetation period due to different timings in fertilizer applications. Samples were analyzed for soil total nitrogen and organic carbon using a LECO-C/N-analyzer and soil $\mathrm{pH}$ was measured in $0.01 \mathrm{M} \mathrm{CaCl}_{2}$ solution. All fields were on loamy soils. The average \pm SD of soil parameters were total nitrogen (\% in dry weight): $0.14 \pm 0.033$ (min: 0.10 , max: 0.23 ), organic carbon (\% in dry weight): 1.4 \pm 0.32 (min: 1.0, max: 2.3), C/N-ratio $10.2 \pm 0.71$ (min: 8.6, max: 12.3), and $\mathrm{pH} 6.2 \pm 0.52$ (min: 4.8, max: 7.0). Soil parameters did not differ significantly between farming systems and regions (all $P$-values $>0.05$ ).

At the end of May 2003, herb and grass species in each field were recorded using two $95 \mathrm{~m}$ transects parallel to the machine track. Each transect consisted of ten plots (5 m x 1 $\mathrm{m}$ ) at intervals of $5 \mathrm{~m}$. One transect followed the field edge adjacent to a field margin and one transect was $30 \mathrm{~m}-50 \mathrm{~m}$ away from the edge transect located in the field center. 
(a)
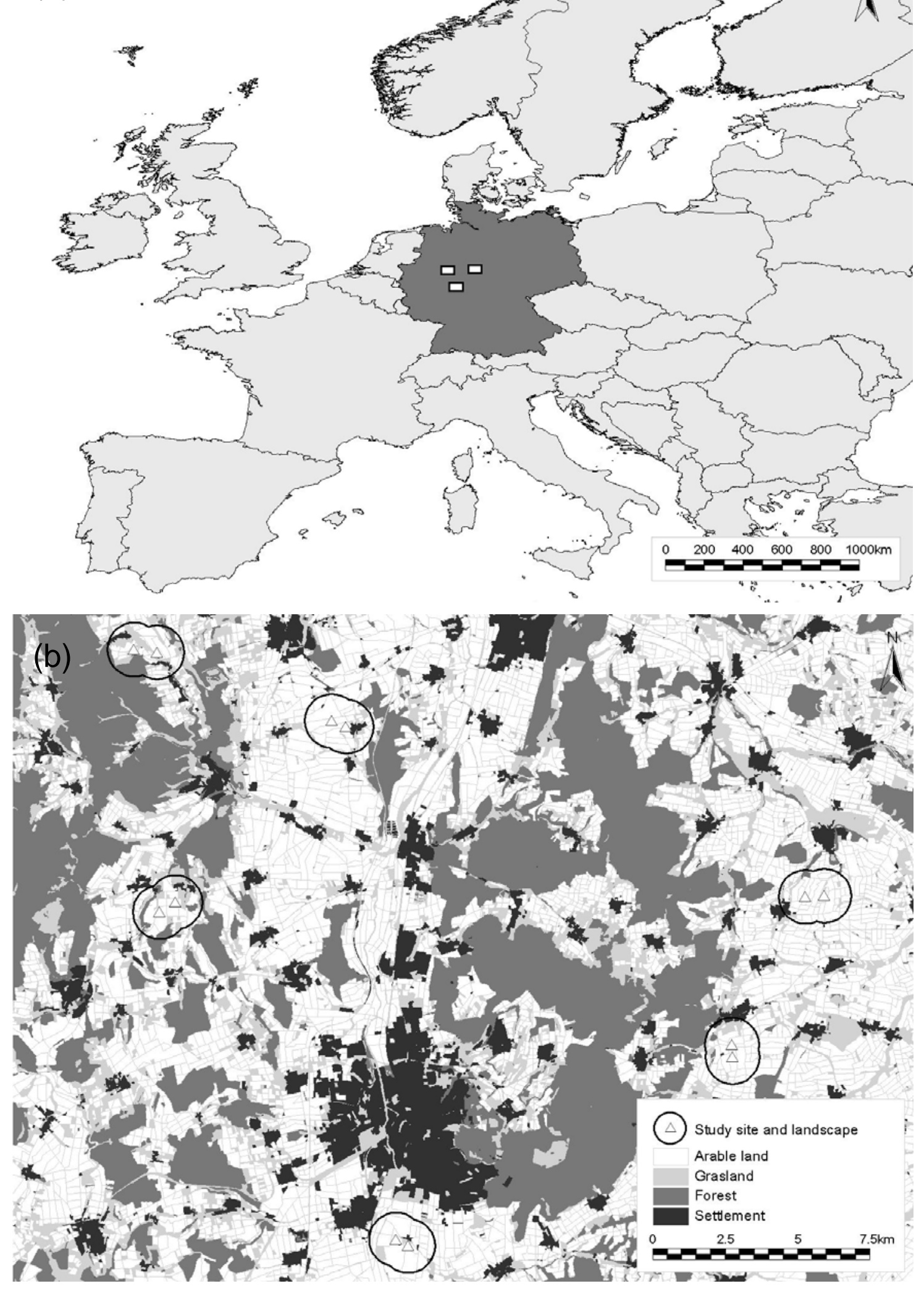

Fig. 4.1. a) Overview of the location of the three study regions in Germany/Europe (data obtained from ArcView 3.2 ESRI). b) Example of the landscape gradient approach within Region Leine Bergland illustrating the paired wheat fields surrounded by landscapes of different complexity (data obtained from ATKIS - digital landscape model 25/1, Landesvermessung und Geobasisinformation, Hannover, Germany 1991-1996). 


\section{Additive partitioning of species richness}

At three spatial scales, we partitioned the total observed species richness (i.e. the number of species) into scale-specific diversity components for each treatment factor (edge/organic, edge/conventional, center/organic, center/conventional) using the additive partitioning approach $\alpha+\beta=\gamma$ (Allan 1975, Lande 1996, Wagner et al. 2000, Gering et al. 2003). The sampling unit at the smallest scale (micro scale) was represented by the plots within a field (field = edge or center transect), the medium scale (meso scale) by the fields within a region, and the largest scale (macro scale) by three regions (Fig. 4.2). $\alpha$-diversity (within-unit diversity) was the average number of species found in a sampling unit (e.g. per plot in a field, per field in a region, or per region), $\gamma$-diversity (total species diversity) was the number of species found in the pooled sampling unit (e.g. in all plots per field, in all fields per region, or in all regions), and $\beta$-diversity (between-unit diversity) was the average number of species found among the sampling units $(\beta=\gamma-\alpha)$. Mean $\gamma$-diversity at a given scale (e.g. micro scale) is equivalent to mean $\alpha$-diversity at the next larger scale (e.g. meso scale). Thus, total diversity at one scale results from the diversity of the next lower scale plus between-unit diversity ( $\beta$-diversity). Therefore, the total observed diversity is the sum of $\alpha$ - and $\beta$-diversity at the micro scale plus $\beta$-diversity at the meso and macro scale.

Additionally, we repeated the complete procedure for a comparison of rare and common plant species. Species that occurred in less than or equal to $5 \%$ of 80 sampling units at the micro scale were defined as rare species (present in $\leq 4$ of 80 transects) and species that occurred in at least $25 \%$ of sampling units were defined as common species (present in $\geq$ 20 of 80 transects).

\section{Statistics}

The variability of $\alpha$-, $\beta$-, and $\gamma$-diversity was analyzed using mixed effect models (Pinheiro and Bates 2000), which account for non-independent errors that may occur due to the hierarchically nested sampling design. At the micro scale, we tested the effect of position in the field (edge/center), farming system (organic/conventional), and region (Soester Boerde/Leine Bergland/Lahn-Dill Bergland) as categorical factors, landscape complexity (percentage arable land) as a continuous variable, and first-order interaction on $\alpha$-, $\beta$-, and $\gamma$-diversity by including the field pairs as random factor. At the meso scale, we tested the effect of position in the field (edge/center), farming system (organic/conventional), and first-order interaction by grouping the regions. In a second analysis at the meso scale, we tested the effect of the region on diversity components by grouping the treatment factors. Models were simplified by removing non-significant interactions ( $P>0.05$, first step) and non-significant factors (second step). Non-significant factors which figured in significant interactions were not removed (Crawley 2002). Statistical analysis was carried out using R (R Development Core Team, 2004). Percentage values of arable land were arcsine-square-root transformed (Sokal and Rohlf 1995). 


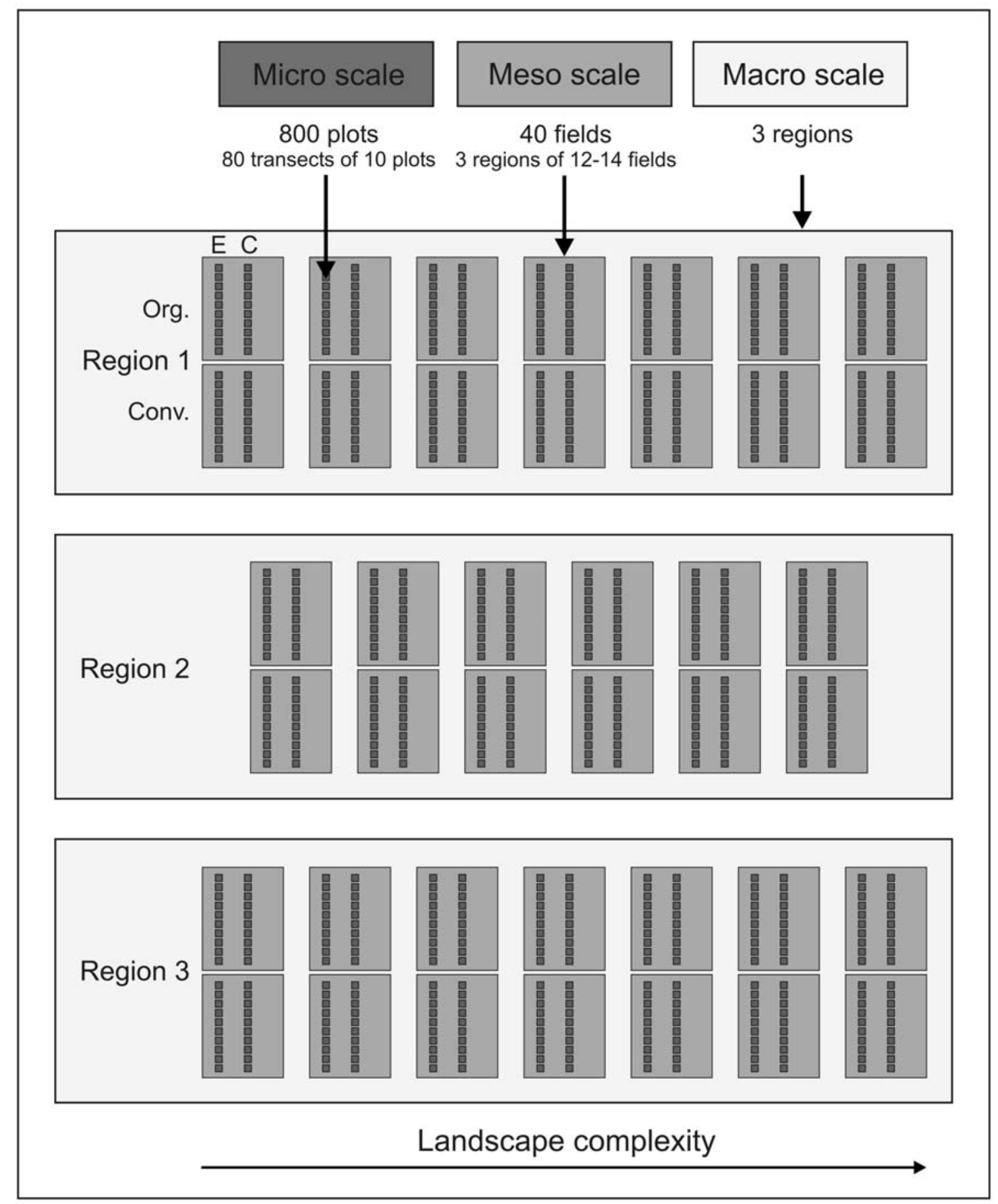

Fig. 4.2. Hierarchical sampling design used to record plant species at three spatial scales: 800 plots within 80 transects (40 edge transects +40 center transects) were nested within 40 fields, and 40 fields (20 organic +20 conventional) were nested within three regions. The arrow indicates the gradient in landscape complexity surrounding the fields. $\mathrm{E}=$ edge plots, $\mathrm{C}=$ center plots, Org. = organic fields, Conv. = conventional fields, Region 1: Soester Boerde, Region 2: Leine Bergland, Region 3: Lahn-Dill Bergland. 


\section{Pre-analyses}

Spatial autocorrelation in species composition was tested in a pre-analysis using the Mantel test (Legendre and Legendre 1998) to relate the floristic similarity between sites to geographic distance between sites. The complement of the Jaccard index (Southwood and Henderson 2000) was used as a measure of floristic distance. Mantel tests (based on Spearman correlations, 1000 permutations) were performed for all sites in three regions and for each region separately, but no spatial autocorellation effect was found (all sites: $P$ $=0.431, \mathrm{R}=0.01, \mathrm{~N}=40$; Soester Boerde: $P=0.871, \mathrm{R}=-0.13, \mathrm{~N}=12$; Leine Bergland: $P=0.239, \mathrm{R}=0.07, \mathrm{~N}=14$; Lahn-Dill Bergland: $P=0.653, \mathrm{R}=-0.08, \mathrm{~N}=14$ ).

As local conditions are often considered to influence plant species richness, a multiple regression model (stepwise forward selection) was used to test the effects of local soil chemistry (total nitrogen, organic carbon, $\mathrm{C} / \mathrm{N}$ ratio and $\mathrm{pH}$-value), geographical coordinates $\mathrm{x}$ and $\mathrm{y}$ including the seven terms of a cubic trend surface: $\mathrm{x}^{2}, \mathrm{xy}, \mathrm{y}^{2}, \mathrm{x}^{3}, \mathrm{x}^{2} \mathrm{y}$, $\mathrm{xy}^{2}, \mathrm{y}^{3}$ (Borcard et al. 1992), and elevation on species richness of arable weeds. No factor entered the model $(P>0.2, \mathrm{R}=0.18, \mathrm{~N}=40)$, indicating neither an association between soil chemistry and patterns of plant species richness nor a predictable spatial pattern of species richness.

Adequacy of sampling effort was validated by calculating species-accumulation curves and the Incidence-based Coverage Estimator (ICE) using EstimateS, Version 5 (Colwell 1997) with 500 randomizations. The degree of species saturation was indicated by the percentage of observed species relative to the estimated species richness. We used sampling units at the micro scale (i.e. pooled transect plots) to avoid pseudo replication. The degree of species saturation was $91.8 \%$ for all samples, and $86.1 \%$ for field edges in organic fields, $83.5 \%$ for centers in organic fields, $83.4 \%$ for edges in conventional fields, and $78.2 \%$ for centers in conventional fields. These results indicated that sample size and sampling effort were sufficient.

\section{Results}

\section{Additive partitioning of arable weed species}

In total, 110 plant species from 28 families were recorded, of which 89 were herbaceous and 21 were graminaceous species (for species list see Appendix). $\alpha-, \beta$-, and $\gamma$-diversity were higher in organic than in conventional fields and higher in field edges than in field centers at all three spatial scales (micro, meso and macro scale, Fig. 4.3a). The contribution of each treatment factor to the total observed species richness of 110 species varied considerably (see $\gamma$-diversity at the macro scale, Table 4.1). 
Table 4.1. Relative contribution (\%) of $\alpha$-diversity at the micro scale, and $\beta$-diversity at the micro, meso, and macro scale and gamma diversity at the macro scale to total observed species richness of all 110 plant species, 43 rare species, and 35 common species in the edges and centers of organic and conventional fields. See also Fig. 4.3.

\begin{tabular}{|c|c|c|c|c|}
\hline & \multicolumn{2}{|c|}{ Organic } & \multicolumn{2}{|c|}{ Conventional } \\
\hline & Edge & Center & Edge & Center \\
\hline \multicolumn{5}{|l|}{ All species } \\
\hline $\begin{aligned} & \alpha_{\text {micro }} \\
+ & \beta_{\text {micro }} \\
+ & \beta_{\text {meso }} \\
+ & \beta_{\text {macro }} \\
= & \gamma_{\text {macro }}\end{aligned}$ & $\begin{array}{l}15.5 \\
15.8 \\
36.6 \\
24.8 \\
92.7\end{array}$ & $\begin{array}{l}11.0 \\
10.1 \\
30.1 \\
21.5 \\
72.7\end{array}$ & $\begin{array}{r}6.4 \\
10.5 \\
27.9 \\
17.0 \\
61.8\end{array}$ & $\begin{array}{r}3.2 \\
5.2 \\
16.8 \\
13.9 \\
39.1\end{array}$ \\
\hline \multicolumn{5}{|l|}{ Rare species } \\
\hline $\begin{aligned} & \alpha_{\text {micro }} \\
+ & \beta_{\text {micro }} \\
+ & \beta_{\text {meso }} \\
+ & \beta_{\text {macro }} \\
= & \gamma_{\text {macro }}\end{aligned}$ & $\begin{array}{r}1.8 \\
4.2 \\
27.0 \\
48.4 \\
81.4\end{array}$ & $\begin{array}{r}1.2 \\
2.5 \\
16.5 \\
28.6 \\
48.8\end{array}$ & $\begin{array}{r}0.2 \\
1.2 \\
5.8 \\
13.7 \\
20.9\end{array}$ & $\begin{array}{l}0.2 \\
0.5 \\
2.6 \\
6.0 \\
9.3\end{array}$ \\
\hline \multicolumn{5}{|l|}{ Common species } \\
\hline $\begin{aligned} & \alpha_{\text {micro }} \\
+ & \beta_{\text {micro }} \\
+ & \beta_{\text {meso }} \\
+ & \beta_{\text {macro }} \\
= & \gamma_{\text {macro }}\end{aligned}$ & $\begin{array}{r}38.6 \\
29.1 \\
30.3 \\
2.0 \\
100.0\end{array}$ & $\begin{array}{r}30.0 \\
22.9 \\
41.4 \\
5.7 \\
100.0\end{array}$ & $\begin{array}{r}17.1 \\
24.3 \\
47.1 \\
11.4 \\
100.0\end{array}$ & $\begin{array}{r}9.7 \\
14.9 \\
44.0 \\
22.8 \\
91.4\end{array}$ \\
\hline
\end{tabular}

Ninety-three percent of the total observed species richness was found in the edges of organic fields, $73 \%$ in the centers of organic fields, $62 \%$ in the edges of conventional fields, and only $39 \%$ in the centers of conventional fields. Thereby $\beta$-diversity among organic fields at the meso and macro scale made the greatest contribution to the observed overall species richness (Table 4.1). The variability of diversity components was mainly explained by the farming system and the position in the field (Table 4.2 and 4.3). In addition, at the micro scale, $\beta$-diversity increased with increasing landscape complexity (i.e. decreasing percentage of arable land in the surrounding landscape). At the meso scale, $\alpha$-, $\beta$-, and $\gamma$-diversity differed between regions, being highest in the Lahn-Dill Bergland and decreased to Leine Bergland and Soester Boerde (all $P$-values $<0.01$ ). 

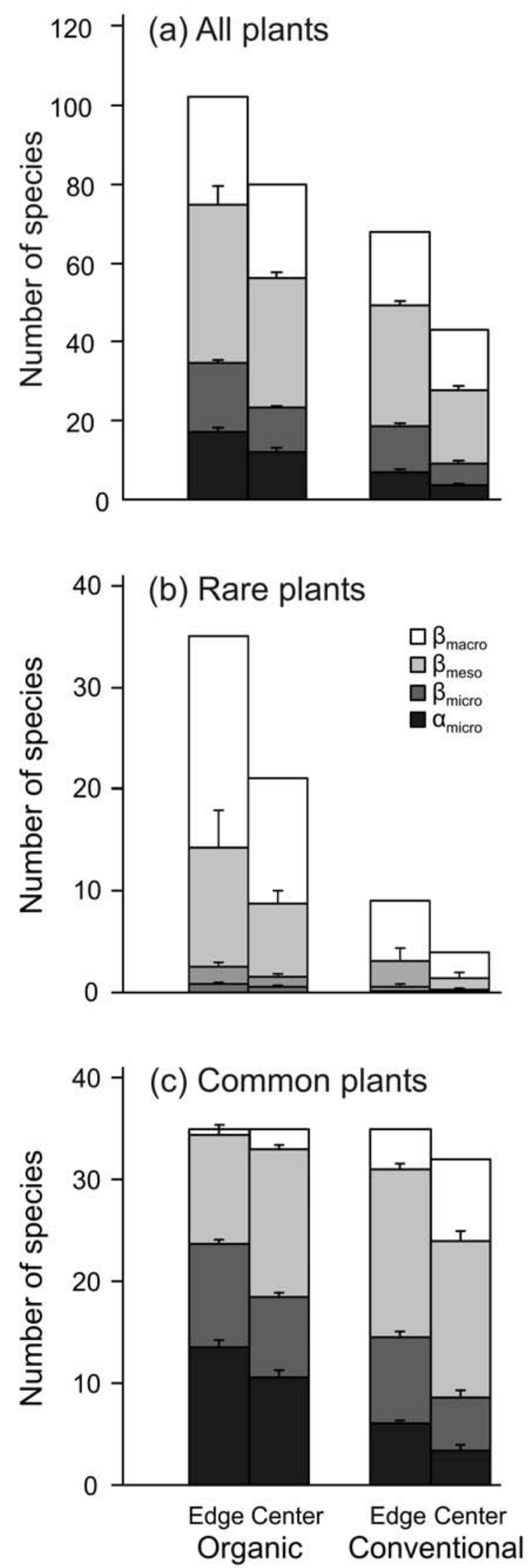

Fig. 4.3. Mean diversity components + standard error of a) all, b) rare, and c) common plant species at three spatial scales (micro, meso, and macro scale) in the edges and centers of organic and conventional fields. See also Table 4.1. 
Table 4.2. F-value and level of significance of mixed effect models testing the effects of position in the field (edge vs. center), farming system (organic vs. conventional), region (Soester Boerde/Leine Bergland/Lahn-Dill Bergland), and landscape complexity (percentage of arable land) for $\alpha-, \beta-$, and $\gamma$-diversity of plant species at the micro scale $(n=80)$. First-order interactions were not significant.

\begin{tabular}{lccc}
\hline & $\boldsymbol{\alpha}$ & $\boldsymbol{\beta}$ & $\gamma$ \\
\hline All species & & & \\
Edge vs. center & $31.6^{* * *}$ & $80.2^{* * *}$ & $65.9^{* * *}$ \\
Organic vs. conventional & $156.0^{* * *}$ & $67.5^{* * *}$ & $139.7^{* * *}$ \\
Region & n.s. & n.s. & n.s. \\
Arable land (\%) & n.s. & $7.6^{* *}$ & n.s. \\
& & & \\
Rare species & & & \\
Edge vs. center & n.s. & $4.7^{*}$ & $5.2^{*}$ \\
Organic vs. conventional & $25.1^{* * *}$ & $25.7^{* * *}$ & $30.8^{* * *}$ \\
Region & n.s. & n.s. & n.s. \\
Arable land (\%) & n.s. & n.s. & n.s. \\
Common species & & & \\
Edge vs. center & & & \\
Organic vs. conventional & $27.0^{* * *}$ & $24.3^{* * *}$ & $42.5^{* * *}$ \\
Region & $178.4^{* * *}$ & $16.6^{* * *}$ & $126.5^{* * *}$ \\
Arable land (\%) & $4.8^{*}$ & n.s. & $4.2^{*}$ \\
\hline
\end{tabular}

Note: Level of significance $* P<0.05$; ** $P<0.01$; *** $P<0.001$.

Table 4.3. F-value and level of significance of mixed effect models testing the effects of position in the field (edge vs. center), farming system (organic vs. conventional), and first-order interaction for $\alpha-, \beta-$, and $\gamma$-diversity of plant species at the meso scale $(\mathrm{n}=12)$.

\begin{tabular}{lccc}
\hline & $\boldsymbol{\alpha}$ & $\boldsymbol{\beta}$ & $\gamma$ \\
\hline All species & & & \\
$\quad$ Edge vs. center & $245.1^{* * *}$ & $26.0^{* *}$ & $106.3^{* * *}$ \\
$\quad$ Organic vs. conventional & $514.7^{* * *}$ & $40.2^{* * *}$ & $193.8^{* * *}$ \\
Rare species & & & \\
Edge vs. center & & & \\
Organic vs. conventional & n.s. & n.s. & n.s. \\
& $24.8^{* *}$ & $17.4^{* *}$ & $18.6^{* *}$ \\
Common species & & & \\
Edge vs. center & & & \\
Organic vs. conventional & $88.4^{* * *}$ & 3.2 & $20.2^{* *}$ \\
Edge/center x organic/conventional & $261.0^{* * *}$ & $19.3^{* *}$ & $44.2^{* * *}$ \\
\hline
\end{tabular}

Note: Level of significance $* P<0.05$; ** $P<0.01$; *** $P<0.001$. 


\section{Additive partitioning of rare and common species}

Forty-three species (35 herbs and 8 grasses) were rare. Differences between organic and conventional fields were markedly larger for rare species compared with all species combined (Fig. 4.3b vs. 4.3a). The contribution of each treatment factor to total rare species richness was $81 \%$ in organic fields at the edge, $49 \%$ in organic fields in the center; $21 \%$ in conventional fields at the edge; and only $9 \%$ in conventional fields in the center. Total richness of rare species was mainly explained by $\beta$-diversity among organic fields at the meso and macro scale (Table 4.1). At all spatial scales, diversity components of rare species were higher in organic than in conventional fields (Table 4.2 and 4.3, Fig. 4.3b). At the micro scale, $\beta$ - and $\gamma$-diversity of rare species were also higher at the field edge than in the field center.

Thirty-five species (30 herbs and 5 grasses) were common. Patterns of diversity components of common species varied strongly compared with all or rare species (Fig. 4.3c vs. 4.3a and b). The relative contribution to total common species richness was $100 \%$ in organic fields (both center and edge) as well as in conventional fields at the edge, and $92 \%$ in conventional fields in the center. Total richness of common species was mainly explained by diversity components at micro and meso scale (Table 4.1). One important deviation from the general patterns of all and rare species is that, at the meso and macro scale, $\beta$-diversity of common species was higher in conventional fields than in organic fields (Table 4.3; Fig. 4.3c). $\beta$-diversity at the meso scale was highest at the edge in conventional fields and lowest at the edge of organic fields. For $\gamma$-diversity, an interaction showed stronger differences between edges and centers in conventional fields than in organic fields. At the micro scale, $\alpha$ - and $\gamma$-diversity were higher in the Lahn-Dill Bergland than in the Soester Boerde and $\gamma$-diversity increased with increasing landscape complexity (i.e. decreasing percentage of arable land in the surrounding landscape). At the meso scale, $\alpha$-diversity differed between regions, being highest in the Lahn-Dill Bergland and decreased to the Leine Bergland and to the Soester Boerde $(P<0.05)$.

\section{Discussion}

Analyses of diversity patterns of arable weeds in field edges and centers of organic and conventional fields at multiple spatial scales (plots, fields, regions) showed that organic farming and field edges contributed most to $\alpha$-, $\beta$-, and $\gamma$-diversity. Our finding that $93 \%$ of the total observed species richness of 110 plant species were found in the edges of organic fields, $73 \%$ in the centers of organic fields, $62 \%$ in the edges of conventional fields, and only $39 \%$ in the centers of conventional fields, underlines the importance of organic farming and field edges for regional diversity. However, in both farming systems the relative contribution to the total observed species richness was mainly determined by $\beta$ diversity at the meso scale (fields) and macro scale (regions), indicating considerable differences in species composition among fields and regions. 


\section{Determinants of $\alpha$-, $\beta$-, and $\gamma$-diversity}

At the micro scale, differences between organic and conventional fields were most pronounced; $\alpha$-, $\beta$-, and $\gamma$-diversity were more than twice as high in organic fields. The lack of herbicides and mineral fertilizers in organic farming as well as the greater variability in crop rotations including spring cropping is known to favor species rich plant communities (Moreby et al. 1994, Hald 1999a,b). Higher plant diversity in field edges compared to field centers supports the findings of Marshall (1989) and Wilson and Aebischer (1995), and may be related to a range of direct and indirect effects (Murcia 1995). First, a reduced intensity of herbicide application or mechanical weed control associated with reduced nitrogen fertilization and increased light supply due to lower crop cover may allow more typical herbaceous arable weed species to establish from the seed bank and survive at the field edge (Kleijn and Vandervoort 1997). In our study, strong edge-center differences in frequency of occurrence were observed for Euphorbia platyphyllos L., Geranium dissectum L. and Arabidopsis thaliana (L.) Heynh. in both farming systems and Aphanes arvensis L., Galeopsis tetrahit L. and Veronica persica Poir. in conventional fields (see Appendix). Second, neighborhood effects due to immigrating species from adjacent field margins might have lead to an increase of $\alpha$-, $\beta$-, and $\gamma$-diversity at the field edge. Marshall and Arnold (1995) found that field margins and crop fields had $25 \%$ of species in common. In our study, a major proportion of plant species that occurred predominately at the field edge were ruderal or grassland species like the grasses Dactylis glomerata L. S. str., Arrhenatherum elatius (L.) P. Beauv. ex J. Presl and C. Presl, Poa pratensis L. s. str. and the herbs Plantago major L. s. str., Potentilla anserina L., and Sisymbrium officinale (L.) Scop. (see Appendix). It is likely that these species originate from the field boundary (Marshall 1989). Consequently, the increased diversity at field edges in organic and conventional fields might result from an ecotone effect harboring an intermixed subset of the adjacent communities (Forman 1995). Increased diversity at the field edge was found in both farming systems, contradicting the results of Hald (1999a), who found a decrease in the number of plant species from the crop margin to the mid-field in conventional but not in organic fields. In addition, $\beta$-diversity of all species and $\gamma$ diversity of common species increased with increasing landscape complexity (i.e., decreasing percentage arable land in the surrounding landscape). We assume that local abiotic conditions within fields in complex landscapes are more variable than in simple landscapes with large, homogeneous fields, promoting heterogeneity in plant communities. Furthermore complex landscapes (characterized by high habitat type diversity and high perimeter-area ratio; Gabriel et al. 2005) provide many disturbed habitats for annual and ruderal plant populations like road verges, fallow land, and dry grassland, which may enhance the probability of invasion from the surrounding landscape to the local field $-\mathrm{a}$ mass effect (analogous to the mass effect of Shmida and Wilson, 1985). However, effects of landscape complexity on plant species richness in arable fields were weaker than the effects of farming system and position in the field. 
At the meso scale, $\alpha$-, $\beta$-, and $\gamma$-diversity differed between regions and were highest in the Lahn-Dill Bergland. Of the three regions, Lahn-Dill Bergland had the largest gradient in landscape complexity (17\% - 85\% arable land), the highest amplitude in elevation (172 m - $496 \mathrm{~m}$ ), and the largest extent (ca. $1000 \mathrm{~km}^{2}$ ).

\section{$\beta$-diversity at different spatial scales}

Comparing $\beta$-diversity at different spatial scales revealed that total observed species richness was mainly explained by $\beta$-diversity at the meso scale (up to $37 \%$ ) and the macro scale (up to 25\%) and to a lesser extent by $\beta$-diversity at the micro scale (up to 16\%).

$\beta$-diversity at each scale is the result of environmental heterogeneity in space, time and/or resources and niche differences among species (Loreau 2000). Environmental heterogeneity may occur from small scales up to large scales. For example, plots (within fields) may vary in soil properties, surface topography, and microclimate. Fields and regions may vary even more in soil type, soil $\mathrm{pH}$, water regime, elevation and/or climate, and they differ in landscape context, including various habitat and land use types and different species pools. It is suggested that these factors influence local assemblages and composition of arable weed communities and increase heterogeneity in plant communities among plots, fields, and regions, i.e. $\beta$-diversity (Loreau 2000, Booth and Swanton 2002, Walter et al. 2002, Kneitel and Chase 2004, Lososová et al. 2004, Pyšek et al. 2005).

$\beta$-diversity of plant communities may be lowered by dispersal between spatial units that acts as a homogenizing force (Shmida and Wilson 1985, Loreau 2000). Thereby dispersal processes operate at different spatial scales (Marshall and Hopkins 1990). At the micro scale, short-distance dispersal causes the majority of seeds to be deposited less than $5 \mathrm{~m}$ away from a parent plant, either by seed rain (Harper 1977, Cousens and Mortimer 1995, Bischoff 2005) or by post-dispersal events such as soil cultivation (Rew and Cussans 1997, Marshall and Brain 1999). At the meso and macro scale, less frequent events such as longdistance dispersal by machinery, animals (mainly vertebrates) and wind may occur (Harper 1977, Marshall and Hopkins 1990, Cousens and Mortimer 1995). Dispersal is irrefutably important for population persistence (Nathan and Muller-Landau 2000, Bullock et al. 2002), but in our study, dispersal obviously did not have a homogenizing effect. Dispersal among fields and regions may have played a minor role relative to environmental factors, as field pairs were widely distributed within a region and plant communities were not spatially autocorrelated, i.e. the similarity of plant communities did not decrease with increasing distance. Thus, the interplay between environmental heterogeneity and dispersal processes influencing local and regional plant community patterns has to be considered. 


\section{Rare and common species}

The spatial scale at which $\beta$-diversity made the greatest contribution to total observed species richness differed between rare and common species. Total richness of rare species was mainly explained by $\beta$-diversity at the meso and macro scale, whereas richness of common species was mainly explained by diversity components at the micro and meso scale. In principle, these patterns correspond with the findings of Gering et al. (2003) from arboreal beetle diversity suggesting that rare species are encountered more frequently at the largest scale. But arable weed patterns differed between farming systems. In our study, richness of rare species was mostly explained by $\beta$-diversity in organic fields at the meso and macro scale, suggesting a high variability in community composition but only in organic fields. In contrast, the majority of common species were found in organic fields at the micro scale, where $\alpha$ - and $\beta$-diversity explained together up to $68 \%$ of the total richness of common species. However, in conventional fields, $\alpha$-diversity at the micro scale was relatively low. Hence, $\beta$-diversity at the micro and meso scale was more important explaining up to $71 \%$ of total richness of common species.

\section{Conclusions and management implications}

Agriculture, occupying about $40 \%$ of the total land surface is one of the predominating land use forms worldwide (Ramankutty and Foley1999). Sustainability and maintenance of biodiversity in these systems is therefore of great importance (Tilman et al. 2002, Foley et al. 2005). We reemphasize that organic fields have significantly higher plant diversity than conventional fields - a finding that is in accordance with previous studies. Organic farming is therefore supported by current agri-environment schemes and may be an example of reconciliation ecology (Rosenzweig 2003a,b) and a conservation tool for diversification of crop fields. However, current agri-environment schemes are almost exclusively locally oriented by tailoring at the field and farm scale. By contrast, our findings make clear that (1) $\beta$-diversity among fields and regions explained most of the total observed species richness in both farming systems, but (2) organic farming contributes also at large spatial scales more to regional diversity than conventional farming. Agri-environment schemes should therefore consider the large-scale contribution of $\beta$-diversity to regional species richness rather than focus entirely on the local field or farm scale. To optimize limited budgets in conservation management, policy-makers at regional level of government (i.e. the administrative agencies of counties, districts and/or states) should be advised to select conservation areas of maximum dissimilarity in abiotic and biotic site conditions using digital data and geographic information systems, thereby taking advantage of the existing environmental heterogeneity among fields and regions. 


\section{Acknowledgements}

We thank Yann Clough, Andrea Holzschuh, Stephanie Domptail and Tobias Purtauf for study site selection and surveying and mapping the landscapes, Katja Poveda, Sabine Eber and Joachim Saborowski for statistical advice. Many thanks to Jens Dauber, Jon Marshall, Erica Fleishman, Tobias Purtauf, Jaan Liira, David Kleijn, Jochen Krauss and Jason Tylianakis for helpful comments and discussions on this manuscript. DG was supported by the Niedersaechsische Graduiertenfoerderung and IR by the German Science Foundation (DFG). The study was part of the EU-project QLK5-CT-2002-01495 “EASY” (Evaluating current European agri-environment schemes to quantify and improve nature conservation efforts in agricultural landscapes). 
Appendix Overview of species and their frequency of occurrence in pooled transects in the edges and centers of organic and conventional fields. (R: rare plant species i.e. present in $\leq 4$ of 80 transects, C: common plant species i.e. present in $\geq 20$ of 80 transects)

\begin{tabular}{|c|c|c|c|c|c|c|}
\hline \multirow[t]{2}{*}{ Species } & \multirow[t]{2}{*}{$\mathbf{R} / \mathbf{C}$} & \multirow[t]{2}{*}{ Occurrence } & \multicolumn{2}{|c|}{ Organic } & \multicolumn{2}{|c|}{ Conventional } \\
\hline & & & Edge & Center & Edge & Center \\
\hline Achillea millefolium L. & $\mathrm{r}$ & 2 & 2 & 0 & 0 & 0 \\
\hline Aegopodium podagraria L. & r & 1 & 1 & 0 & 0 & 0 \\
\hline Aethusa cynapium L. & & 11 & 5 & 3 & 2 & 1 \\
\hline Agropyron repens L. & c & 46 & 15 & 8 & 16 & 7 \\
\hline Agrostis stolonifera L. & $\mathrm{r}$ & 1 & 0 & 0 & 1 & 0 \\
\hline Alopecurus myosuroides Huds. & c & 68 & 18 & 16 & 19 & 15 \\
\hline Alopecurus pratensis L. & & 5 & 2 & 0 & 3 & 0 \\
\hline Amaranthus graecizans L. & & 5 & 1 & 3 & 1 & 0 \\
\hline Anagallis arvensis L. & & 10 & 5 & 4 & 1 & 0 \\
\hline Anchusa officinalis L. & r & 4 & 1 & 3 & 0 & 0 \\
\hline Anthemis arvensis $\mathrm{L}$. & & 7 & 3 & 4 & 0 & 0 \\
\hline Anthriscus sylvestris (L.) Hoffm. & & 9 & 4 & 1 & 4 & 0 \\
\hline Apera spica-venti (L.) P. Beauv. & c & 44 & 16 & 13 & 7 & 8 \\
\hline Aphanes arvensis L. & c & 26 & 10 & 7 & 7 & 2 \\
\hline Arabidopsis thaliana (L.) Heynh. & & 12 & 8 & 2 & 2 & 0 \\
\hline Arenaria serpyllifolia L. s. l. & $\mathrm{r}$ & 2 & 1 & 1 & 0 & 0 \\
\hline \multicolumn{7}{|l|}{ Arrhenatherum elatius (L.) } \\
\hline P. Beauv. ex J. Presl \& C. Presl & & 9 & 2 & 0 & 7 & 0 \\
\hline Atriplex patula L. & c & 24 & 9 & 8 & 4 & 3 \\
\hline Avena fatua $\mathrm{L}$. & $\mathrm{r}$ & 1 & 0 & 0 & 1 & 0 \\
\hline Bromus arvensis L. & $\mathrm{r}$ & 2 & 1 & 0 & 1 & 0 \\
\hline Bromus hordeaceus L. & & 7 & 4 & 0 & 2 & 1 \\
\hline Bromus sterilis L. & & 8 & 4 & 0 & 4 & 0 \\
\hline Capsella bursa-pastoris (L.) Med. & c & 38 & 16 & 17 & 3 & 2 \\
\hline Centaurea cyanus L. & $\mathrm{r}$ & 2 & 2 & 0 & 0 & 0 \\
\hline Cerastium glomeratum Thuill. & $\mathrm{r}$ & 3 & 2 & 1 & 0 & 0 \\
\hline Cerastium holosteoides Fr. & $\mathrm{r}$ & 3 & 3 & 0 & 0 & 0 \\
\hline Chenopodium album L. & c & 29 & 11 & 9 & 5 & 4 \\
\hline Cirsium arvense (L.) Scop. & c & 58 & 19 & 17 & 16 & 6 \\
\hline Convolvulus arvensis L. & c & 21 & 11 & 3 & 7 & 0 \\
\hline Dactylis glomerata L. s. str. & & 16 & 7 & 0 & 9 & 0 \\
\hline Epilobium tetragonum L. s. str. & & 8 & 2 & 4 & 1 & 1 \\
\hline Equisetum arvense L. & c & 30 & 11 & 2 & 14 & 3 \\
\hline Erophila verna (L.) Chevall. s. l. & $\mathrm{r}$ & 3 & 1 & 2 & 0 & 0 \\
\hline Euphorbia exigua L. & r & 4 & 2 & 2 & 0 & 0 \\
\hline Euphorbia helioscopia L. & & 9 & 5 & 3 & 0 & 1 \\
\hline Euphorbia platyphyllos L. & & 7 & 5 & 1 & 1 & 0 \\
\hline Fallopia convolvulus (L.) Å. Löve & c & 50 & 17 & 16 & 10 & 7 \\
\hline Festuca arundinacea Schreb. & $\mathrm{r}$ & 1 & 1 & 0 & 0 & 0 \\
\hline Festuca rubra L. & $\mathrm{r}$ & 1 & 0 & 1 & 0 & 0 \\
\hline Filago arvensis L. & $\mathrm{r}$ & 4 & 1 & 2 & 1 & 0 \\
\hline Fumaria officinalis L. s. l. & c & 27 & 8 & 10 & 3 & 6 \\
\hline Galeopsis angustifolia Ehrh. ex Hoffm. & $\mathrm{r}$ & 1 & 1 & 0 & 0 & 0 \\
\hline Galium aparine L. & c & 63 & 18 & 15 & 18 & 12 \\
\hline Galeopsis ladanum L. & $\mathrm{r}$ & 2 & 1 & 1 & 0 & 0 \\
\hline Galinsoga parviflora Cav. & $\mathrm{r}$ & 4 & 1 & 2 & 0 & 1 \\
\hline Galeopsis pubescens Besser & $\mathrm{r}$ & 2 & 1 & 1 & 0 & 0 \\
\hline
\end{tabular}




\begin{tabular}{|c|c|c|c|c|c|c|}
\hline \multirow[t]{2}{*}{ Species } & \multirow[t]{2}{*}{$\mathbf{R} / \mathbf{C}$} & \multirow[t]{2}{*}{ Occurrence } & \multicolumn{2}{|c|}{ Organic } & \multicolumn{2}{|c|}{ Conventional } \\
\hline & & & Edge & Center & Edge & Center \\
\hline Galeopsis segetum Neck. & $\mathrm{r}$ & 1 & 1 & 0 & 0 & 0 \\
\hline Galeopsis tetrahit L. & c & 21 & 9 & 7 & 5 & 0 \\
\hline Geranium dissectum L. & & 12 & 5 & 0 & 6 & 1 \\
\hline Geranium pusillum Burm. f. & $\mathrm{r}$ & 4 & 1 & 0 & 2 & 1 \\
\hline Heracleum sphondylium L. & & 6 & 3 & 0 & 3 & 0 \\
\hline Holcus lanatus L. & $\mathrm{r}$ & 1 & 1 & 0 & 0 & 0 \\
\hline Hypericum perforatum L. & $\mathrm{r}$ & 1 & 0 & 0 & 1 & 0 \\
\hline Juncus sp. & $\mathrm{r}$ & 2 & 0 & 2 & 0 & 0 \\
\hline Lamium amplexicaule L. & & 11 & 4 & 6 & 0 & 1 \\
\hline Lamium purpureum L. s. l. p. p. & c & 45 & 15 & 16 & 10 & 4 \\
\hline Lapsana communis L. & & 7 & 4 & 3 & 0 & 0 \\
\hline Lathyrus sp. & & 6 & 4 & 1 & 1 & 0 \\
\hline Lolium multiflorum Lam. & & 9 & 7 & 2 & 0 & 0 \\
\hline Lolium perenne L. & & 18 & 6 & 3 & 9 & 0 \\
\hline Matricaria recutita $\mathrm{L}$. & c & 39 & 15 & 10 & 6 & 8 \\
\hline Matricaria discoidea DC. & c & 29 & 12 & 8 & 6 & 3 \\
\hline Medicago falcata L. s. str. & $\mathrm{r}$ & 3 & 1 & 1 & 0 & 1 \\
\hline Myosotis arvensis (L.) Hill & c & 42 & 16 & 14 & 8 & 4 \\
\hline Microrrhinum minus (L.) Fourr. & $\mathrm{r}$ & 2 & 1 & 1 & 0 & 0 \\
\hline Myosurus minimus L. & $\mathrm{r}$ & 2 & 0 & 2 & 0 & 0 \\
\hline Papaver dubium L. s. str. & $\mathrm{r}$ & 2 & 1 & 1 & 0 & 0 \\
\hline Papaver rhoeas L. & c & 23 & 10 & 6 & 7 & 0 \\
\hline Phleum pratense L. s. str. & $\mathrm{r}$ & 1 & 1 & 0 & 0 & 0 \\
\hline Plantago major L. s. str. & & 6 & 5 & 0 & 1 & 0 \\
\hline Plantago lanceolata L. & $\mathrm{r}$ & 1 & 1 & 0 & 0 & 0 \\
\hline Poa annua L. & c & 27 & 11 & 4 & 9 & 3 \\
\hline Poa pratensis L. s. str. & & 12 & 8 & 1 & 3 & 0 \\
\hline Poa trivialis L. s. l. & c & 54 & 20 & 9 & 19 & 6 \\
\hline Polygonum aviculare L. (s. l.) & c & 56 & 20 & 17 & 11 & 8 \\
\hline Persicaria hydropiper (L.) Delarbre & $\mathrm{r}$ & 3 & 2 & 1 & 0 & 0 \\
\hline Persicaria lapathifolia (L.) Delarbre s. str. & c & 30 & 8 & 11 & 8 & 3 \\
\hline Persicaria maculosa Gray & $\mathrm{r}$ & 1 & 1 & 0 & 0 & 0 \\
\hline Potentilla anserina L. & $\mathrm{r}$ & 4 & 3 & 0 & 1 & 0 \\
\hline Ranunculus ficaria L. & $\mathrm{r}$ & 1 & 0 & 0 & 1 & 0 \\
\hline Ranunculus repens L. & & 19 & 15 & 2 & 2 & 0 \\
\hline Raphanus raphanistrum L. & & 9 & 5 & 4 & 0 & 0 \\
\hline Rumex acetosa L. & $\mathrm{r}$ & 1 & 1 & 0 & 0 & 0 \\
\hline Rumex crispus L. & c & 34 & 14 & 11 & 6 & 3 \\
\hline Rumex obtusifolius L. & & 8 & 4 & 2 & 2 & 0 \\
\hline Scleranthus annuus L. s. str. & $\mathrm{r}$ & 2 & 0 & 2 & 0 & 0 \\
\hline Sinapis arvensis L. & c & 31 & 13 & 12 & 4 & 2 \\
\hline Sisymbrium officinale (L.) Scop. & $\mathrm{r}$ & 3 & 2 & 0 & 1 & 0 \\
\hline Sonchus arvensis L. & c & 23 & 13 & 7 & 1 & 2 \\
\hline Sonchus asper (L.) Hill & & 6 & 4 & 2 & 0 & 0 \\
\hline Spergula arvensis L. & $\mathrm{r}$ & 1 & 1 & 0 & 0 & 0 \\
\hline Stellaria graminea L. & $\mathrm{r}$ & 2 & 2 & 0 & 0 & 0 \\
\hline Stellaria media (L.) Vill. s. str. & c & 48 & 20 & 17 & 3 & 8 \\
\hline
\end{tabular}




\begin{tabular}{|c|c|c|c|c|c|c|}
\hline \multirow[t]{2}{*}{ Species } & \multirow[t]{2}{*}{$\mathbf{R} / \mathbf{C}$} & \multirow[t]{2}{*}{ Occurrence } & \multicolumn{2}{|c|}{ Organic } & \multicolumn{2}{|c|}{ Conventional } \\
\hline & & & Edge & Center & Edge & Center \\
\hline Taraxacum officinale Weber & & 16 & 9 & 3 & 3 & 1 \\
\hline Thlaspi arvense L. & c & 50 & 18 & 14 & 10 & 8 \\
\hline Trifolium hybridum L. & $\mathrm{r}$ & 4 & 2 & 1 & 0 & 1 \\
\hline Trifolium incarnatum L. & $\mathrm{r}$ & 3 & 2 & 1 & 0 & 0 \\
\hline Trifolium pratense L. & & 13 & 9 & 4 & 0 & 0 \\
\hline Trifolium repens L. & c & 36 & 16 & 11 & 4 & 5 \\
\hline Urtica urens L. & & 11 & 6 & 1 & 4 & 0 \\
\hline Veronica arvensis L. & c & 22 & 9 & 8 & 3 & 2 \\
\hline Veronica hederifolia L. s. l. & c & 36 & 10 & 8 & 9 & 9 \\
\hline Veronica persica Poir. & c & 35 & 17 & 9 & 7 & 2 \\
\hline Veronica polita Fr. & & 7 & 4 & 2 & 1 & 0 \\
\hline Vicia hirsuta (L.) Gray & $\mathrm{r}$ & 3 & 1 & 2 & 0 & 0 \\
\hline Vicia sativa L. s. str. & $\mathrm{r}$ & 2 & 1 & 1 & 0 & 0 \\
\hline Vicia tetrasperma (L.) Schreb. & c & 39 & 13 & 13 & 10 & 3 \\
\hline Vicia villosa Roth s. str. & & 14 & 9 & 4 & 1 & 0 \\
\hline Viola arvensis Murray & c & 40 & 10 & 11 & 10 & 9 \\
\hline Viola tricolor L. & c & 20 & 6 & 5 & 3 & 6 \\
\hline
\end{tabular}


Chapter 5

The effects of landscape complexity on arable weed species diversity in organic and conventional farming

Indra Roschewitz, Doreen Gabriel, Teja Tscharntke \& Carsten Thies

In: Journal of Applied Ecology (2005) 42: 873-882. 


\begin{abstract}
There is growing concern about declining species diversity in agroecosystems, caused by agricultural intensification at the field and the landscape scale. Species diversity of arable weeds is classically related to local abiotic factors and resource conditions. It has been suggested to be enhanced by organic farming, but the surrounding landscape may also be important. This study assesses the weed vegetation in 24 winter wheat fields, combined with seed rain and seedbank analyses, to examine the relative importance of organic vs. conventional farming and landscape complexity for weed species diversity. Diversity was partitioned into its additive components alpha, beta, and gamma diversity. Percent arable land in a circular landscape sector of $1 \mathrm{~km}$ radius around each study site was used as indicator for landscape complexity. Weed species diversity in the vegetation, the seed rain and the seedbank was higher in organic than in conventional fields. Increasing landscape complexity enhanced species diversity in the vegetation of conventional, but little of organic fields, resulting in nearly similar diversity in both farming systems when the landscape was complex. Species diversity of the seedbank was increased by landscape complexity irrespective of farming system. Overall diversity was greatly determined by the high heterogeneity between and within the fields (beta diversity). Higher weed species diversity in complex landscapes and/or organic farming could only in very few cases be related to particular species depending on such landscapes or farming system.

Synthesis and applications. Local weed species diversity was influenced by both landscape complexity and farming system. Species diversity in organic farming was clearly higher only in simple landscapes, because the conventional vegetation reached similar diversity levels when the surrounding landscape was complex, providing refuges for weed populations. Consequently, agri-environment schemes to preserve and enhance biodiversity should not only consider the management of single fields, but also of the surrounding landscape.
\end{abstract}

Keywords: Additive partitioning, beta diversity, biodiversity, conservation, seedbank, seed rain, winter wheat. 


\section{Introduction}

Species richness in agroecosystems dramatically declined during the last decades, mainly due to the intensification of land-use practices (Krebs et al. 1999; Tilman et al. 2002). On the one hand, intensification occurred at the field scale through the intensive use of pesticides and mineral fertilizers. On the other hand, it also occurred at the landscape scale, due to the aggregation of intensively managed arable fields as well as to land consolidations which resulted in a transformation of formerly complex landscapes with relatively high proportions of (semi-)natural habitats to simple landscapes dominated by arable fields.

Annual crop fields are characterised by a high frequency and intensity of disturbances. Organisms have to adapt to these disturbances or recolonise the fields afterwards. Organic farming is expected to maintain higher species richness as pesticides are not applied in this farming system. As a general rule, species richness of the aboveground vegetation (Moreby et al. 1994; Hald 1999a; Menalled, Gross \& Hammond 2001; Hyvönen et al. 2003b), the seedbank (Menalled et al. 2001), and several groups of arthropods (e.g., Letourneau \& Goldstein 2001; Hutton \& Giller 2003) have been reported to be higher in organic and extensive than conventional farms. However, several studies found no effects of farming system on species richness of plants (Weibull, Östman \& Granqvist 2003) and arthropods (Kleijn et al. 2001; Weibull et al. 2003).

Arable fields in complex landscapes should also harbour higher species richness than in simple landscapes as complex landscapes may provide alternative habitats and thereby sources for a recolonisation of fields. The relation between local species richness and landscape context has been addressed for several groups of arthropods (e.g., Menalled et al. 1999; Krauss, Steffan-Dewenter \& Tscharntke 2003; Schmidt et al. 2005), but only Weibull et al. (2003) and Krauss et al. (2004) investigated this relationship for plants in agricultural landscapes. However, they did not detect an effect of landscape context on plant species richness. Holl \& Crone (2004) found only weak importance of landscapescale variables for the diversity of native riparian understorey plants. Despite these findings, the species diversity of weeds in annual crop fields should depend on both local management and surrounding landscape, as the weeds are a highly dynamic group adapted to a frequently disturbed habitat, relying on their seedbank as well as on immigration of seeds through the seed rain from surrounding habitats. Thereby, weed species diversity in conventional fields should especially benefit from the landscape as these are more frequently disturbed (e.g. by herbicide use) than organic fields. Knowledge on these relations is crucial for a better understanding of weed species diversity patterns and should be helpful for future conservation management decisions. However, to our knowledge, this is the first study analysing how species diversity of arable weeds in the vegetation, seed rain, and seedbank respond to the surrounding landscape in organic and conventional fields. In addition, the contribution of the heterogeneity in community composition between weed samples - within and between fields - to field and to regional diversity is 
little known. The concept of additive partitioning of species (Allan 1975; Lande 1996) addresses this problem by dividing total diversity of a given number of samples (gamma diversity) into the additive components alpha (mean diversity) and beta (between sample heterogeneity) thereby allowing to scale up the species diversity at several spatial scales up to whole regions (e.g., Wagner, Wildi \& Ewald 2000; Gering \& Crist 2002; Crist et al. 2003; Gering, Crist \& Veech 2003).

In this study, we used this concept to characterise the diversity of arable weeds at two spatial scales. At the regional scale, gamma diversity is the overall number of species found in our study region. Alpha diversity is the average number of species of the studied fields within the region, while beta diversity accounts for the within-region heterogeneity (average number of species not found in a field). At the field scale, gamma diversity is the overall number of species found in the samples of one field. Alpha diversity is the average number of species found in the samples of one field, and beta diversity accounts for the within-field heterogeneity (average number of species not found in a sample). At both scales, the relative beta diversity (the percentage of beta contributing to gamma) was also calculated. We analysed the relative importance of local management (organic vs. conventional) and landscape complexity (gradient from simple to complex) on species diversity of arable weeds in the vegetation, the seed rain, and the seedbank (at the field scale) of 24 winter wheat fields.

We hypothesised that the field scale alpha, beta, and gamma diversity of weeds should be higher in organic than in conventional fields and in complex than in simple landscapes, and tested the idea that landscape complexity may compensate for the reduced diversity in conventional fields. In contrast, the relative within-field heterogeneity, beta (\%), was expected to be higher in conventional fields, because these fields should have a low alpha diversity and, consequently, the relative contribution of beta to gamma diversity should be high. In particular, we expected that several species (e.g. threatened species of the Red List of Lower Saxony, Germany (Garve \& Letschert 1991; Garve 1993; Korneck, Schnittler \& Vollmer 1996)) which are more susceptible to disturbances than common species would especially profit from organic farming and/or from a certain degree of landscape complexity (Korneck \& Sukopp 1988; Jedicke 1997; Hofmeister \& Garve 1998).

\section{Methods}

\section{Study area and analysis of landscape complexity}

The study was conducted in the year 2002 in 12 agricultural landscapes around the city of Göttingen (North Germany). This area covers approx. $1350 \mathrm{~km}^{2}$ and is dominated by an arable land-grassland mosaic covering about $75 \%$ of the region, while the remaining area is characterised by patchily distributed fragments of near-natural and semi-natural habitats such as forests, fallows, field margins, and hedgerows. We selected the 12 landscapes along a gradient of landscape complexity ranging from very simple landscapes with high 
percentage of arable land ( 95\%) to complex landscapes with less percentage of arable land ( 30\%). These complex landscapes exhibit large areas of non-crop habitats such as field margins, fallows, grassland, and garden land, which should be potential weed habitats. All landscapes were at least $3 \mathrm{~km}$ (from centre to centre) away from each other. In the centre of each landscape, we selected a pair of one conventionally and one organically (according to European Union Regulation 2092/91/EEC) managed winter wheat field located close to each other $(<400 \mathrm{~m})$ as study sites. The organic fields were under organic management for at least 7 years.

Landscape complexity was measured around each studied field in a circular landscape sector of $1 \mathrm{~km}$ radius. Official digital thematic maps (ATKIS - Digitales Landschaftsmodell 25/1; Landesvermessung und Geobasisinformation, Hannover, Germany, 1991-1996) and the Geographical Information System ArcView 3.1 (ESRI Geoinformatik GmbH, Hannover, Germany) were used to determine the area of arable land, perennial grassland, forests, hedgerows, garden land, and settlement in each landscape sector. The percentage of arable land per landscape was considered as indicator for landscape complexity, because it is related to other important landscape metrics such as habitat-type diversity after Shannon-Wiener $(F=124.12 ; P<0.001 ; R=-0.80)$ and perimeter-to area ratio ( $F=61.28 ; P<0.001 ; R=-0.69$ ). In the studied landscapes, arable land was the predominant land-use type, covering $63 \pm 22 \%$ of the total area (arithmetic mean \pm standard deviation, min.: 30\%, max.: 95\%). The mean size of the study fields was $3.5 \pm 1$.7ha (arithmetic mean \pm standard deviation), and was neither related to landscape complexity (linear regression: $R=0.29 ; P=0.17$ ) nor to farming system (paired t-test: $t=$ 1.3, $P=0.21$ ). All fields were bordered by old grassy margins that were $1-3 \mathrm{~m}$ wide and mowed once per year. The majority of adjacent crops for both field types were conventional winter cereals. In organic fields, winter wheat was grown after a mixture of clover and grass, while the preceding crops of conventional winter wheat were mostly winter wheat and oilseed rape.

Local abiotic factors such as soil quality and factors of land-use intensity such as nitrogen fertilisation and herbicide use are known to be important determinants of local arable weed species diversity (e.g., Grime 1979; Tilman 1982; Ellenberg 1988; Hyvönen \& Salonen 2002; Gerowitt 2003). For our study, we selected exclusively loamy soils. Therefore, the variability of local soil characteristics was low. However, in a pre-analysis (linear regressions), we tested if several soil and land-use characteristics were correlated with landscape complexity or weed species diversity. Therefore, one soil sample per field, consisting of 16 randomly taken sub samples from the top $30 \mathrm{~cm}$ was analysed. Data on land use were based on interviewing the farmers. Soil characteristics (total nitrogen contents, organic carbon contents, ratio of organic carbon to total nitrogen, $\mathrm{pH}$-value) in conventional as well as in organic fields were unrelated to percent arable land in the landscape $(R=-0.39$ to 0.18 ; all $P>0.2)$. Additionally, these soil characteristics were not related with any component of weed species diversity (i.e., alpha, beta, and gamma diversity, all $P$-values from linear regressions $>0.2$ ). The number of herbicide applications 
in conventional fields was one to three per year and also neither related to percent arable land $(R=-0.01 ; P=0.99)$ nor to weed species diversity (e.g., gamma diversity: $R=-0.01$; $P=0.98$ ). In contrast to expectations (Roschewitz, Thies \& Tscharntke 2005), mineral nitrogen fertilizers $\left(\mathrm{kg} \mathrm{N} \mathrm{ha}^{-1}\right)$ applied in conventional fields even tended to decrease with increasing percent arable land $(R=-0.58 ; P=0.05)$, but they did not influence weed species diversity (e.g., gamma diversity: $R=0.43$; $P=0.17$ ).

\section{Quantification of arable weed species diversity \\ Vegetation}

The diversity and abundance of weeds were recorded three times during the growing season. The first sample date was in the beginning of April to record the initial state of the weeds in spring. This date was before herbicides were applied in the conventional fields (all conventional farmers used herbicides against broadleaves and grasses). The second sampling was conducted in the second half of May, the third in the middle of July. Sampling in all periods was conducted within one week. All broadleaf and grass species and their percentage cover were recorded in four $3 \mathrm{~m} x 10 \mathrm{~m}$ plots per field using the nomenclature of plant names of Wisskirchen \& Haeupler (1998), and tree seedlings were not considered. Two plots were situated in the centre of the field (approx. 30m apart from any edge as well as $30 \mathrm{~m}$ from each other) and two plots at the field edge (0m - 3m apart from the first drill row and $30 \mathrm{~m}$ from each other). The locations of the vegetation plots were the same in all three samplings. Species numbers per plot were cumulated and percentage cover was averaged for the three sample dates.

\section{Germinable seed rain}

Germinable seed rain was measured from the beginning of April until the middle of July, which is the time where the seeds of most central European weeds are produced and dispersed (Kästner, Jäger \& Schubert 2001). To catch and hold the seeds, eight plastic boxes with a size of $50 \mathrm{~cm} \times 32 \mathrm{~cm} \times 6 \mathrm{~cm}$ filled with seedless garden soil were used. Four of the boxes were buried in the centre of the fields (30m apart from the edge), the other four boxes at the field edge ( $1 \mathrm{~m}-1.5 \mathrm{~m}$ apart from the first drill row). The boxes were arranged in pairs, with a distance of $50 \mathrm{~cm}$ to each other, the distance between the two pairs was $25 \mathrm{~m}$. The box pairs were placed close to and between the vegetation plots. The flower soil was watered regularly, depending on weather conditions. Once a month, all germinated plants were identified to species, counted and removed from the boxes. In the middle of July, before the wheat harvest, all boxes were removed from the fields and brought into the greenhouse, where all germinated plants were identified, counted and removed monthly for another 10 months. To initiate also the germination of frost germinators, we induced a three weeks frost period during the winter (by turning off the heating in strong frost period). Species numbers per box pair were cumulated for the 14 sample dates. This experiment was conducted in all fields, but one organic field was skipped due to destroyed boxes. 


\section{Germinable seedbank}

To measure the germinable weed seedbank, we collected four samples of the soil of each winter wheat field at the beginning of September, after wheat harvest. Each sample consisted of eight sub-samples randomly taken from a plot of $20 \mathrm{~m}^{2}$. Two plots were located in the field centre and two at the edge, analogous to the seed rain experiment. The sub-samples were taken from the top $25 \mathrm{~cm}$ of the soil with the help of a spade. Most weeds are known to germinate and emerge from the first centimetres of the soil (Buhler 1995). However, $25 \mathrm{~cm}$ was chosen in order to get all seeds which potentially could germinate in the next years, as annual ploughing is normally conduced in this depth in our region (IR, unpublished data). The eight sub-samples were mixed and put into a plastic box (similar to the boxes in the seed rain experiment). The boxes were brought into the greenhouse, where all germinated plants were recorded monthly for 14 months. The samples were kept under the same conditions as the seed rain samples. Species numbers per box were cumulated for the 14 sample dates.

\section{Additive partitioning of weed species diversity}

The total regional diversity can be seen as the sum of alpha diversity (mean diversity within the sampling units) and beta diversity (difference in diversity between the sampling units) (Allan 1975; Lande 1996). This relationship is not only valid for regional diversity but also for smaller scale diversity (Wagner et al. 2000). Thus, it is possible to additively partition species diversity in a region into scale-specific components. In our study, we partitioned species richness at two spatial scales, the regional and the field scale.

To describe the overall regional weed species diversity of the winter wheat fields (gamma diversity), we first calculated diversity of all species found on the regional scale (vegetation, seed rain, and seedbank pooled). The alpha diversity of the region was calculated as the mean number of species of all 24 wheat fields, as well as separately for 12 organic and 12 conventional fields. The gamma diversity of the region was calculated as the total species number of all 24 fields, and separately for 12 organic and 12 conventional fields. The beta diversity of the region (between-field diversity) was calculated by subtracting $\alpha$ from $\gamma$.

In all three studies (vegetation, seed rain, and seedbank) the number of weed species was recorded for four plots per field, which allowed us to have a closer look at the withinfield heterogeneity. The gamma diversity of a field $\left(\gamma_{\mathrm{f}}\right)$ was calculated as the total number of species per field. The alpha diversity $\left(\alpha_{\mathrm{f}}\right)$ was calculated as the mean number of species of the four plots per field. The beta diversity of a field ( $\beta_{\mathrm{f}}$, between-plot diversity) was generated by subtracting $\alpha_{\mathrm{f}}$ from $\gamma_{\mathrm{f}}$ and represents a measure of within-field heterogeneity. As species numbers were generally lower in conventional than in organic fields, we additionally calculated a relative beta diversity $(\beta \%=\beta / \gamma \times 100)$ on the regional as well as on the field level. This measure can be seen as the opposite of Lande's (1996) measure of 
community similarity, which was calculated as $\Psi_{D}=1-D_{\text {among }} / D_{\mathrm{T}}$ (in our terminology: 1 $-\beta / \gamma)$.

\section{Statistical analysis}

Mixed effect models (Pinheiro \& Bates 2000) with stepwise backward selection were used to analyse the effects of farming system, landscape complexity, and first order interaction on the alpha, beta, and gamma diversity of arable weeds at the field scale, and on the number of species registered in the Red List of threatened plant species of Lower Saxony (Germany) (Garve \& Letschert 1991; Garve 1993; Korneck et al. 1996). By blocking field pairs (organic/conventional), these models account for non-independent errors. Multiple logistic regressions (with stepwise backward selection) were used to examine which plant species were affected by landscape complexity and/or farming system. Therefore, the presence/absence of each species occurring in at least four fields (pooled for vegetation, seed rain, and seedbank) was related to the percentage of arable land and farming system. Statistical analyses were carried out using R (R Development Core Team 2004) and Statgraphics Plus 5.1 (Statistical Graphics Corp. 2001). Logarithmic transformation of the variables was used to achieve normality of the residuals, and arcsinesquare-root transformation for the percentages (Sokal \& Rohlf 1995). In the text and tables, arithmetic means \pm standard deviations (SD) from original values are given.

\section{Results}

\section{Overview}

In total, we found a gamma diversity in the region of 153 weed species, of which 135 were broadleaves and 18 grasses. In conventionally managed fields, 104 species were recorded (86 broadleaves and 18 grasses), in organically managed fields 142 species (126 broadleaves, 16 grasses) (Appendix). The average percentage of vegetation cover and numbers of seedlings germinated from the seed rain and seedbank are shown in Table 5.1. Eleven weed species were detected in conventional, but not in organic fields, and 49 species only in organic fields. Most of these species were only detected in one or two fields, indicating a high variability in local occurrence. 31 weed species were only found growing in crop fields, 10 species only in the seed rain, and 24 species only in the seedbank. 58 species appeared in the vegetation, the seed rain, and the seedbank. 23 species were registered in the Red List of threatened plant species of Lower Saxony (Germany), whereof 21 species were found in organic and 10 in conventional fields (Appendix).

Alpha diversity at the regional scale (mean diversity per field) was 53.1 species (conventional fields: 43.7; organic fields: 62.6). Beta diversity (between-field diversity) was 99.9 species (conventional fields: 60.3; organic fields: 79.4). Hence, the relative beta diversity was $65.3 \%$ (conventional fields: 58.0; organic fields: 55.9\%). The species 
diversity and numbers of Red List species at the field scale are outlined in Table 5.2, separated for vegetation, seed rain, and seedbank. Diversity varied considerably between the two farming systems and the 12 landscapes.

Table 5.1. Percentage cover of weeds in the vegetation, numbers of seedlings $\mathrm{m}^{-2}$ ground in the seed rain, and numbers of seedlings $\mathrm{m}^{-2}$ ground in $0-25 \mathrm{~cm}$ depth in the seedbank. Medians, minima, and maxima are given for 12 organic and 12 conventional winter wheat fields (seed rain: 11 organic fields).

\begin{tabular}{|c|c|c|c|c|c|c|}
\hline & \multicolumn{2}{|c|}{ Median } & \multicolumn{2}{|c|}{ Minimum } & \multicolumn{2}{|c|}{ Maximum } \\
\hline & Organic & Conv. & Organic & Conv. & Organic & Conv. \\
\hline \multicolumn{7}{|c|}{ Vegetation (\% cover) } \\
\hline Broadleaves & 10.6 & 1.3 & 4.0 & 0.2 & 28.6 & 11.7 \\
\hline Grasses & 3.9 & 1.6 & 1.1 & 0.5 & 10.3 & 28.3 \\
\hline \multicolumn{7}{|c|}{ Seed rain (seedlings $\mathrm{m}^{-2}$ ) } \\
\hline Broadleaves & 2332 & 1779 & 1210 & 402 & 8996 & 3578 \\
\hline Grasses & 2300 & 1955 & 164 & 222 & 65148 & 36566 \\
\hline \multicolumn{7}{|c|}{$\begin{array}{l}\text { Seedbank } \\
\text { (seedlings } \mathrm{m}^{-2} \text { in } 0-25 \mathrm{~cm} \text { ) }\end{array}$} \\
\hline Broadleaves & 8093 & 2343 & 2015 & 968 & 23007 & 7414 \\
\hline Grasses & 2187 & 1371 & 242 & 445 & 9757 & 64046 \\
\hline
\end{tabular}

Relative influence of farming system and landscape complexity on weed species diversity

In the vegetation, weed alpha, beta, and gamma diversity responded similarly to farming system and landscape complexity (= percent arable land). They were higher in organic than in conventional fields and decreased as percentage of arable land increased, i.e. they were higher in complex than in simple landscapes. This decrease was very steep in conventional, but not in organic fields, resulting in nearly similar diversities in the two farming systems in complex landscapes, and higher diversities in organic fields in simple landscapes (indicated by the interaction between percent arable land and farming system) (Fig. 5.1a-c, Table 5.3). In the seed rain, weed alpha, beta, and gamma diversity were higher in organic than in conventional fields and not related to percent arable land (Fig. 5.1d-f, Table 5.3). In the seedbank, weed alpha and gamma diversity were significantly higher in organic than in conventional fields. Additionally, they decreased with increasing percentage of arable land, irrespective of farming system (Fig. 5.1g, i, Table 5.3). For the beta diversity, no significant model could be found (Fig. 5.1h, Table 5.3). In all three studies, the relative within-field heterogeneity (beta \%) of weeds was significantly higher in conventional than in organic fields (vegetation: $F=27.0 ; P<0.001$; seed rain: $F=7.6 ; P<0.05$; seedbank: $F$ $=8.9 ; P<0.05$ ), and not related to landscape complexity.

When alpha, beta, gamma, and relative beta diversity were partitioned in broadleaf and grass diversity, it became clear that the above described patterns were mainly determined by the broadleaves (Table 5.3). Though alpha diversity of grasses in the vegetation 
increased with decreasing percent arable land and was higher in organic than in conventional fields, there was no significant interaction between percent arable land and farming system. Beta and gamma diversity of grasses in the vegetation also increased with decreasing percent arable land, but irrespective of farming system. Only the alpha and gamma diversity of grasses in the seed rain showed the same pattern as all weeds (higher in organic than in conventional fields). No significant models for the diversity of grasses could be found for beta diversity in the seed rain, relative beta diversity in all three studies, and all diversity components in the seedbank (for statistics, see Table 5.3).

Table 5.2. The alpha $\left(\alpha_{\mathrm{f}}\right)$, beta $\left(\beta_{\mathrm{f}}\right)$, relative beta $\left(\beta \%_{\mathrm{f}}\right)$, gamma $\left(\gamma_{\mathrm{f}}\right)$, and Red List species diversity of weeds at the field scale: data from vegetation, seed rain, and seedbank mappings. Means \pm SD, minima, and maxima are given for 12 organic and 12 conventional winter wheat fields (seed rain: 11 organic fields).

\begin{tabular}{|c|c|c|c|c|c|c|}
\hline & \multicolumn{2}{|c|}{ Mean \pm SD } & \multicolumn{2}{|c|}{ Minimum } & \multicolumn{2}{|c|}{ Maximum } \\
\hline & Organic & Conv. & Organic & Conv. & Organic & Conv. \\
\hline \multicolumn{7}{|l|}{ Vegetation } \\
\hline$\alpha_{\mathrm{f}}$ & $29.7 \pm 7.4$ & $14.2 \pm 5.4$ & 19.8 & 6.8 & 43.0 & 21.3 \\
\hline$\beta_{\mathrm{f}}$ & $18.1 \pm 4.0$ & $12.5 \pm 5.1$ & 10.3 & 5.3 & 23.0 & 20.5 \\
\hline$\beta \%_{f}(\%)$ & $38.0 \pm 5.4$ & $46.6 \pm 4.2$ & 29.0 & 40.3 & 47.9 & 52.5 \\
\hline$\gamma_{\mathrm{f}}$ & $47.8 \pm 10.2$ & $26.7 \pm 10.4$ & 30.0 & 13.0 & 66.0 & 40.0 \\
\hline Red List species & $1.4 \pm 1.8$ & $0.8 \pm 0.9$ & 0.0 & 0.0 & 6.0 & 2.0 \\
\hline \multicolumn{7}{|l|}{ Seed rain } \\
\hline$\alpha_{\mathrm{f}}$ & $17.7 \pm 5.2$ & $10.2 \pm 3.6$ & 13.0 & 4.0 & 30.8 & 18.3 \\
\hline$\beta_{\mathrm{f}}$ & $13.1 \pm 3.6$ & $10.3 \pm 2.3$ & 8.5 & 5.0 & 20.3 & 12.8 \\
\hline$\beta \%_{\mathrm{f}}(\%)$ & $42.6 \pm 6.9$ & $51.0 \pm 6.3$ & 34.0 & 39.2 & 52.4 & 61.3 \\
\hline$\gamma_{\mathrm{f}}$ & $30.8 \pm 7.6$ & $20.4 \pm 5.2$ & 23.0 & 9.0 & 51.0 & 30.0 \\
\hline Red List species & $1.0 \pm 1.2$ & $0.4 \pm 0.8$ & 0.0 & 0.0 & 3.0 & 2.0 \\
\hline \multicolumn{7}{|l|}{ Seedbank } \\
\hline$\alpha_{\mathrm{f}}$ & $22.8 \pm 6.0$ & $14.6 \pm 3.7$ & 17.5 & 9.5 & 35.8 & 24.3 \\
\hline$\beta_{\mathrm{f}}$ & $15.1 \pm 3.4$ & $13.1 \pm 2.9$ & 10.5 & 8.5 & 22.5 & 18.0 \\
\hline$\beta \%_{\mathrm{f}}(\%)$ & $40.1 \pm 5.5$ & $47.3 \pm 6.9$ & 31.3 & 34.5 & 50.7 & 56.9 \\
\hline$\gamma_{\mathrm{f}}$ & $31.8 \pm 8.2$ & $21.6 \pm 5.6$ & 23.0 & 14.0 & 46.0 & 31.0 \\
\hline Red List species & $1.9 \pm 2.1$ & $1.0 \pm 0.7$ & 0.0 & 0.0 & 6.0 & 2.0 \\
\hline
\end{tabular}


Vegetation

(a)

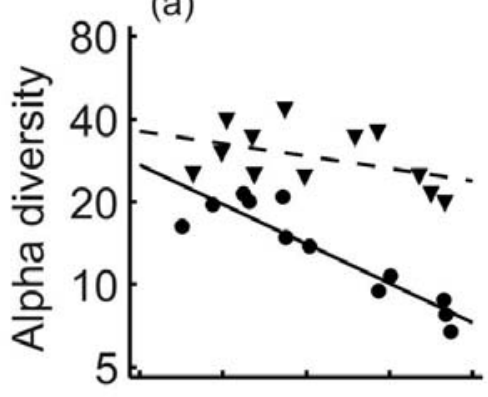

(b)

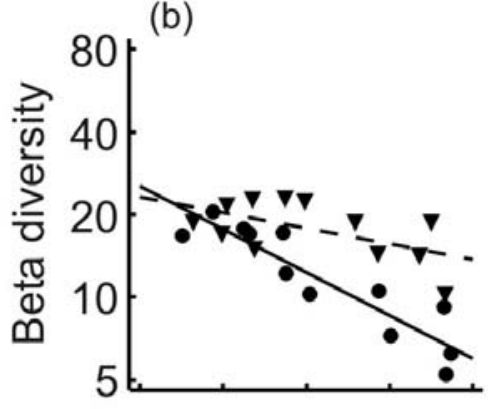

(c)

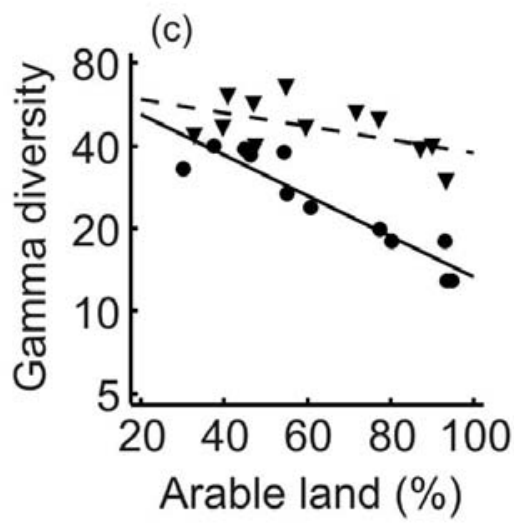

Seed rain

(d)

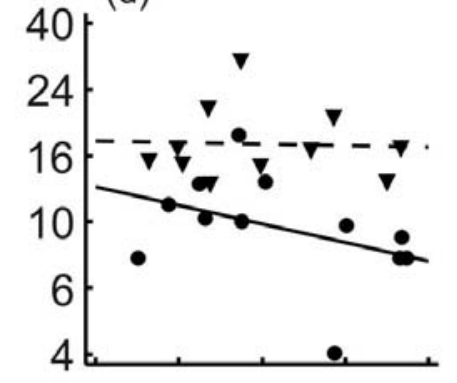

(e)
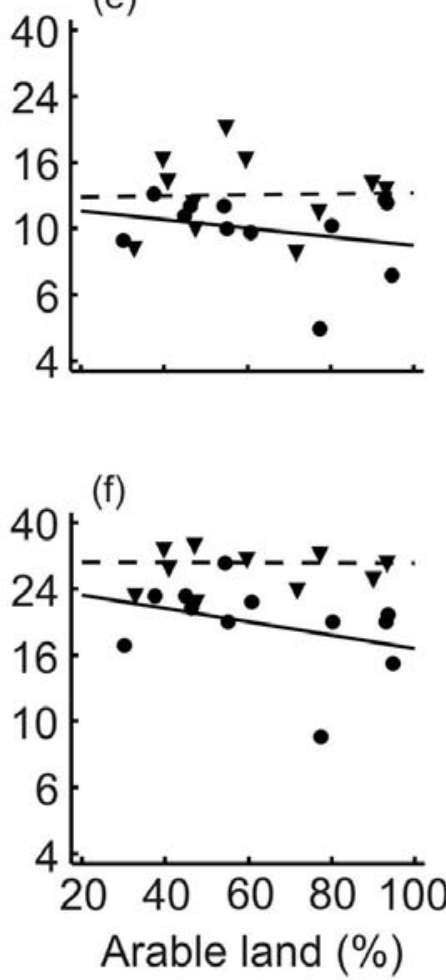

Seed bank

(g)

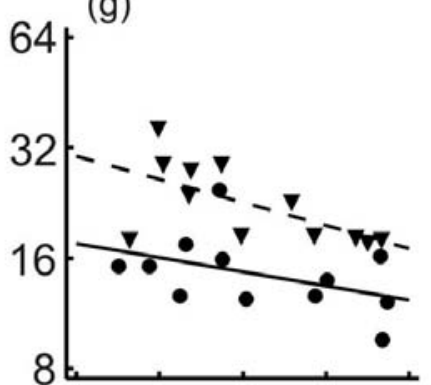

(h)
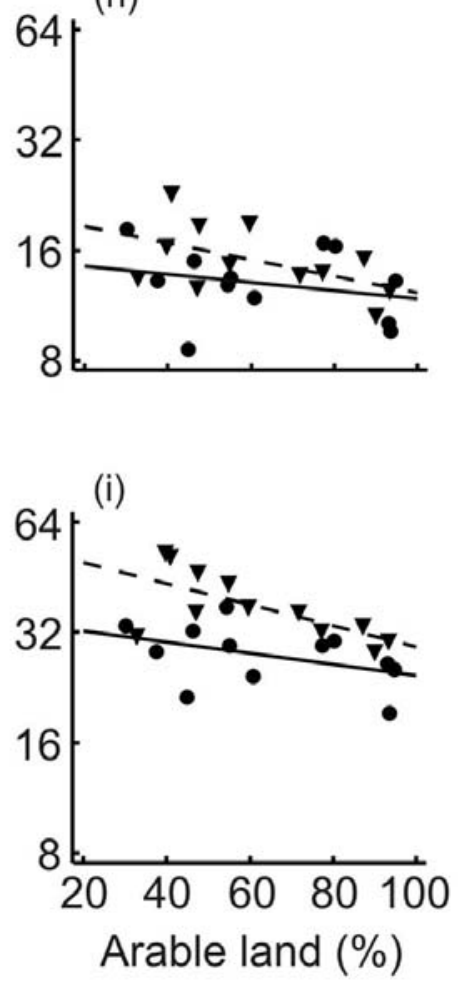

Fig. 5.1. The field-scale alpha, beta, and gamma diversity of weeds in the vegetation (a, b, c), seed rain (d, e, f), and seedbank ( $g, h, i)$ in dependence of percent arable land and farming system (organic vs. conventional). Results from mixed effect models (see Table 5.3). Organic fields = triangles and dashed regression lines; conventional fields = points and solid regression lines. 
Table 5.3. The alpha $\left(\alpha_{\mathrm{f}}\right)$, beta $\left(\beta_{\mathrm{f}}\right)$, and gamma $\left(\gamma_{\mathrm{f}}\right)$ diversity of weeds (field scale) in the vegetation, seed rain, and seedbank in dependence of farming system and landscape complexity. Fvalues and levels of significance $(*$ : $\mathrm{P}<0.05$, **: $\mathrm{P}<0.01$, ***: $\mathrm{P}<0.001)$ from mixed effect models, $\mathrm{n}=24$ wheat fields (seed rain: $\mathrm{n}=22$ fields).

\begin{tabular}{|c|c|c|c|}
\hline & Vegetation & Seed rain & Seedbank \\
\hline \multicolumn{4}{|l|}{ All weeds } \\
\hline \multicolumn{4}{|l|}{$\alpha_{\mathrm{f}}$} \\
\hline A: Arable land (\%) & $35.0 * * *$ & n.s. & $9.0^{*}$ \\
\hline B: Farming system & $128.5^{* * *}$ & $24.5^{* * *}$ & $31.4^{* * *}$ \\
\hline$A \times B$ & $13.5^{* *}$ & n.s. & n.s. \\
\hline \multicolumn{4}{|l|}{$\beta_{\mathrm{f}}$} \\
\hline A: Arable land (\%) & $39.3 * * *$ & n.s. & n.s. \\
\hline B: Farming system & $29.8 * * *$ & $5.2^{*}$ & n.s. \\
\hline$A \times B$ & $9.4^{*}$ & n.s. & n.s. \\
\hline \multicolumn{4}{|l|}{$\gamma_{\mathrm{f}}$} \\
\hline A: Arable land (\%) & $46.6^{* * *}$ & n.s. & $10.3^{* *}$ \\
\hline B: Farming system & $98.3 * * *$ & $19.3^{* *}$ & $18.4^{* *}$ \\
\hline $\mathrm{A} \times \mathrm{B}$ & $15.1^{* *}$ & n.s. & n.s. \\
\hline \multicolumn{4}{|l|}{ Broadleaves } \\
\hline \multicolumn{4}{|l|}{$\alpha_{\mathrm{f}}$} \\
\hline A: Arable land (\%) & $40.9 * * *$ & n.s. & $8.5^{*}$ \\
\hline B: Farming system & $150.5^{* * *}$ & $19.9 * *$ & $34.8 * * *$ \\
\hline $\mathrm{A} \times \mathrm{B}$ & $18.5^{* * *}$ & n.s. & n.s. \\
\hline \multicolumn{4}{|l|}{$\beta_{\mathrm{f}}$} \\
\hline A: Arable land (\%) & $34.3 * * *$ & n.s. & n.s. \\
\hline B: Farming system & $29.9 * * *$ & n.s. & n.s. \\
\hline $\mathrm{A} \times \mathrm{B}$ & $12.5^{* *}$ & n.s. & n.s. \\
\hline \multicolumn{4}{|l|}{$\gamma_{\mathrm{f}}$} \\
\hline A: Arable land (\%) & $45.5 * * *$ & n.s. & $6.5^{*}$ \\
\hline B: Farming system & $107.8 * * *$ & $18.6^{* *}$ & $16.3^{* *}$ \\
\hline$A \times B$ & $19.5^{* *}$ & n.s. & n.s. \\
\hline \multicolumn{4}{|l|}{ Grasses } \\
\hline \multicolumn{4}{|l|}{$\alpha_{\mathrm{f}}$} \\
\hline A: Arable land (\%) & $7.6^{*}$ & n.s. & n.s. \\
\hline B: Farming system & $8.3^{*}$ & $10.9 * *$ & n.s. \\
\hline $\mathrm{A} \times \mathrm{B}$ & n.s. & n.s. & n.s. \\
\hline \multicolumn{4}{|l|}{$\beta_{\mathrm{f}}$} \\
\hline A: Arable land (\%) & $6.5^{*}$ & n.s. & n.s. \\
\hline B: Farming system & n.s. & n.s. & n.s. \\
\hline$A \times B$ & n.s. & n.s. & n.s. \\
\hline \multicolumn{4}{|l|}{$\gamma_{\mathrm{f}}$} \\
\hline A: Arable land (\%) & $10.6^{* *}$ & n.s. & n.s. \\
\hline B: Farming system & n.s. & $10.4^{* *}$ & n.s. \\
\hline$A \times B$ & n.s. & n.s. & n.s. \\
\hline
\end{tabular}




\section{Single species}

Many species were either abundant in only very few or in nearly all fields. However, cumulated for vegetation, seed rain and seedbank, 64 out of 153 species were suitable for logistic regressions, i.e. they were present or absent in at least four fields (see Appendix). Only four of these species could be related to the percentage of arable land: Poa pratense L. occurred with $75 \%$ probability when percent arable land was lower than $34.7 \%$ ( $P<$ 0.01 ; percentage of deviance explained by the model (similar to $R^{2}$ ) $=39.2 \%$ ), Euphorbia helioscopia L. when arable land was lower than 33.2\% $(P<0.01 ; 26.0 \%)$, and Lamium amplexicaule $\mathrm{L}$. when arable land was lower than $54.0 \%(P<0.05 ; 17.4 \%)$. Taraxacum officinale Weber occurred when arable land was lower than $83.7 \%$ in organic fields, and $66.6 \%$ in conventional fields $\left(P_{\text {arable land }}<0.001 ; P_{\text {farming system }}<0.05 ; P_{\text {model }}<0.001\right.$; 84.4\%). Another eight species (Cerastium dubium (Bastard) Guépin, Equisetum arvensis L., Medicago sativa L., Potentilla reptans L., Trifolium pratense L., Tussilago farfara L., Vicia cracca L., Vicia faba L.) were significantly more present in organic farming, irrespective of landscape complexity ( $P$-values ranging from $<0.05$ to $<0.001$; percentages of deviance explained by the model ranging from 20.0 to $57.5 \%$ ). Independent of farming system, the number of Red List species per field in the vegetation decreased significantly when percent arable land increased (mixed effect models: $F=7.4 ; P<0.05$ ).

\section{Discussion}

In this study, local management (organic vs. conventional) and complexity of the surrounding landscape had an influence on alpha, beta, and gamma diversity of weeds in 24 winter wheat fields. The arable weed gamma diversity in the whole study region was 153 species. This overall diversity was greatly determined by the heterogeneity between the fields, as beta diversity made up $~ 65 \%$. Similarly, Wagner et al. (2000) described low within-field diversity and large between-field diversity in arable fields and attributed this to crop variability. In our study, the crop species was the same in all analysed fields, which underlines the high variability of weed community structure in the region.

At the field scale, the gamma diversity of weeds in the vegetation was higher in organic than in conventional fields, a finding consistent with the results of other studies (Moreby et al. 1994; Hald 1999a; Hyvönen et al. 2003b). But our results showed that this was especially valid in fields located in simple landscapes with high percent arable land, as gamma diversity in conventional fields was strongly positively affected by landscape complexity, which resulted in nearly similar gamma diversities in organic and conventional fields when landscapes were complex with high percentages of non-crop areas. Gamma diversity of organic fields was only weakly related with landscape complexity, suggesting organic fields to be more or less self-sufficient ecosystems, not depending on species immigration from surrounding habitats in complex landscapes. Plant diversity of organic and conventional farms in Sweden showed a similar tendency: in conventional pastures 
and field margins, diversity tended to increase steeper with increasing perimeter-to area ratio than in organic (Weibull et al. 2003), but this could not be proven statistically. Alpha and beta diversity revealed a similar pattern as gamma diversity.

In contrast to broadleaf diversity, the gamma and beta diversity of grasses in the vegetation did not differ between the farming systems, but were also negatively related with the percentage of arable land. The number of grass species was generally much lower than of broadleaves - in the whole study, only 18 grass species were found - which may partly explain why the observed differences between organic and conventional fields in broadleaf diversity could not generally be found in grasses. As all conventional farmers applied herbicides, broadleaf species may generally have been more affected by the applications than grasses, as suggested by Hole et al. (2005).

Reasons for the high importance of landscape complexity for the local weed species diversity, especially in conventional fields, might be found in the analysis of species entering the fields through the seed rain. Unexpectedly, species diversity in the seed rain appeared to be mainly determined by the local vegetation, as it was higher in organic than in conventional fields and not related to percent arable land. Many seeds appeared to come from the fields themselves, but not from the landscape. This is supported by several studies showing that seeds of many arable weeds were dispersed only a few meters from the mother plant (e.g., Rew, Froud-Williams \& Boatman 1996; Bischoff \& Mahn 2000). However, Fig. 5.1 shows a trend that in complex landscapes, diversity was high in both organic and conventional fields, whereas it decreased with increasing percentage of arable land only in conventional fields. This trend might not have been significant in the statistical models because of the high variability in the data, compared to the data of the vegetation analysis. But most of the weed species occurring in the seed rain, but not in the vegetation and seedbank (Appendix) should be relatively good dispersers because they are anemochor and/or zoochor (see Kästner et al. 2001). Their seeds should have had the potential to reach an arable field from the surrounding habitats which should provide a higher species pool in complex than in simple landscapes.

The gamma and alpha diversity in the seedbank were generally higher in organic than in conventional fields. The organic fields were at least for 7 years under organic management, which should be a time span long enough to fill the seedbank with species not occurring until the conversion to organic farming. Long-term effects of farming systems on weed species richness were also shown by Menalled et al. (2001). Additionally, weed species diversity decreased with increasing percentage of arable land, but in contrast to the diversity of the vegetation, the surrounding landscape affected both, organic and conventional fields similarly. So, landscape complexity did not seem to determine the weed species diversity of organic fields immediately (i.e. in the vegetation), but revealed the potential to do so in the following years, expressed via the more diverse germinable seedbank in complex landscapes.

In contrast to the absolute beta diversities, the relative beta diversities of weeds in the vegetation, the seed rain, and the seedbank were higher in conventional than in organic 
fields, irrespective of landscape complexity. This shows the particular importance of the species heterogeneity within a field for the gamma diversity of conventional fields, as the mean (alpha) diversity within a field was comparatively low. Heterogeneity in conventional fields may be due to less intensive herbicide spraying and fertilisation at the field edges. Wilson and Aebischer (1995) showed that several weed species in conventional fields declined with increasing distance from the field edges, and Hald (1999a) found a gradient in species density from edge to centre in conventional, but not in organic fields.

The number of Red List species in the vegetation was shown to be higher in complex than in simple landscapes, indicating a high importance of alternative habitats in the surrounding landscape for these species. However, numbers of species did not differ between organic and conventional fields. Thus, our study only partly supports the general opinion that the decline of particular species is caused by intensive agricultural practices at the field scale and the simplification of landscape complexity (e.g., Korneck \& Sukopp 1988; Jedicke 1997; Hofmeister \& Garve 1998). The unexpected similar numbers of Red List species in organic and conventional farming may result from a gradual decrease in the land-use intensity of conventional fields, which seemed to be irrespective of landscape complexity (see Methods). For example, the fertilizer consumption in Germany decreased from $\sim 3$ million $t$ (1991) to 2.6 million $t$ (2001), and the herbicide consumption from 18000t (1991) to 15000t (2001) (FAO 2001). However, out of the 23 Red List species, 21 were found in organic fields, and only half of it (10 species) in conventional fields.

Results of multiple logistic regressions showed that only very few single species depended on landscape complexity and/or organic farming. Thus, higher species numbers found in complex landscapes and in organic farming cannot only be attributed to single species depending on such landscapes and/or organic farming. Which particular species have contributed to higher species numbers in complex landscapes is more likely to be a matter of chance. This might suggest mass effect (Shmida \& Wilson 1985; Auerbach \& Shmida 1987; Palmer 1992), which explains high local species richness with a continuously immigration from nearby but dissimilar habitats. One characteristic of many arable weed species is their ability to quickly colonise and survive in ruderal and disturbed habitats. Thus, the probability that many species randomly immigrate into a field is obviously greater when the proportion of alternative habitats in the landscape is increased. Eight species could be shown to depend on organic farming. These species were hemicryptophytes or geophytes and some of them legumes, which may have profited from diverse crop rotations including perennial crops for green manure. Legumes should be more competitive in organic than in conventional fields due to absent mineral nitrogen input.

Our results have implications for future management of both arable fields and landscape complexity to conserve species diversity of arable weeds, which are important components of the biodiversity in agricultural landscapes (Marshall et al. 2003). Organic farming generally promoted species diversity of arable weeds and the surrounding landscape was 
important for the seedbank. In conventional fields, species diversity strongly increased with increasing landscape complexity, thereby generating nearly similar diversity levels as in organic fields when the surrounding landscape was complex. Hence, organic farming contributed best to weed species diversity in simple agricultural landscapes. Therefore, the conversion of conventional to organic farming should be particularly effective and therefore especially supported in these areas. This is in contrast to present uptake of agrienvironment schemes which is highest in areas where biodiversity is already relatively high and lowest where biodiversity is low (Kleijn \& Sutherland 2003), thereby not using species potential of agricultural landscapes to full capacity. Promoting non-crop habitats in agricultural landscapes as refuges for weed species appears to be of particular importance for landscape management, especially when organically managed fields are rare. Moreover, differences in species composition (beta diversity) have been shown to be very large within fields (particularly in conventional farming) and between fields thereby making an important contribution to overall diversity (gamma diversity) at the field and regional scale. Future management policies should therefore take into account the heterogeneity in community composition at different spatial scales.

\section{Acknowledgements}

We are grateful to the farmers who allowed us to work in their fields, Katja Poveda for statistical advice, Christof Bürger for GIS-support, and Jochen Krauss, Fabian Menalled, Thomas O. Crist and one anonymous referee for helpful comments on previous versions of the manuscript. This project was financially supported by the German Science Foundation (DFG) and the German Ministry for Research and Education (BMBF). 
Appendix. Abundance (number of fields, in which each species occurred) and conservation status of weed species in the vegetation (V), seed rain (SR), and seedbank (SB) of 12 organic and 12 conventional winter wheat fields (seed rain: 11 organic fields).

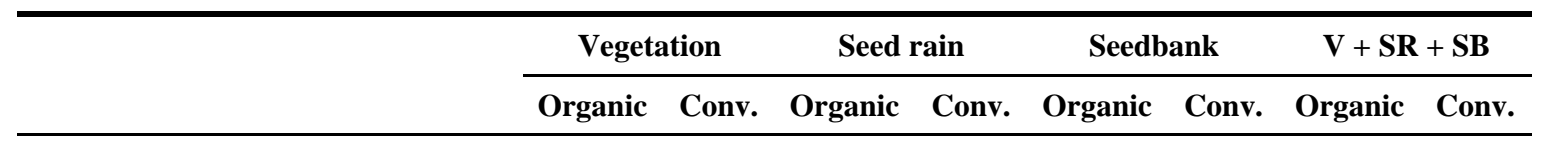

Broadleaves:

Achillea millefolium L.

Aegopodium podagraria L.

Aethusa cynapium L.

Agrimonia eupatoria L.

Agrostemma githago L. ${ }^{1}$

Allium vineale $\mathrm{L}$.

Anagallis arvensis $\mathrm{L}$.

Androsace elongata L. ${ }^{5}$

Anthemis arvensis L. ${ }^{3}$

Anthriscus sylvestris (L.) Hoffm.

Aphanes arvensis L.

Arabidopsis thaliana (L.) Heynh.

Artemisia vulgaris L.

Atriplex patula L.

Brassica rapa L.

Capsella bursa-pastoris (L.) Med.

Carum carvi L. ${ }^{3}$

Centaurea cyanus L.

Cerastium arvense $\mathrm{L}$.

Cerastium dubium (Bastard) Guépin ${ }^{4}$

Cerastium glomeratum Thuill.

Cerastium holosteoides Fr.

Chaenorhinum minus (L.) Lange

Chenopodium album L.

Chrysanthemum segetum L.

Cirsium arvense (L.) Scop.

Cichorium intybus L.

Consolida regalis ${ }^{3}$

Convolvulus arvensis L.

Crepis tectorum L. ${ }^{3}$

Daucus carota L.

Epilobium tetragonum L.

Equisetum arvensis L.

Erophila verna (L.) DC.

Euphorbia exigua L.

Euphorbia helioscopia L.

Euphorbia platyphyllos L. ${ }^{2}$

Fallopia convolvulus (L.) Å. Löve

Filago arvensis L. ${ }^{2}$

Fumaria officinalis L.

Galeopsis segetum Neck. ${ }^{2}$

Galeopsis tetrahit L.

\begin{tabular}{|c|c|c|c|c|c|c|c|}
\hline 3 & 0 & 0 & 0 & 1 & 1 & 3 & 1 \\
\hline 1 & 0 & 0 & 0 & 0 & 0 & 1 & 0 \\
\hline 2 & 1 & 0 & 0 & 0 & 0 & 2 & 1 \\
\hline 1 & 0 & 0 & 0 & 0 & 0 & 1 & 0 \\
\hline 0 & 0 & 0 & 0 & 1 & 0 & 1 & 0 \\
\hline 1 & 1 & 0 & 0 & 0 & 0 & 1 & 1 \\
\hline 3 & 0 & 0 & 0 & 2 & 1 & 4 & 1 \\
\hline 0 & 0 & 3 & 2 & 3 & 0 & 5 & 2 \\
\hline 2 & 0 & 0 & 0 & 4 & 1 & 4 & 1 \\
\hline 4 & 3 & 0 & 0 & 0 & 0 & 4 & 3 \\
\hline 11 & 7 & 7 & 3 & 11 & 5 & 11 & 10 \\
\hline 6 & 2 & 7 & 2 & 6 & 1 & 10 & 4 \\
\hline 1 & 0 & 0 & 0 & 0 & 0 & 1 & 0 \\
\hline 1 & 0 & 1 & 0 & 0 & 0 & 2 & 0 \\
\hline 1 & 5 & 0 & 0 & 0 & 0 & 1 & 5 \\
\hline 10 & 4 & 4 & 2 & 11 & 12 & 12 & 12 \\
\hline 1 & 0 & 1 & 0 & 0 & 0 & 1 & 0 \\
\hline 3 & 1 & 0 & 0 & 5 & 0 & 5 & 1 \\
\hline 0 & 0 & 0 & 0 & 3 & 1 & 3 & 1 \\
\hline 2 & 0 & 2 & 0 & 2 & 0 & 4 & 0 \\
\hline 2 & 0 & 1 & 0 & 0 & 0 & 3 & 0 \\
\hline 4 & 1 & 0 & 0 & 0 & 0 & 4 & 1 \\
\hline 0 & 0 & 0 & 0 & 1 & 0 & 1 & 0 \\
\hline 3 & 1 & 2 & 1 & 10 & 8 & 10 & 9 \\
\hline 0 & 0 & 0 & 1 & 0 & 0 & 0 & 1 \\
\hline 12 & 10 & 7 & 6 & 8 & 3 & 12 & 11 \\
\hline 0 & 0 & 0 & 0 & 0 & 1 & 0 & 1 \\
\hline 0 & 0 & 0 & 0 & 1 & 0 & 1 & 0 \\
\hline 7 & 6 & 0 & 1 & 0 & 1 & 7 & 6 \\
\hline 2 & 1 & 2 & 2 & 0 & 0 & 4 & 3 \\
\hline 1 & 0 & 0 & 0 & 1 & 3 & 2 & 3 \\
\hline 8 & 3 & 11 & 12 & 12 & 11 & 12 & 12 \\
\hline 8 & 2 & 1 & 0 & 1 & 0 & 8 & 2 \\
\hline 1 & 0 & 1 & 1 & 2 & 0 & 2 & 1 \\
\hline 3 & 0 & 0 & 0 & 0 & 0 & 3 & 0 \\
\hline 5 & 3 & 0 & 0 & 1 & 0 & 5 & 3 \\
\hline 0 & 0 & 0 & 4 & 3 & 1 & 3 & 4 \\
\hline 12 & 7 & 6 & 3 & 11 & 8 & 12 & 10 \\
\hline 0 & 0 & 0 & 0 & 5 & 5 & 5 & 5 \\
\hline 5 & 2 & 1 & 0 & 2 & 1 & 6 & 3 \\
\hline 0 & 0 & 0 & 0 & 1 & 0 & 1 & 0 \\
\hline 8 & 4 & 3 & 0 & 2 & 2 & 8 & 4 \\
\hline
\end{tabular}




\begin{tabular}{|c|c|c|c|c|c|c|c|c|}
\hline & \multicolumn{2}{|c|}{ Vegetation } & \multicolumn{2}{|c|}{ Seed rain } & \multicolumn{2}{|c|}{ Seedbank } & \multicolumn{2}{|c|}{$\mathbf{V}+\mathbf{S R}+\mathbf{S B}$} \\
\hline & Organic & Conv. & Organic & Conv. & Organic & Conv. & Organic & Conv. \\
\hline Galium aparine L. & 12 & 12 & 7 & 8 & 7 & 5 & 12 & 12 \\
\hline Galium mollugo L. ${ }^{5}$ & 0 & 1 & 0 & 0 & 0 & 0 & 0 & 1 \\
\hline Geranium dissectum L. & 3 & 2 & 0 & 0 & 2 & 3 & 3 & 4 \\
\hline Geranium pusillum Burm. f. & 4 & 3 & 1 & 1 & 1 & 1 & 4 & 3 \\
\hline Geranium rotundifolium L. & 0 & 0 & 1 & 0 & 0 & 0 & 1 & 0 \\
\hline Geum urbanum L. & 1 & 1 & 0 & 0 & 0 & 0 & 1 & 1 \\
\hline Glechoma hederacea L. & 2 & 0 & 0 & 0 & 0 & 0 & 2 & 0 \\
\hline Gnaphalium uliginosum L. & 0 & 0 & 0 & 0 & 1 & 0 & 1 & 0 \\
\hline Heracleum sphondylium L. & 4 & 3 & 0 & 1 & 0 & 0 & 4 & 4 \\
\hline Hieracium lachenalii C.C. Gmel. & 1 & 1 & 0 & 0 & 0 & 0 & 1 & 1 \\
\hline Holosteum umbellatum L. ${ }^{3}$ & 0 & 0 & 0 & 0 & 1 & 0 & 1 & 0 \\
\hline Hypericum perforatum L. & 1 & 0 & 0 & 0 & 2 & 2 & 3 & 2 \\
\hline Lamium amplexicaule $\mathrm{L}$. & 9 & 5 & 2 & 1 & 2 & 2 & 9 & 6 \\
\hline Lamium purpureum L. & 10 & 10 & 10 & 6 & 9 & 11 & 11 & 12 \\
\hline Lapsana communis L. & 6 & 1 & 8 & 4 & 9 & 5 & 10 & 7 \\
\hline Lathyrus hirsutus L. & 0 & 0 & 0 & 0 & 1 & 0 & 1 & 0 \\
\hline Legousia speculum-veneris L. Chaix ${ }^{1}$ & 0 & 0 & 0 & 0 & 1 & 1 & 1 & 1 \\
\hline Leontodon hispidus L. & 0 & 0 & 1 & 1 & 0 & 1 & 1 & 1 \\
\hline Linaria vulgaris Mill. & 0 & 0 & 0 & 0 & 0 & 1 & 0 & 1 \\
\hline Matricaria perforata Mérat & 10 & 4 & 6 & 0 & 12 & 10 & 12 & 10 \\
\hline Matricaria recutita $\mathrm{L}$. & 12 & 11 & 9 & 8 & 11 & 12 & 12 & 12 \\
\hline Medicago sativa $\mathrm{L}$. & 5 & 0 & 3 & 0 & 1 & 0 & 6 & 0 \\
\hline Melampyrum arvense $\mathrm{L}^{2}$ & 1 & 0 & 0 & 0 & 0 & 0 & 1 & 0 \\
\hline Mentha arvensis L. & 1 & 0 & 0 & 0 & 0 & 0 & 1 & 0 \\
\hline Myosotis arvensis (L.) Hill. & 11 & 9 & 11 & 10 & 11 & 10 & 12 & 12 \\
\hline Myosurus minimus L. ${ }^{3}$ & 0 & 1 & 1 & 0 & 2 & 3 & 2 & 3 \\
\hline Odontites vernus agg. & 0 & 0 & 1 & 2 & 0 & 0 & 1 & 2 \\
\hline Papaver dubium L. & 0 & 0 & 0 & 1 & 0 & 0 & 0 & 1 \\
\hline Papaver rhoeas L. & 9 & 5 & 9 & 4 & 9 & 8 & 11 & 9 \\
\hline Persicaria amphibia (L.) Delarbre & 0 & 0 & 0 & 0 & 1 & 1 & 1 & 1 \\
\hline Persicaria lapathifolia (L.) Delarbre & 1 & 0 & 5 & 5 & 8 & 3 & 12 & 6 \\
\hline Persicaria maculosa Gray & 3 & 1 & 4 & 5 & 1 & 1 & 5 & 6 \\
\hline Pimpinella major (L.) Huds. & 2 & 0 & 0 & 0 & 0 & 0 & 2 & 0 \\
\hline Plantago lanceolata L. & 1 & 0 & 0 & 0 & 0 & 0 & 1 & 0 \\
\hline Plantago major ssp. major & 1 & 0 & 0 & 1 & 2 & 0 & 2 & 1 \\
\hline Polygonum aviculare L. & 12 & 7 & 4 & 1 & 11 & 10 & 12 & 11 \\
\hline Potentilla anserina L. & 2 & 2 & 0 & 0 & 0 & 0 & 2 & 2 \\
\hline Potentilla reptans L. & 5 & 0 & 0 & 0 & 0 & 0 & 5 & 0 \\
\hline Primula vulgaris Huds. ${ }^{1}$ & 0 & 1 & 0 & 0 & 0 & 0 & 0 & 1 \\
\hline Ranunculus arvensis L. ${ }^{2}$ & 2 & 0 & 1 & 0 & 0 & 0 & 3 & 0 \\
\hline Ranunculus repens L. & 10 & 3 & 1 & 1 & 3 & 2 & 11 & 4 \\
\hline Raphanus raphanistrum L. ${ }^{3}$ & 3 & 1 & 0 & 0 & 1 & 0 & 4 & 1 \\
\hline Rhinanthus alectorolophus (Scop.) & 0 & 0 & 1 & 0 & 0 & 0 & 1 & 0 \\
\hline \multicolumn{9}{|l|}{ Pollich ${ }^{1}$} \\
\hline Rubus caesius L. & 4 & 0 & 0 & 8 & 0 & 0 & 4 & 8 \\
\hline Rumex acetosella L. & 1 & 1 & 0 & 0 & 0 & 0 & 1 & 1 \\
\hline Rumex crispus L. L. & 11 & 2 & 6 & 4 & 11 & 8 & 12 & 10 \\
\hline
\end{tabular}




\begin{tabular}{|c|c|c|c|c|c|c|c|c|}
\hline & \multicolumn{2}{|c|}{ Vegetation } & \multicolumn{2}{|c|}{ Seed rain } & \multicolumn{2}{|c|}{ Seedbank } & \multicolumn{2}{|c|}{$\mathbf{V}+\mathbf{S R}+\mathbf{S B}$} \\
\hline & Organic & Conv. & Organic & Conv. & Organic & Conv. & Organic & Conv. \\
\hline Rumex obtusifolius L. & 11 & 2 & 6 & 2 & 6 & 4 & 12 & 7 \\
\hline Scleranthus annuus L. & 1 & 0 & 1 & 0 & 2 & 0 & 3 & 0 \\
\hline Sedum telephium agg. & 0 & 0 & 0 & 0 & 1 & 0 & 1 & 0 \\
\hline Senecio vulgaris L. & 0 & 0 & 0 & 0 & 0 & 1 & 0 & 1 \\
\hline Sherardia arvensis L. ${ }^{3}$ & 1 & 0 & 0 & 0 & 1 & 0 & 1 & 0 \\
\hline Sinapis arvensis L. & 7 & 3 & 5 & 6 & 7 & 8 & 10 & 9 \\
\hline Sisymbrium officinale (L.) Scop. & 0 & 0 & 0 & 0 & 1 & 3 & 1 & 3 \\
\hline Solanum nigrum L. & 0 & 0 & 0 & 0 & 2 & 0 & 2 & 0 \\
\hline Sonchus arvensis L. & 8 & 1 & 5 & 6 & 9 & 6 & 11 & 10 \\
\hline Sonchus asper (L.) Hill & 0 & 0 & 3 & 0 & 3 & 2 & 4 & 2 \\
\hline Sonchus oleraceus L. & 0 & 0 & 0 & 0 & 1 & 0 & 1 & 0 \\
\hline Spergula arvensis L. & 0 & 0 & 0 & 0 & 2 & 0 & 2 & 0 \\
\hline Spergularia rubra (L.) J.\&C. Presl & 0 & 0 & 1 & 0 & 0 & 0 & 1 & 0 \\
\hline Stachys arvensis (L.) L. ${ }^{2}$ & 0 & 1 & 0 & 1 & 0 & 1 & 0 & 3 \\
\hline Stellaria aquatica (L.) Scop. & 0 & 0 & 0 & 0 & 1 & 0 & 1 & 0 \\
\hline Stellaria media (L.) Vill. & 12 & 9 & 10 & 9 & 11 & 10 & 12 & 11 \\
\hline Symphytum officinale L. & 0 & 1 & 0 & 0 & 0 & 1 & 0 & 1 \\
\hline Taraxacum officinale Weber & 10 & 6 & 6 & 2 & 0 & 2 & 10 & 7 \\
\hline Thlaspi arvense L. & 12 & 4 & 6 & 1 & 12 & 11 & 12 & 11 \\
\hline Trifolium arvense L. & 0 & 0 & 0 & 0 & 1 & 0 & 1 & 0 \\
\hline Trifolium hybridum L. & 1 & 0 & 0 & 0 & 2 & 0 & 3 & 0 \\
\hline Trifolium incarnatum L. & 1 & 0 & 0 & 1 & 1 & 0 & 2 & 1 \\
\hline Trifolium pratense $\mathrm{L}$. & 8 & 0 & 0 & 0 & 2 & 0 & 9 & 0 \\
\hline Trifolium repens L. & 12 & 2 & 5 & 1 & 9 & 2 & 12 & 4 \\
\hline Trifolium resupinatum L. & 1 & 0 & 0 & 0 & 0 & 0 & 1 & 0 \\
\hline Tussilago farfara $\mathrm{L}$. & 6 & 0 & 0 & 0 & 1 & 0 & 7 & 0 \\
\hline Urtica dioica $\mathrm{L}$. & 2 & 2 & 0 & 0 & 5 & 2 & 5 & 4 \\
\hline Urtica urens L. & 0 & 0 & 0 & 0 & 2 & 2 & 2 & 2 \\
\hline Valerianella locusta (L.) Laterr. & 1 & 0 & 0 & 0 & 0 & 0 & 1 & 0 \\
\hline Veronica arvensis L. & 7 & 5 & 5 & 2 & 9 & 5 & 10 & 7 \\
\hline Veronica chamaedrys L. & 1 & 0 & 0 & 0 & 0 & 0 & 1 & 0 \\
\hline Veronica hederifolia L. & 12 & 10 & 11 & 10 & 11 & 8 & 12 & 11 \\
\hline Veronica opaca Fr. ${ }^{2}$ & 0 & 0 & 1 & 0 & 0 & 0 & 1 & 0 \\
\hline Veronica persica Poir. & 11 & 9 & 10 & 8 & 11 & 10 & 12 & 12 \\
\hline Veronica polita Fr. & 8 & 5 & 5 & 1 & 7 & 3 & 12 & 6 \\
\hline Veronica triphyllos L. ${ }^{3}$ & 0 & 0 & 1 & 0 & 0 & 0 & 1 & 0 \\
\hline Veronica verna $\mathrm{L}^{2}$ & 0 & 0 & 1 & 0 & 0 & 0 & 1 & 0 \\
\hline Vicia articulata Hornem. & 1 & 0 & 0 & 0 & 0 & 0 & 1 & 0 \\
\hline Vicia cracca L. & 2 & 0 & 1 & 0 & 6 & 0 & 7 & 0 \\
\hline Vicia faba $\mathrm{L}$. & 0 & 0 & 0 & 0 & 6 & 0 & 6 & 0 \\
\hline Vicia hirsuta (L.) Gray & 4 & 1 & 0 & 0 & 0 & 0 & 4 & 1 \\
\hline Vicea lutea L. & 0 & 0 & 0 & 0 & 1 & 0 & 1 & 0 \\
\hline Vicia sativa $\mathrm{L}$. & 0 & 0 & 1 & 0 & 2 & 0 & 3 & 0 \\
\hline Vicia sepium L. & 2 & 0 & 0 & 0 & 0 & 0 & 2 & 0 \\
\hline Vicia tetrasperma (L.) Schreb. & 10 & 4 & 5 & 1 & 6 & 1 & 11 & 4 \\
\hline Vicia villosa subsp. villosa & 5 & 1 & 0 & 0 & 0 & 0 & 5 & 1 \\
\hline Viola arvensis Murray & 11 & 11 & 9 & 7 & 11 & 11 & 12 & 11 \\
\hline
\end{tabular}




\begin{tabular}{|c|c|c|c|c|c|c|c|c|}
\hline & \multicolumn{2}{|c|}{ Vegetation } & \multicolumn{2}{|c|}{ Seed rain } & \multicolumn{2}{|c|}{ Seedbank } & \multicolumn{2}{|c|}{$\mathbf{V}+\mathbf{S R}+\mathbf{S B}$} \\
\hline & Organic & Conv. & Organic & Conv. & Organic & Conv. & Organic & Conv. \\
\hline \multicolumn{9}{|l|}{ Grasses: } \\
\hline Alopecurus myosuroides Huds. & 12 & 12 & 11 & 12 & 12 & 12 & 12 & 12 \\
\hline Alopecurus pratensis L. & 5 & 3 & 0 & 0 & 0 & 0 & 5 & 3 \\
\hline Apera spica-venti (L.) P. Beauv. & 11 & 12 & 9 & 5 & 12 & 11 & 12 & 12 \\
\hline $\begin{array}{l}\text { Arrhenatherum elatius (L.) P. Beauv. } \\
\text { ex J.\&C. Pesl }\end{array}$ & 7 & 4 & 1 & 1 & 0 & 1 & 7 & 6 \\
\hline Bromus arvensis L. ${ }^{2}$ & 3 & 4 & 0 & 2 & 0 & 0 & 3 & 4 \\
\hline Bromus hordeaceus L. & 0 & 0 & 0 & 1 & 0 & 0 & 0 & 1 \\
\hline Bromus sterilis L. & 3 & 4 & 2 & 2 & 0 & 1 & 4 & 5 \\
\hline Dactylis glomerata $\mathrm{L}$. & 9 & 10 & 11 & 9 & 4 & 6 & 12 & 11 \\
\hline Elymus repens (L.) Gould & 12 & 12 & 10 & 6 & 11 & 8 & 12 & 12 \\
\hline Festuca rubra L. & 0 & 1 & 0 & 0 & 0 & 0 & 0 & 1 \\
\hline Holcus lanatus L. & 1 & 0 & 4 & 1 & 0 & 0 & 5 & 1 \\
\hline Juncus sphaerocarpus Nees ${ }^{5}$ & 4 & 0 & 5 & 5 & 7 & 7 & 10 & 9 \\
\hline Lolium multiflorum Lam. & 12 & 0 & 10 & 1 & 3 & 0 & 12 & 1 \\
\hline Lolium perenne L. & 6 & 8 & 3 & 7 & 2 & 4 & 9 & 11 \\
\hline Phleum pratense L. & 4 & 1 & 0 & 0 & 0 & 0 & 4 & 1 \\
\hline Poa anпua L. & 8 & 7 & 11 & 11 & 11 & 12 & 12 & 12 \\
\hline Poa pratensis L. & 3 & 2 & 1 & 0 & 0 & 0 & 4 & 2 \\
\hline Poa trivialis L. & 12 & 12 & 11 & 12 & 11 & 12 & 12 & 12 \\
\hline
\end{tabular}

Note: Conservation status according to the Red List of threatened plant species of Lower Saxony (Germany) (Garve \& Letschert 1991; Garve 1993; Korneck et al. 1996):

${ }^{1}$ critically endangered

${ }^{2}$ endangered

${ }^{3}$ vulnerable

${ }^{4}$ rare, potentially vulnerable

${ }^{5}$ regionally weaker vulnerable 
Chapter

6

Insect pollinated plants benefit from organic farming

Doreen Gabriel \& Teja Tscharntke

Submitted to Agriculure, Ecosystems and Environment

$-82-$ 


\begin{abstract}
Organic farming is predicted to enhance diversity in agroecosystems. This study addresses the question of whether the often observed positive effect of organic farming on arable weed and pollinator diversity results in a significant shift in arable weed community structure toward a higher proportion of insect pollinated species in organic crop fields. To examine whether plant community patterns were consistent with this hypothesis, we compared arable weed communities with respect to the type of pollination (i.e. insect pollination vs. non-insect pollination) in the edges and centres of 20 organic and 20 conventional wheat fields. Plant species numbers of both pollination types were much higher in organic than in conventional fields and higher in the field edge than in the field centre. A comparison of the proportions of both pollination types to all plant species revealed that the relative number of insect pollinated species was higher in organic than in conventional fields and higher at the field edge than in the field centre, whereas the relative number of non-insect pollinated species was higher in conventional fields and in the field centre. Our results show that insect pollinated plants benefit disproportionately from organic farming, which appeared to be related to higher pollinator densities in organic fields, whereas in the centres of conventional fields non-insect pollinated plants dominate presumably due to a limitation of pollinators. Hence, disruption of plant-pollinator interactions due to agricultural intensification may cause important shifts in plant community structure.
\end{abstract}

Keywords: arable weeds, conventional farming, plant-animal interaction, species richness, mass effect 


\section{Introduction}

Pollination plays an important role in flowering plant reproduction and fruit set for wild plant communities (Corbet et al. 1991, Buchman and Nabhan 1996). In natural and seminatural habitats up to $90 \%$ of all flowering plant species rely on pollination by animals mainly insects such as bees (Richards 1986, Buchman and Nabhan 1996, Daily et al. 1997, Michener 2000). However, in highly disturbed systems such as arable fields, plants are well adapted to changing conditions created by annual soil cultivation, harvest of crops, and crop rotation. The majority of arable weeds are annuals and prevalently self pollinated. They produce large amounts of seeds without dependence on other plants as pollen donors and insect pollinators, which themselves depend on weather condition, nesting habitats etc. (Baker 1974, Hess 1983). Therefore, plant community structure of disturbed habitats is characterised by higher proportions of self pollinated plants compared to natural and seminatural systems (Regal 1982, Hess 1983). Out of 108 rare arable weed species in Germany, about $45 \%$ are mainly self pollinated of which $8 \%$ are obligatory autogamous, $47 \%$ are pollinated by animals and 9\% by wind (Schneider et al. 1994). The most important pollinators for arable weeds are wild bees, honeybees and bumblebees, and sometimes flies and butterflies (Schneider et al. 1994).

In the last decades both plant and animal diversity have decreased in agroecosystems due to an increasing intensification in agricultural practices (Vandermeer et al. 1998, Robinson and Sutherland, 2002) including large declines and changes in species richness and abundance of arable weeds (Albrecht 1995, Sutcliffe and Kay, 2000) and their pollinator guilds (Osborne et al. 1991, Buchman and Nabhan 1996, Allen-Wardell et al. 1998, Kearns et al. 1998). Organic farming is generally found to enhance biodiversity in agroecosystems because of the lack of use of pesticides and mineral fertilizer, and the greater variability in crop rotation (van Elsen 2000; Bengtsson et al. 2005, Hole et al. 2005). Beneficial effects of organic farming on the abundance and species richness of arable weeds and pollinators have been reported (Moreby et al. 1994; Hald 1999a,b, Menalled et al. 2001, Hyvönen et al. 2003b, Holzschuh et al. 2005, Morandin and Winston 2005, Roschewitz et al. 2005a, but see Weibull et al. 2000). Hence, an increased diversity on both sides of plant-pollinator interactions might lead to a significant shift in plant community structure toward more insect pollinated species in organic crop fields.

To address this question, we analysed arable weed communities with respect to the type of pollination (insect vs. non-insect pollination) in the edges and centres of 20 organic and 20 conventional wheat fields in Germany. We expected (1) that arable weed species richness and percentage cover would be higher in organic than in conventional fields and higher in the field edges than in the field centres, and (2) that insect pollinated plant species benefit disproportionately from organic farming due to higher densities of pollinators in organic fields. 


\section{Methods}

\section{Study sites and sampling design}

The study was conducted in three agricultural regions in Germany: Soester Boerde (51 ${ }^{\circ}$ $35^{\prime} 00^{\prime \prime} \mathrm{N} 008^{\circ} 07^{\prime} 00^{\prime \prime}$ E, North-Rhine Westphalia), Leine Bergland (51 $32^{\prime} 00^{\prime \prime} \mathrm{N} 009^{\circ}$ 56' 00" E, Lower-Saxony), and Lahn-Dill Bergland (5049' 00" N 008 46' 00" E, Hesse). We selected seven field pairs of one organic and one conventional winter wheat field (Triticum aestivum L.) in the regions Soester Boerde and Lahn-Dill Bergland and six field pairs in the region Leine Bergland. The matched fields were in close proximity to ensure similar abiotic conditions. Organic fields were managed according to European Union Regulation 2092/91/EEC, which prohibits the use of synthetic fertilisers and pesticides. The average time since conversion to organic farming was 11.6 years \pm 5.9 years, varied between 2 years and 24 years and was not related to species richness and percentage cover of insect and non-insect pollinated species (all P-values $>0.1, \mathrm{~N}=40$ ).

At the end of May 2003, herbaceous plant species were recorded and the percentage cover of each species was estimated visually along two $95 \mathrm{~m}$ transects in each field. Each transect consisted of ten plots ( $5 \mathrm{~m} \times 1 \mathrm{~m}$ ) at intervals of $5 \mathrm{~m}$. One transect followed the field edge adjacent to a field margin and one transect was at least $30 \mathrm{~m}$ away from the edge transect, running parallel to it in the field centre. Species richness is the total number of plant species within a transect. The percentage cover is the average cover within a transect. The classification of herbaceous species into pollination types (i.e. self and wind pollination $=$ non-insect vs. insect pollination) was done by selecting the most frequent pollen vector according to the BIOLFLOR-data base (Durka 2002, Klotz et al. 2002).

\section{Statistics}

The response variables were (i) arable weed species number and (ii) percentage cover of insect and non-insect pollinated species per site and (iii) the relative species number and (iv) the relative percentage cover of insect pollinated species per site (i.e. proportion of insect pollinated species to all species found in the site, i.e. transect).

The variability of the response variables were analysed using mixed effect models (Pinheiro and Bates 2000), which account for non-independent errors that may occur due to the hierarchically nested sampling design. We tested the effect of farming system (organic/conventional), position in the field (edge/centre), and region (Soester Boerde/Leine Bergland/Lahn-Dill Bergland) and first-order interactions on the response variables. Additionally, we included the following error structure: "field pairs"/“farming system"/"position in the field" in the models to account for the variance that may be explained by the study design. Poisson errors and log link function were specified for models analysing species numbers and normal errors for the percentage cover. Binomial and quasibinomial errors and logit link function were specified for the model analysing the relative species numbers and percentage cover of insect pollinated plants, respectively. Additionally the species number and percentage cover of all species were used in binomial 
and quasibinomial models as weights to prevent that the proportions that were estimated from small samples (e.g. small species number) from having undue influence (Crawley 2002). Models were simplified by removing first non-significant interactions $(P>0.05)$ and then non-significant factors. Non-significant factors which figured in significant interactions were not removed (Crawley 2002). The appropriateness of statistical models was checked by plotting standardized residuals against fitted values. Mantel tests (Legendre and Legendre 1998) were performed to test for spatial autocorrelation by relating residuals from statistical models with xy-coordinates of study fields. No spatial autocorellation was found (all P-values $>0.1$ and $\mathrm{R}<0.05$ ). Percentage cover values were logarithmic transformed. Statistical analysis was carried out using R (R Development Core Team, 2004).

\section{Results}

\section{Occurrence of insect vs. non-insect pollinated plant species}

A total of 87 herbaceous species was identified, of which 85 species occurred in organic fields and 56 species in conventional fields (Appendix). The species pool of the investigated wheat fields was composed of 36 insect pollinated species (34 in organic, 21 in conventional) and 51 non-insect pollinated species (51 in organic, 35 in conventional). Non-insect pollinated plant species were composed of 42 self pollinated species and 9 wind pollinated species. The average number and percentage cover of herbaceous species per field was mainly determined by non-insect pollinated species (especially by self pollinated species, Table 6.1). Species number and percentage cover of arable weeds were highly correlated for insect pollinated species $(\mathrm{P}<0.001, \mathrm{R}=0.77, \mathrm{~N}=40)$ and non-insect pollinated species $(\mathrm{P}<0.001, \mathrm{R}=0.76, \mathrm{~N}=40)$.

Table 6.1. The average \pm SD, minimum and maximum of the species number and percentage cover of insect and non-insect pollinated (i.e. self and wind pollinated species) species observed in 20 organic and 20 conventional wheat fields $(\mathrm{N}=40)$.

\begin{tabular}{crcc}
\hline & $\overline{\mathbf{x}} \pm \mathbf{S}_{\mathbf{D}}$ & Min & Max \\
\hline Species number & & & \\
Insect pollinated & $8.2 \pm 4.5$ & 2 & 18 \\
Non-insect pollinated & $15.4 \pm 6.0$ & 5 & 25 \\
Self pollinated & $13.2 \pm 5.2$ & 5 & 22 \\
Wind pollinated & $2.2 \pm 1.4$ & 0 & 6 \\
Percentage cover & & & \\
Insect pollinated & $2.7 \pm 4.5$ & 0.01 & 27 \\
Non-insect pollinated & $5.6 \pm 7.2$ & 0.03 & 36 \\
Self pollinated & $5.1 \pm 6.5$ & 0.02 & 33 \\
Wind pollinated & $0.6 \pm 0.9$ & 0.00 & 4 \\
\hline
\end{tabular}




\section{Effects of farming system and position in the field}

Results of the statistical analyses are summarized in Table 6.2. Numbers of insect pollinated and non-insect pollinated species were much higher in organic than in conventional fields and higher in the field edge than in the field centre (Fig. 6.1a). The percentage cover of plants of both pollination types was also higher in organic than conventional fields and the percentage cover of insect pollinated plant species was higher in the edges than in the centres (Fig. 6.1b). The number and percentage cover of insect pollinated species varied between regions, being similar in the regions Soester Boerde and Leine Bergland and higher in Lahn-Dill Bergland. However, the effects of farming system and position in the field were consistent across the regions as indicated by the lack of significant interactions (Table 6.2).

The analysis of the proportions of both pollination types relative to all plant species revealed different responses to the farming system and position in the field. The relative number of insect pollinated species was higher in organic than in conventional fields and higher in the field edge than in the centre (Fig. 6.1c, Table 6.2), whereas the relative number of non-insect pollinated species was higher in conventional fields and in the field centre. The relative percentage cover of insect pollinated species did not differ between farming systems and the position in the field, but an interaction between farming system and position in the field indicated large differences between edges and centres in conventional fields (Fig. 6.1c). The relative species number and percentage cover of insect pollinated species varied between regions (Table 6.2), increasing from Soester Boerde to Leine Bergland to Lahn-Dill Bergland.

Table 6.2. F-value and the level of significance of the minimal adequate mixed effect models testing the effects of farming system (organic vs. conventional), position in the field (edge vs. centre), region (Soester Boerde/Leine Bergland/Lahn-Dill Bergland) on the species number and percentage cover of insect and non-insect pollinated species and the proportion of insect pollinated species on all species per site $(\mathrm{N}=80)$. Non significant first-order interactions are not shown.

\begin{tabular}{lcc}
\hline & Species number & Percentage cover \\
\hline Insect pollinated species & & \\
Organic vs. conventional & $108.7^{* * *}$ & $50.3^{* * *}$ \\
Edge vs. centre & $41.4^{* * *}$ & $9.5^{* *}$ \\
Region & $6.0^{*}$ & $4.6^{*}$ \\
Non-insect pollinated species & & \\
Organic vs. conventional & $89.7^{* * *}$ & $43.4^{* * *}$ \\
Edge vs. centre & $13.6^{* * *}$ & n.s. \\
Region & $n .5$. & $n . s$. \\
Proportion of insect pollinated species & & \\
Organic vs. conventional & $9.9^{* *}$ & 0.1 \\
Edge vs. centre & $14.2^{* * *}$ & 0.2 \\
Region & $4.7^{*}$ & $5.5^{*}$ \\
Organic/conventional x edge/centre & $n . s$. & $10.7^{* *}$ \\
\hline
\end{tabular}

Notes: Level of significance $* \mathrm{P}<0.05$; ** $\mathrm{P}<0.01$; *** $\mathrm{P}<0.001$. 

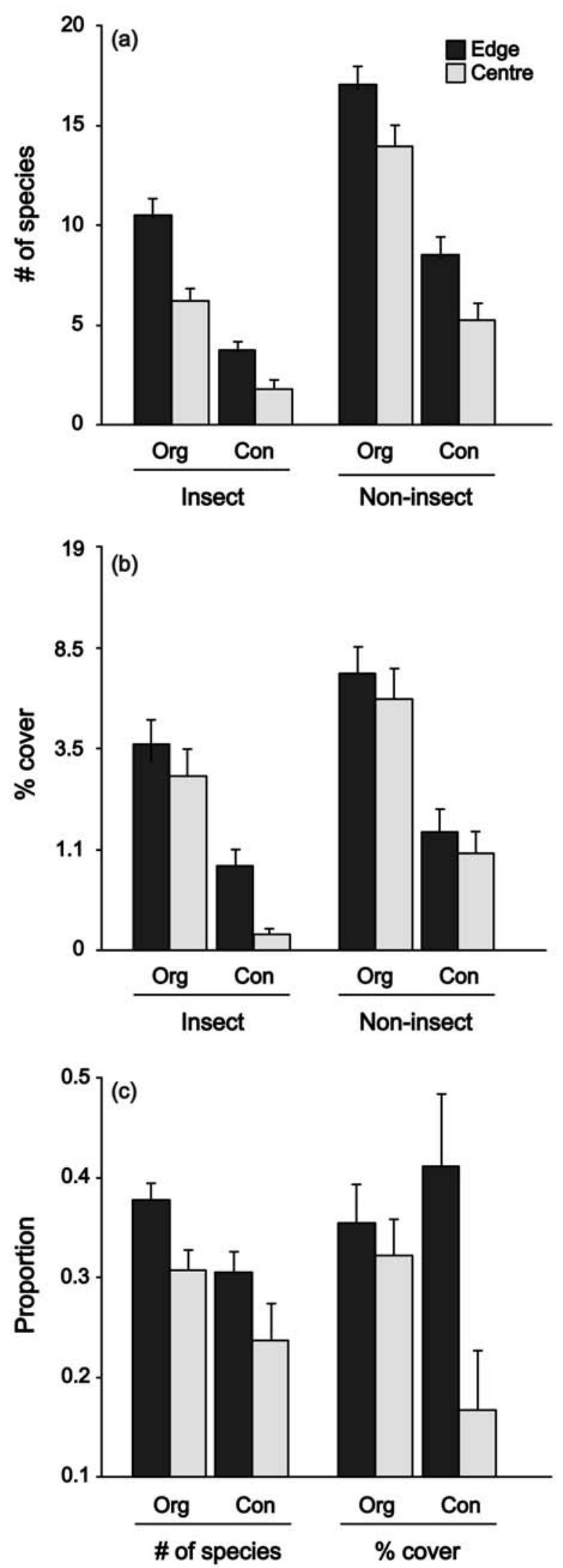

Fig. 6.1. The average (a) species number and (b) percentage cover \pm SE of insect pollinated and non-insect pollinated arable weeds per site and (c) the average proportion \pm SE in species number and percentage cover of insect pollinated species on all species found per site in the edges and centres of 20 organic and 20 conventional fields. Org = organic fields; Con = conventional fields. 


\section{Discussion}

Our results showed that organic agriculture increased species richness of arable weed species irrespective of the pollination type. However, the relative number of insect pollinated species was higher in organic fields and at the field edge, whereas the relative number of non-insect pollinated species was higher in conventional fields and in the field centre. Therefore, insect pollinated arable weed species appeared to have benefited disproportionately from organic farming.

In our study, organic fields had a larger species pool than conventional fields (85 vs. 56 species). In both systems non-insect pollinated plants predominated with about $60-62.5 \%$ of the species (50\% self pollinated, $10 \%-12.5 \%$ wind pollinated species) followed by $37.5 \%$ - 40\% insect pollinated plant species.

At the field scale, organic fields and field edges had a higher species richness of all pollination types than conventional fields and field centres. This corresponds to a general positive effect of organic farming and field edges on floristic diversity irrespective of the type of pollination (Marshall, 1989, Moreby et al. 1994, Wilson and Aebischer 1995, Hald 1999a,b, Menalled et al. 2001, Hyvönen et al. 2003b, Roschewitz et al. 2005a). However, comparing the proportions of both pollination types to all plant species per site revealed that insect pollinated species benefited more from organic farming and field edges than non-insect pollinated species, which might be attributed to two possible causes. First, organic fields that harbour a high diversity and abundance of flowering plants have a greater floral attractiveness and resource availability and therefore may attract more pollinators such as bees compared to conventional fields (Holzschuh et al. 2005, Morandin and Winston 2005) and the attracted pollinators are not harmed directly or indirectly by pesticides (Free 1993, Kearns 1998, Thompson 2001 and 2003). Holzschuh (personal communication) found that bee density in organic wheat fields was seven times higher than that in conventional fields. Along the field edges, pollinators are more frequent, since field margins and other semi-natural habitats are important habitats for pollinators in agricultural landscapes (Osborne et al. 1991, Banaszak 1992, Lagerlöf et al. 1992, SteffanDewenter and Tscharntke 2001, Bäckman and Tiainen 2002). Therefore, organic fields and edge zones of arable fields may be favourable for insect pollinated plants by increasing plant fitness i.e. increasing seed set due to high pollinator densities (Kwak and Jennersten 1991, Free 1993, Burd 1994, Steffan-Dewenter and Tscharntke 1999). In contrast, a limitation of pollination may occur in the centres of conventional fields, where on average only 1.9 insect pollinated arable weed species were found and non-insect pollinated species dominated the local species pool making up about $76 \%$ of all species.

A second explanation for the higher number of insect pollinated plant species in organic fields and field edges might be related to a "diversity-dependent” mass effect similarly to Whitehead (1968) and Regal (1982). Our data strongly support the hypothesis that with increasing local species richness the proportion of insect pollinated plants increases (Fig. 6.2), whereas the proportion of non-insect pollinated plants decreases. Since the species 
richness in organic fields is much higher than that of conventional fields, the proportion of insect pollinated species might be increased by chance. Additionally, plant species in field edges such as Achillea millefolium L., Anthriscus sylvestris (L.) Hoffm. and Potentilla anserina L. may have immigrated from neighbouring habitats into the field. Perennial habitats such as grasslands and field margins may act as source due to the higher proportions of insect pollinated plants over self or wind pollinated plants in semi-natural habitats (Hess 1983, Durka 2002).

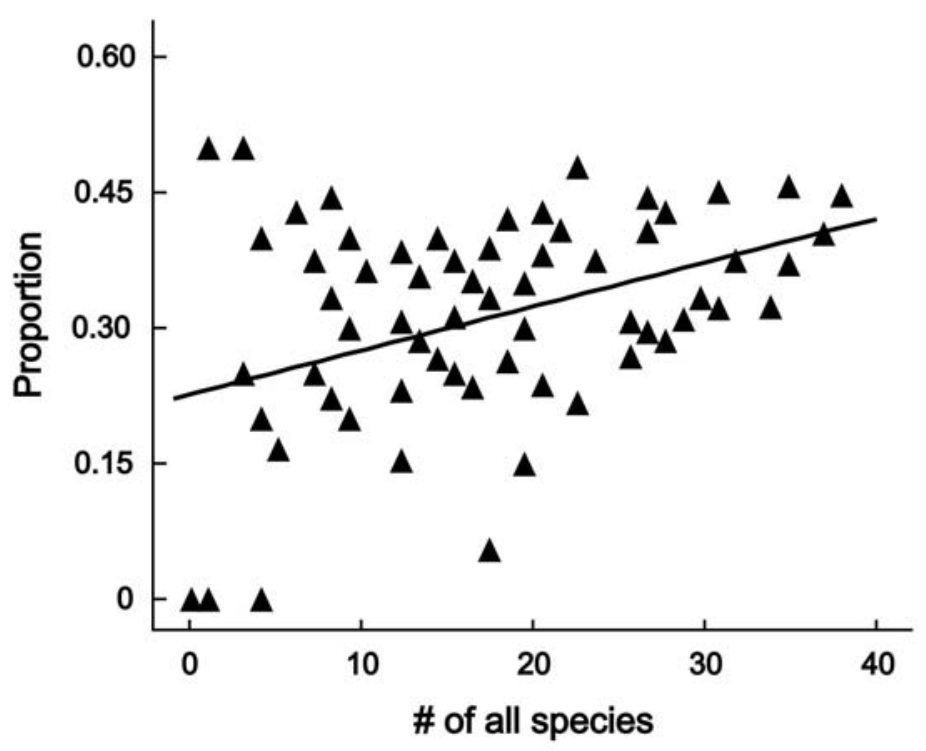

Fig. 6.2. The relationship between the proportion of insect pollinated species per site in dependence to the number of all species per site $(P=0.002, \mathrm{~N}=80)$; statistics: GLM was performed with binomial error, logit link function, and weighting by the number of all species (Crawley 2002).

Diversity and community structure of arable weeds is affected by many other important factors such as local site characteristics, farming intensity, and landscape context (Pyšek and Lepš 1991, Dale et al. 1992, McCloskey et al. 1996, Andersson and Milberg 1998, Hyvönen and Salonen 2002, Gabriel et al. 2005, Roschewitz et al. 2005a). But the absence of pollination often limits seed production (Burd 1994), and therefore it may also be important for plant community structure in highly disturbed habitats such as arable fields. Close plant-pollinator-relationships have been reported between annual plants and pollinating insects in arable fields (Haughton et al. 2003, Hawes et al. 2003) and other disturbed habitats (Steffan-Dewenter and Tscharntke 2001, Potts et al. 2003) but mostly from the pollinators perspective i.e. how pollinator communities depend on floral communities. In this study, we observed patterns that suggest feedbacks between plant and pollinator diversity. It is consistent with the hypothesis that insect pollinated plants profit from organic farming through a higher diversity and density of pollinators or rather that in conventional fields insect pollinated plants are disadvantaged due to the lack of pollinators. 
Hence, the disruption of plant-pollinator interactions due to the current agricultural intensification may cause important shifts in plant community structure.

In conclusion, our study supports the idea that organic farming enhances the abundance and species richness of arable weeds, in particular of insect pollinated plant species, which underscores the specific value of organic farming as base of plant-pollinator interactions. However, field experiments on seed set of arable weeds in relation to farming system and/or floral resource availability are needed to give further insights into the underlying processes.

\section{Acknowledgements}

We thank Yann Clough, Andrea Holzschuh, and Tobias Purtauf for study site selection, and Indra Roschewitz for assistance in the field. Many thanks to Tatyana Rand, Terho Hyvönen, Ingolf Kühn, Jens Dauber and Carsten Thies for helpful comments on this manuscript. DG was supported by the Niedersaechsische Graduiertenfoerderung. The study was part of the EU-project QLK5-CT-2002-01495 "EASY” (Evaluating current European agri-environment schemes to quantify and improve nature conservation efforts in agricultural landscapes). 
Appendix Overview of arable weed species, their pollination type ( $\mathrm{I}=$ insect pollinated, $\mathrm{N}=$ noninsect pollinated) and frequency of occurrence in the edges and centres of 20 organic and 20 conventional fields.

\begin{tabular}{|c|c|c|c|c|c|}
\hline \multirow[t]{2}{*}{ Species } & \multirow{2}{*}{$\begin{array}{c}\text { Pollination } \\
\text { type }\end{array}$} & \multicolumn{2}{|c|}{ Organic } & \multicolumn{2}{|c|}{ Conventional } \\
\hline & & Edge & Centre & Edge & Centre \\
\hline Achillea millefolium L. & I & 2 & 0 & 0 & 0 \\
\hline Aegopodium podagraria L. & I & 1 & 0 & 0 & 0 \\
\hline Aethusa cynapium L. & $\mathrm{N}$ & 5 & 3 & 2 & 1 \\
\hline Amaranthus graecizans L. & $\mathrm{N}$ & 1 & 3 & 1 & 0 \\
\hline Anagallis arvensis $\mathrm{L}$. & I & 5 & 4 & 1 & 0 \\
\hline Anchusa officinalis L. & I & 1 & 3 & 0 & 0 \\
\hline Anthemis arvensis L. & I & 3 & 4 & 0 & 0 \\
\hline Anthriscus sylvestris (L.) Hoffm. & I & 4 & 1 & 4 & 0 \\
\hline Aphanes arvensis L. & $\mathrm{N}$ & 10 & 7 & 7 & 2 \\
\hline Arabidopsis thaliana (L.) Heynh. & $\mathrm{N}$ & 8 & 2 & 2 & 0 \\
\hline Arenaria serpyllifolia L. s. l. & $\mathrm{N}$ & 1 & 1 & 0 & 0 \\
\hline Atriplex patula L. & $\mathrm{N}$ & 9 & 8 & 4 & 3 \\
\hline Capsella bursa-pastoris (L.) Med. & $\mathrm{N}$ & 16 & 17 & 3 & 2 \\
\hline Centaurea cyanus L. & I & 2 & 0 & 0 & 0 \\
\hline Cerastium glomeratum Thuill. & $\mathrm{N}$ & 2 & 1 & 0 & 0 \\
\hline Cerastium holosteoides Fr. & I & 3 & 0 & 0 & 0 \\
\hline Chenopodium album L. & $\mathrm{N}$ & 11 & 9 & 5 & 4 \\
\hline Cirsium arvense (L.) Scop. & I & 19 & 17 & 16 & 6 \\
\hline Convolvulus arvensis L. & I & 11 & 3 & 7 & 0 \\
\hline Epilobium tetragonum L. s. str. & $\mathrm{N}$ & 2 & 4 & 1 & 1 \\
\hline Erophila verna (L.) Chevall. s. l. & $\mathrm{N}$ & 1 & 2 & 0 & 0 \\
\hline Euphorbia exigua L. & I & 2 & 2 & 0 & 0 \\
\hline Euphorbia helioscopia L. & I & 5 & 3 & 0 & 1 \\
\hline Euphorbia platyphyllos L. & I & 5 & 1 & 1 & 0 \\
\hline Fallopia convolvulus (L.) Å. Löve & $\mathrm{N}$ & 17 & 16 & 10 & 7 \\
\hline Filago arvensis L. & $\mathrm{N}$ & 1 & 2 & 1 & 0 \\
\hline Fumaria officinalis L. s. l. & $\mathrm{N}$ & 8 & 10 & 3 & 6 \\
\hline Galeopsis angustifolia Ehrh. ex Hoffm. & $\mathrm{N}$ & 1 & 0 & 0 & 0 \\
\hline Galeopsis ladanum L. & I & 1 & 1 & 0 & 0 \\
\hline Galeopsis pubescens Besser & I & 1 & 1 & 0 & 0 \\
\hline Galeopsis segetum Neck. & I & 1 & 0 & 0 & 0 \\
\hline Galeopsis tetrahit L. & $\mathrm{N}$ & 9 & 7 & 5 & 0 \\
\hline Galinsoga parviflora Cav. & $\mathrm{N}$ & 1 & 2 & 0 & 1 \\
\hline Galium aparine L. & $\mathrm{N}$ & 18 & 15 & 18 & 12 \\
\hline Geranium dissectum L. & $\mathrm{N}$ & 5 & 0 & 6 & 1 \\
\hline Geranium pusillum Burm. f. & $\mathrm{N}$ & 1 & 0 & 2 & 1 \\
\hline Heracleum sphondylium L. & I & 3 & 0 & 3 & 0 \\
\hline Hypericum perforatum L. & I & 0 & 0 & 1 & 0 \\
\hline Lamium amplexicaule L. & $\mathrm{N}$ & 4 & 6 & 0 & 1 \\
\hline Lamium purpureum L. s. l. p. p. & I & 15 & 16 & 10 & 4 \\
\hline Lapsana communis L. & $\mathrm{N}$ & 4 & 3 & 0 & 0 \\
\hline Lathyrus sp. & & 4 & 1 & 1 & 0 \\
\hline Matricaria recutita $\mathrm{L}$. & I & 15 & 10 & 6 & 8 \\
\hline Matricaria discoidea DC. & $\mathrm{N}$ & 12 & 8 & 6 & 3 \\
\hline Medicago falcata L. s. str. & I & 1 & 1 & 0 & 1 \\
\hline Microrrhinum minus (L.) Fourr. & $\mathrm{N}$ & 1 & 1 & 0 & 0 \\
\hline Myosotis arvensis (L.) Hill & $\mathrm{N}$ & 16 & 14 & 8 & 4 \\
\hline Myosurus minimus L. & $\mathrm{N}$ & 0 & 2 & 0 & 0 \\
\hline
\end{tabular}




\begin{tabular}{|c|c|c|c|c|c|}
\hline \multirow[t]{2}{*}{ Species } & \multirow{2}{*}{$\begin{array}{c}\text { Pollination } \\
\text { type }\end{array}$} & \multicolumn{2}{|c|}{ Organic } & \multicolumn{2}{|c|}{ Conventional } \\
\hline & & Edge & Centre & Edge & Centre \\
\hline Papaver dubium L. s. str. & I & 1 & 1 & 0 & 0 \\
\hline Papaver rhoeas L. & I & 10 & 6 & 7 & 0 \\
\hline Plantago major L. s. str. & $\mathrm{N}$ & 5 & 0 & 1 & 0 \\
\hline Plantago lanceolata L. & $\mathrm{N}$ & 1 & 0 & 0 & 0 \\
\hline Polygonum aviculare L. (s. l.) & $\mathrm{N}$ & 20 & 17 & 11 & 8 \\
\hline Persicaria hydropiper (L.) Delarbre & $\mathrm{N}$ & 2 & 1 & 0 & 0 \\
\hline Persicaria lapathifolia (L.) Delarbre s. str. & $\mathrm{N}$ & 8 & 11 & 8 & 3 \\
\hline Persicaria maculosa Gray & $\mathrm{N}$ & 1 & 0 & 0 & 0 \\
\hline Potentilla anserina L. & I & 3 & 0 & 1 & 0 \\
\hline Ranunculus ficaria L. & I & 0 & 0 & 1 & 0 \\
\hline Ranunculus repens L. & I & 15 & 2 & 2 & 0 \\
\hline Raphanus raphanistrum L. & I & 5 & 4 & 0 & 0 \\
\hline Rumex acetosa L. & $\mathrm{N}$ & 1 & 0 & 0 & 0 \\
\hline Rumex crispus L. & $\mathrm{N}$ & 14 & 11 & 6 & 3 \\
\hline Rumex obtusifolius L. & $\mathrm{N}$ & 4 & 2 & 2 & 0 \\
\hline Scleranthus annuus L. s. str. & $\mathrm{N}$ & 0 & 2 & 0 & 0 \\
\hline Sinapis arvensis L. & I & 13 & 12 & 4 & 2 \\
\hline Sisymbrium officinale (L.) Scop. & $\mathrm{N}$ & 2 & 0 & 1 & 0 \\
\hline Sonchus arvensis L. & I & 13 & 7 & 1 & 2 \\
\hline Sonchus asper (L.) Hill & $\mathrm{N}$ & 4 & 2 & 0 & 0 \\
\hline Spergula arvensis L. & $\mathrm{N}$ & 1 & 0 & 0 & 0 \\
\hline Stellaria graminea L. & I & 2 & 0 & 0 & 0 \\
\hline Stellaria media (L.) Vill. s. str. & $\mathrm{N}$ & 20 & 17 & 3 & 8 \\
\hline Taraxacum officinale Weber & I & 9 & 3 & 3 & 1 \\
\hline Thlaspi arvense L. & $\mathrm{N}$ & 18 & 14 & 10 & 8 \\
\hline Trifolium hybridum L. & I & 2 & 1 & 0 & 1 \\
\hline Trifolium incarnatum L. & I & 2 & 1 & 0 & 0 \\
\hline Trifolium pratense L. & I & 9 & 4 & 0 & 0 \\
\hline Trifolium repens L. & I & 16 & 11 & 4 & 5 \\
\hline Urtica urens L. & $\mathrm{N}$ & 6 & 1 & 4 & 0 \\
\hline Veronica arvensis L. & $\mathrm{N}$ & 9 & 8 & 3 & 2 \\
\hline Veronica hederifolia L. s. l. & $\mathrm{N}$ & 10 & 8 & 9 & 9 \\
\hline Veronica persica Poir. & $\mathrm{N}$ & 17 & 9 & 7 & 2 \\
\hline Veronica polita Fr. & $\mathrm{N}$ & 4 & 2 & 1 & 0 \\
\hline Vicia hirsuta (L.) Gray & $\mathrm{N}$ & 1 & 2 & 0 & 0 \\
\hline Vicia sativa L. s. str. & $\mathrm{N}$ & 1 & 1 & 0 & 0 \\
\hline Vicia tetrasperma (L.) Schreb. & $\mathrm{N}$ & 13 & 13 & 10 & 3 \\
\hline Vicia villosa Roth s. str. & I & 9 & 4 & 1 & 0 \\
\hline Viola arvensis Murray & $\mathrm{N}$ & 10 & 11 & 10 & 9 \\
\hline Viola tricolor L. & I & 6 & 5 & 3 & 6 \\
\hline
\end{tabular}




\section{References}

Albrecht, H. (1995) Changes in the arable weed flora of Germany during the last five decades. In: 9th EWRS (European Weed Research Society) Symposium "Challenges for Weed Science in Changing Europe", Budapest, 41-48.

Albrecht, H. \& Pilgram, M. (1997) The weed seed bank of soils in a landscape segment in Southern Bavaria. II. Relation to environmental variables and to surface vegetation. Plant Ecology, 131, 31-43.

Allan, J.D. (1975) Components of Diversity. Oecologia, 18, 359-367.

Allen-Wardell, G., Bernhardt, P., Bitner, R., Burquez, A., Buchmann, S., Cane, J., Cox, P.A., Dalton, V., Feinsinger, P., Ingram, M., Inouye, D., Jones, C.E., Kennedy, K., Kevan, P., Koopowitz, H., Medellin, R., Medellin-Morales, S., Nabhan, G.P., Pavlik, B., Tepedino, V., Torchio, P. \& Walker, S. (1998) The potential consequences of pollinator declines on the conservation of biodiversity and stability of food crop yields. Conservation Biology, 12, 8-17.

Andersson, T.N. \& Milberg, P. (1998) Weed flora and the relative importance of site, crop, crop rotation, and nitrogen. Weed Science, 46, 30-38.

Andreasen, C., Stryhn, H. \& Streibig, J.C. (1996) Decline of the flora in Danish arable fields. Journal of Applied Ecology, 33, 619-626.

Auerbach, M. \& Shmida, A. (1987) Spatial scale and the determinants of plant species richness. Trends in Ecology and Evolution, 2, 238-242.

Bäckman, J.P.C. \& Tiainen, J. (2002) Habitat quality of field margins in a Finnish farmland area for bumblebees (Hymenoptera: Bombus and Psithyrus). Agriculture, Ecosystems and Environment, 89, 53-68.

Baker, H.G. (1974) The evolution of weeds. Annual Review of Ecology and Systematics, 5, $1-24$.

Banaszak, J. (1992) Strategy for conservation of wild bees in an agricultural landscape. Agriculture, Ecosystems and Environment, 40, 179-192.

Barberi, P., Silvestri, N., \& Bonari, E. (1997) Weed communities of winter wheat as influenced by input level and rotation. Weed Research, 37, 301-313.

Baskin, J.M. \& Baskin, C.C. (1985) The annual dormancy cycle in buried weed seeds: a continuum. BioScience, 35, 492-498.

Baskin, C.C \& Baskin, J.M (2000) Seeds: Ecology, Biogeography, and Evolution of Dormancy and Germination. Academic Press, London.

Bazzas, F.A. (1996) Plants in changing environments: linking physiological, population, and community ecology. Cambridge University Press, Cambridge.

Bengtsson, J., Ahnström, J. \& Weibull, A.C. (2005) The effects of organic agriculture on biodiversity and abundance: a meta-analysis. Journal of Applied Ecology, 42, 261269.

Benton, T.G., Vickery, J.A. \& Wilson, J.D. (2003) Farmland biodiversity: Is habitat heterogeneity the key? Trends in Ecology and Evolution, 4, 182-188. 
Bischoff, A. (2005) Analysis of weed dispersal to predict changes of re-colonisation. Agriculture, Ecosystems and Environment, 106, 377-387.

Bischoff, A. \& Mahn, E.-G. (2000) The effects of nitrogen and diaspore availability on the regeneration of weed communities following extensification. Agriculture, Ecosystems and Environment, 77, 237-246.

Booth, B.D. \& Swanton, C.J. (2002) Assembly theory applied to weed communities. Weed Science, 50, 2-13.

Borcard, D., Legendre, P. \& Drapeau, P. (1992) Partialling out the spatial component of ecological variation. Ecology, 73, 1045-1055.

Brown, J.H. (1984) On the relationship between abundance and distribution of species. The American Naturalist, 124, 255-279.

Buchmann, S.L. \& G.P. Nabhan (1996) The Forgotten Pollinators. Island Press, Washington, DC.

Buhler, D.D. (1995) Influence of tillage systems on weed population dynamics and management in corn and soybean in the central USA. Crop Science, 35, 1247-1258.

Bullock, J.M., Moy, I.L., Pywell, R.F., Coulson, S.J., Nolan, A.M. \& Caswell, H. (2002) Plant dispersal and colonization processes at local and landscape scales. In: Dispersal ecology (eds J.M. Bullock, R.E. Kenward and R.S. Hails) pp. 279-302, Blackwell Science, Oxford.

Burd, M. (1994) Bateman's principle and plant reproduction: the role of pollen limitation in fruit and seed set. Botanical Review, 60, 83-139.

Burnett, M., August, P.V., Brown, J.H. \& Killingbeck, K.T. (1998) The influence of geomorphological heterogeneity on biodiversity. I. A patch-scale perspective. Conservation Biology, 12, 363-370.

Caley, M.J. \& Schluter, D. (1997) The relationship between local and regional diversity. Ecology, 78, 70-80.

Clarke K.R. (1993) Nonparametric multivariate analyses of changes in community structure. Australian Journal of Ecology, 18, 117-143.

Collins, S.L., Glenn, G.S. \& Briggs, J.M. (2002) Effect of local and regional processes on plant species richness in tallgrass prairie. Oikos, 99, 571-579.

Colwell, R. K. (1997) EstimateS: Statistical estimation of species richness and shared species from samples. Version 5. URL http://viceroy.eeb.uconn.edu/EstimateS.

Corbet, S.A., Williams, I.H. \& Osborne, J. (1991) Bees and the pollination of crops and wild flowers in the European Community. Bee World, 72, 47-59.

Cousens, R. \& Mortimer, M. (1995) Dynamics of Weed Populations. Cambridge University Press, Cambridge.

Crawley, M.J. (2002) Statistical Computing. An Introduction to Data Analysis using SPlus. John Wiley and Sons Ltd., Chichester, UK.

Crist, T.O., Veech, J.A., Gering, J.C. \& Summerville, K.S. (2003) Partitioning species diversity across landscapes and regions: a hierarchical analysis of $\alpha, \beta$, and $\gamma$ diversity. The American Naturalist, 162, 734-743. 
Daily, G., Alexander, S., Ehrlich P. R., Goulder, L., Lubchenco, J., Matson, P. A., Mooney, H. A., Postel, S., Schneider, S. H., Tilman, D. \& Woodwell, G. M. (1997) Ecosystem services: benefits supplied to human societies by natural ecosystems. Issues in Ecology, 2, 2-16.

Dale, M.R.T., Thomas, A.G. \& John, E.A. (1992) Environmental factors including management practices as correlates of weed community composition in spring seeded crops. Canadian Journal of Botany, 70, 1931-1939.

De Blois, S., Domon, G. \& Bouchard, A. (2002) Landscape issues in plant ecology. Ecography, 25, 244-256.

Dunning, J.B., Danielson, B.J. \& Pulliam, H.R. (1992) Ecological processes that affect populations in complex landscapes. Oikos, 65, 169-175.

Durka, W. (2002) Floral and reproductive biology. In: Klotz S, Kühn I, Durka W (eds) BIOLFLOR- Eine Datenbank mit biologisch-ökologischen Merkmalen zur Flora von Deutschland, Schriftenreihe für Vegetationskunde 38, 133-175. Bundesamt für Naturschutz, Bonn.

Eggers, T. (1987) Environmental impact of chemical weed control in arable fields in the Federal Republic of Germany. Proceedings 1987 Brighton Crop Protection Conference - Weeds, 267-275.

Ellenberg, H. (1988) Vegetation Ecology of Central Europe, 4th edn. Cambridge University Press.

Ervio, R., Hyvarinen S., Ervio, L.R. \& Salonen, J. (1994) Soil properties affecting weed distribution in spring cereal and vegetable fields. Agricultural Science in Finland, 3, 497-504.

Firbank, L.G. (1988) Biological flora of the British Isles: Agrostemma githago L. Journal of Ecology, 76, 1232-1246.

Firbank, L.G. (1993) Short-term variability of plant-populations within a regularly disturbed habitat. Oecologia, 94, 351-355.

Fleishman, E., Betrus, C.J. \& Blair, R.B. (2003) Effects of spatial scale and taxonomic group on partitioning of butterfly and bird diversity in the Great Basin, USA. Landscape Ecology, 18, 675-685.

Foley, J.A., Defries, R., Asner, G.P., Barford, C., Bonan, G., Carpenter, S.R., Chapin, F.S., Coe, M.T., Daily, G.C., Gibbs, H.K., Helkowski, J.H., Holloway, T., Howard, E.A., Kucharik, C.J., Monfreda, C., Patz, J.A., Prentice, I.C., Ramankutty, N. \& Snyder, P.K. (2005) Global consequences of land use. Science, 309, 570-574.

Food and Agriculture Organization of the United Nations (FAO) (2001) FAO Statistical Databases. http://apps.fao.org/.

Forman, R.T.T. (1995) Land mosaics: The ecology of landscapes and regions. Cambridge University Press, Cambridge.

Fournier, E. \& Loreau, M. (2001) Respective roles of recent hedges and forest patch remnants in the maintenance of ground-beetle (Coleoptera: Carabidae) diversity in an agricultural landscape. Landscape Ecology, 16, 17-32.

Free, J.B. 1993. Insect pollination of crops. 2nd edn. London, Academic Press. 
Gabriel, D., Thies, C. \& Tscharntke, T. (2005) Local diversity of arable weeds increases with landscape complexity. Perspectives in Plant Ecology, Evolution and Systematics, 7, 85-93.

Garve, E. (1993) Rote Liste der gefährdeten Farn- und Blütenpflanzen in Niedersachsen und Bremen. Informationsdienst Naturschutz Niedersachsen, 1/93, 47.

Garve, E. \& Letschert, D. (1991) Liste der wildwachsenden Farn- und Blütenpflanzen Niedersachsens. 1. Fassung vom 31.12.1990. Naturschutz und Landschaftspflege in Niedersachsen, 24, 154.

Gaston, K.J. (1994) Rarity. Population and community biology series 13. Chapman \& Hall, New York.

Gering, J.C. \& Crist, T.O. (2002) The alpha-beta-regional relationship: providing new insights into local-regional patterns of species richness and scale dependence of diversity components. Ecology Letters, 5, 433-444.

Gering, J.C., Crist, T.O. \& Veech, J.A. (2003) Additive partitioning of species diversity across multiple scales: implications for regional conservation of biodiversity. Conservation Biology, 17, 488-499.

Gerowitt, B. (2003) Development and control of weeds in arable farming systems. Agriculture, Ecosystems and Environment, 98, 247-254.

Grime, J.P., 1979. Plant strategies and vegetation processes. Wiley, Chichester.

Guo, Q.F. \& Brown, J. H. (1996) Temporal fluctuations and experimental effects in desert plant communities. Oecologia, 107, 568-577.

Graham, M.H., (2003) Confronting multicollinearity in ecological multiple regression. Ecology, 84, 2809-2815.

Gustafson, E.J. (1998) Quantifying landscape spatial pattern: what is the state of art? Ecosystem, 1, 143-156.

Hald, A.B. (1999a) Weed vegetation (wild flora) of long established organic versus conventional cereal fields in Denmark. Annals of Applied Biology, 134, 307-314.

Hald, A.B. (1999b) The impact of changing the season in which cereals are sown on the diversity of the weed flora in rotational fields in Denmark. Journal of Applied Ecology, 36, 24-32.

Hallgren, E., Palmer, M. W. \& Milberg, P. (1999) Data diving with cross-validation: an investigation of broad-scale gradients in Swedish weed communities. Journal of Ecology, 87, 1037-1051.

Harper, J.L. (1977) Population biology of plants. London, New York. Academic Press.

Haughton, A.J., Bell, J.R., Boatman, N.D. \& Wilcox, A. (2001) The effects of the herbicide glyphosate on non-target spiders: Part II. Indirect effects on Lepthyphantes tenuis in field margins. Pest Management Science, 57, 1037-1042.

Haughton, A.J., Champion, G.T., Hawes, C., Heard, M.S., Brooks, D.R., Bohan, D.A., Clark, S.J., Dewar, A.M., Firbank, L.G., Osborne, J.L., Perry, J.N., Rothery, P., Roy, D.B., Scott, R.J., Woiwod, I.P., Birchall, C., Skellern, M.P., Walker, J.H., Baker, P., Browne, E.L., Dewar, A.J.G., Garner, B.H., Haylock, L.A., Horne, S.L., Mason, N.S., Sands, R.J.N. \& Walker, M.J. (2003) Invertebrate responses to the management of genetically modified herbicide-tolerant and conventional spring crops. II. Within-field 
epigeal and aerial arthropods. Philosophical Transactions of the Royal Society of London Series B - Biological Sciences, 358, 1863-1877.

Hawes, C., Haughton, A.J., Osborne, J.L., Roy, D.B., Clark, S.J., Perry, J.N., Rothery, P., Bohan, D.A., Brooks, D.R., Champion, G.T., Dewar, A.M., Heard, M.S., Woiwod, I.P., Daniels, R.E., Young, M.W., Parish, A.M., Scott, R.J., Firbank, L.G. \& Squire, G.R. (2003) Responses of plants and invertebrate trophic groups to contrasting herbicide regimes in the Farm Scale Evaluations of genetically modified herbicidetolerant crops. Philosophical Transactions of the Royal Society of London Series B Biological Sciences, 358, 1899-1913.

Heitzmann, A., Lys, J.A. \& Nentwig, W. (1992) Nützlingsförderung am Rand - oder: Vom Sinn des Unkrauts. Landwirtschaft Schweiz, 5, 25-36.

Hess, D. (1983) Die Blüte. Eine Einführung in Struktur und Funktion, Ökologie und Evolution der Blüte. Stuttgart, Ulmer.

Hofmeister, H. \& Garve, E. (1998) Lebensraum Acker. 2nd edn. Parey, Berlin.

Hole, D.G., Perkins, A.J., Wilson, J.D., Alexander, I.H., Grice, P.V. \& Evans, A.D. (2005) Does organic farming benefit biodiversity? Biological Conservation, 122, 113-130.

Holl, K.D. \& Crone, E.E. (2004) Applicability of landscape and island biogeography theory to restoration of riparian understorey plants. Journal of Applied Ecology, 41, 922-933.

Holzschuh, A., Steffan-Dewenter, I., Kleijn, D. \& Tscharntke, T. (2005) Effects of organic farming, landscape complexity and regional context on bee diversity in cereal fields. submitted.

Honnay, O., Piessens, K., Van Landuyt, W., Hermy, M. \& Gulink, H. (2003) Satellite based land use and landscape complexity indices as predictor for regional plant species diversity. Landscape and Urban Planning, 63, 241-250.

Horn, B.K.P. (1981) Hillshading and the reflectance map. Proceedings of the Institute of Electrical and Electronics Engineers IEEE, 69, 14-47.

Huston M.A. (1999) Local processes and regional patterns: appropriate scales for understanding variation in the diversity of plants and animals. Oikos, 86, 393-401.

Hutton, S.A. \& Giller, P.S. (2003) The effects of the intensification of agriculture on northern temperate dung beetle communities. Journal of Applied Ecology, 40, 9941007.

Hyvönen, T. \& Salonen, J. (2002) Weed species diversity and community composition in cropping practices at two intensity levels - a six-year experiment. Plant Ecology, 159, 73-81.

Hyvönen T., Ketoja E. \& Salonen J. (2003a) Changes in the abundance of weeds in spring cereal fields in Finland. Weed Research, 43, 348-356.

Hyvönen, T., Ketoja, E., Salonen, J., Jalli, H. \& Tianinen, J. (2003b) Weed species diversity and community composition in cropping of spring cereals. Agriculture, Ecosystems and Environment, 97, 131-149.

Hyvönen, T., Holopainen, J. \& Tiainen, J. (2005) Detecting the spatial component of variation in the weed community at the farm scale with variation partitioning by canonical correspondence analysis. Weed Research, 45, 48-56. 
Jedicke, E. (Ed.) (1997) Die Roten Listen. Gefährdete Pflanzen, Tiere, Pflanzengesellschaften und Biotope in Bund und Ländern. E. Ulmer, Stuttgart.

Kästner, A., Jäger, E. \& Schubert, R. (2001) Handbuch der Segetalpflanzen Mitteleuropas. Springer, Wien.

Kareiva, P. \& Wennergren, U. (1995) Connecting landscape patterns to ecosystem and population processes. Nature, 373, 299-302.

Kay, S. \& Gregory, S. (1998; 1999) Rare arable flora survey. The Soil Association (2000). The biodiversity benefits of organic farming. www.soilassociation.org.

Kearns, C.A., Inouye, D.W. \& Waser, N.M. (1998) Endangered mutualisms: the conservation of plant-pollinator interactions. Annual Review of Ecology and Systematics, 29, 83-112.

Kleijn, D. \& Vandervoort, L.A.C. (1997) Conservation headlands for rare arable weeds: the effects of fertilizer application and light penetration on plant growth. Biological Conservation, 81, 57-67.

Kleijn, D., Berendse, F., Smit, R. \& Gilissen, N. (2001) Agri-environment schemes do not effectively protect biodiversity in Dutch agricultural landscapes. Nature, 413, 723725.

Kleijn, D. \& Sutherland, W. J. (2003) How effective are European agri-environment schemes in conserving and promoting biodiversity? Journal of Applied Ecology, 40, 947-969.

Klotz, S., Kühn, I. \& Durka, W., (ed.) (2002) BIOLFLOR - Eine Datenbank zu biologischökologischen Merkmalen der Gefäßpflanzen in Deutschland. Schriftenreihe für Vegetationskunde, 38. Bundesamt für Naturschutz, Bonn.

Kneitel, J.M. \& Chase, J.M. (2004) Trade-offs in community ecology: linking spatial scales and species coexistence. Ecology Letters, 7, 69-80.

Korneck, D. \& Sukopp, H. (1988) Rote Liste der in der Bundesrepublik Deutschland ausgestorbenen, verschollenen und gefährdeten Farn- und Blütenpflanzen und ihre Auswertung für den Arten- und Biotopschutz. Schriftenreihe für Vegetationskunde, 19, Bonn-Bad Godesberg.

Korneck, D., Schnittler, M. \& Vollmer, I. (1996) Rote Liste der Farn- und Blütenpflanzen (Pteridophyta et Spermatophyta) Deutschlands. Schriftenreihe für Vegetationskunde, 28, 21-187.

Krauss, J., Steffan-Dewenter, I. \& Tscharntke, T. (2003) How does landscape context contribute to effects of habitat fragmentation on diversity and population density of butterflies? Journal of Biogeography, 30, 889-900.

Krauss, J., Klein, A.M., Steffan-Dewenter, I. \& Tscharntke, T. (2004) Effects of habitat area, isolation, and landscape diversity on plant species richness of calcareous grasslands. Biodiversity and Conservation, 13, 1427-1439.

Krebs, C.J. (1989) Ecological methodology. Harper Collins, New York.

Krebs, J.R., Wilson, J.D., Bradbury, R.B. \& Siriwardena, G.M. (1999) The second silent spring? Nature, 400, 611-612.

Kwak, M.M. \& Jennersten, O. (1991) Bumblebee visitation and seedset in Melampyrum pratense and Viscaria vulgaris: heterospecific pollen and pollen limitation. Oecologia, 86, 99-104. 
Lagerlöf, J., Stark, J. \& Svensson, B. (1992) Margins of agricultural fields as habitats for pollinating insects. Agriculture, Ecosystems and Environment, 40, 117-124.

Lande, R. (1996) Statistics and partitioning of species diversity, and similarity among multiple communities. Oikos, 76, 5-13.

Lawton, J.H. (1999) Are there general laws in ecology? Oikos, 84, 177-192.

Legendre, P. \& Legendre, L. (1998) Numerical Ecology. 2nd English Edition, Elsevier.

Legere, A., Stevenson, F.C. \& Benoit, D.L. (2005) Diversity and assembly of weed communities: contrasting responses across cropping systems. Weed Research, 45, 303-315.

Letourneau, D.K. \& Goldstein, B. (2001) Pest damage and arthropod community structure in organic vs. conventional tomato production in California. Journal of Applied Ecology, 38, 557-570.

Loreau, M. (2000) Are communities saturated? On the relationship between alpha, beta and gamma diversity. Ecology Letters, 3, 73-76.

Lososova, Z., Chytry, M., Cimalova, S., Kropac, Z., Otypkova, Z., Pysek, P., \& Tichy, L. (2004) Weed vegetation of arable land in Central Europe: gradients of diversity and species composition. Journal of Vegetation Science, 15, 415-422.

Mahn, E.G., (1992) Ackerwildkräuter - ihre Bedeutung im Agro-Ökosystem aus ökologischer Sicht. In: Zwerger P., Kemmer A., Hurle K.Z. (Eds.) Zeitschrift für Pflanzenkrankheiten und Pflanzenschutz, Verlag Eugen Ulmer, Sonderheft XIII 2130.

Marshall, E.J.P. (1989) Distribution patterns of plants associated with arable field edges. Journal of Applied Ecology, 26, 247-257.

Marshall, E.J.P. \& Arnold, G.M. (1995) Factors affecting field weed and field margin flora on a farm in Essex, UK. Landscape and Urban Planning, 31, 205-216.

Marshall, E.J.P. \& Brain, P. (1999) The horizontal movement of seeds in arable soil by different soil cultivation methods. Journal of Applied Ecology, 36, 443-454.

Marshall, E.J.P., Brown, V.K., Boatman, N.D., Lutman, P.J.W., Squire, G.R. \& Ward, L.K. (2003) The role of weeds in supporting biological diversity within crop fields. Weed Research, 43, 77-89.

Marshall, E.J.P. \& Hopkins, A. (1990) Plant species composition and dispersal in agricultural land. In: Species dispersal in agricultural habitats (eds R.G.H. Bunce and D.C. Howard), pp. 98-116, Belhaven Press, London.

McCloskey, M., Firbank, L.G., Watkinson, A.R. \& Webb, D.J. (1996) The dynamics of experimental arable weed communities under different management practices. Journal of Vegetation Science, 7, 799-808.

McLaughlin, A. \& Mineau, P. (1995) The impact of agricultural practices on biodiversity. Agriculture, Ecosystems and Environment, 55, 201-212.

Menalled, F.D., Marino, P.C., Gage, S.H. \& Landis, D.A. (1999) Does agricultural landscape structure affect parasitism and parasitoid diversity? Ecological Applications, 9, 634-641.

Menalled, F.D., Gross, K.L. \& Hammond, M. (2001) Weed aboveground and seedbank community responses to agricultural management systems. Ecological Applications, $11,1586-1601$. 
Micheli, F., Cottingham, K.L., Bascompte, J., Bjornstad, O.N., Eckert, G.L., Fischer, J.M., Keitt, T.H., Kendall, B.E., Klug, J.L. \& Rusak, J.A. (1999) The dual nature of community variability. Oikos, 85, 161-169.

Michener, C.D. (2000) The bees of the world. John Hopkins University Press, Baltimore, Maryland, USA.

Milberg, P., Hallgren, E. \& Palmer, M.W. (2000) Interannual variation in weed biomass on arable land in Sweden. Weed Research, 40, 311-321.

Milberg, P., Hallgren, E. \& Palmer, M.W. (2001) Timing of disturbance and vegetation development: how sowing date affects the weed flora in spring-sown crops. Journal of Vegetation Science, 12, 93-98.

Moran, M.D. (2003) Arguments for rejecting the sequential Bonferroni in ecological studies. Oikos, 100, 403-405.

Morandin, L.A. \& Winston, M.L. (2005) Wild bee abundance and seed production in conventional, organic, and genetically modified canola. Ecological Applications, 15, 871-881.

Moreby, S.J., Aebischer, N.J., Southway, S.E. \& Sotherton, N.W. (1994) A comparison of the flora and arthropod fauna of organically and conventionally grown winter-wheat in Southern England. Annals of Applied Biology, 125, 13-27.

Murcia, C. (1995) Edge effects in fragmented forests: implications for conservation. Trends in Ecology and Evolution, 10, 58-62.

Nathan, R. \& Muller-Landau, H.C. (2000) Spatial patterns of seed dispersal, their determinants and consequences for recruitment. Trends in Ecology and Evolution, 15, 278-285.

Nentwig, W. (1994) Wechselwirkungen zwischen Ackerwildpflanzen und der Entomofauna. Berichte über Landwirtschaft, 209, 123-135.

Nichols, W.N., Killingbeck, K.T. \& August, P.V. (1998) The influence of geomorphological heterogeneity on biodiversity. II. a landscape perspective. Conservation Biology, 12, 371-379.

Östman, Ö., Ekbom, B. \& Bengtsson, J. (2001) Landscape heterogeneity and farming practice influence biological control. Basic and Applied Ecology, 2, 365-371.

Osborne, J.L., Williams, I.H. \& Corbet, S. (1991) Bees, pollination and habitat change in the European Community. Bee World, 72, 98-116.

Palmer, M.W. (1992) The coexistence of species in fractal landscapes. The American Naturalist, 139, 375-397.

Pinheiro, J.C. \& Bates, D.M. (2000) Mixed-effect models in S and S-plus. Springer-Verlag New York, NY, USA.

Potts, S.G., Vulliamy, B., Dafni, A., Ne'eman, G. \& Willmer, P. (2003) Linking Bees and Flowers: How Do Floral Communities Structure Pollinator Communities? Ecology, 84, 2628-2642.

Pyšek, P. \& Lepš, J. (1991) Response of a weed community to nitrogen-fertilization - a multivariate-analysis. Journal of Vegetation Science, 2, 237-244.

Pyšek, P., Jarošík, V., Kropáč, Z., Chytrý, M., Wild, J. \& Tichý, L. (2005) Effects of abiotic factors on species richness and cover in Central European weed communities. Agriculture, Ecosystems and Environment, 109, 1-8. 
R Development Core Team (2004) R: A language and environment for statistical computing. $\mathrm{R}$ Foundation for Statistical Computing, Vienna, Austria. URL http://www.R-project.org.

Ramankutty, N. \& Foley, J.A. (1999) Estimating Historical Changes in Global Land Cover: Croplands From 1700 to 1992. Global Biogeochemical Cycles, 13, 997-1027.

Regal, P.J. (1982) Pollination by wind and animals: Ecology of geographic patterns. Annual Review of Ecology and Systematics, 13, 497-524.

Rew, L.J. \& Cussans, G.W. (1997) Horizontal movement of seeds following tine and plough cultivation: implications for spatial dynamics of weed infestations. Weed Research, 37, 247-256.

Rew, L.J., Froud-Williams, R.J. \& Boatman, N.D. (1996) Dispersal of Bromus sterilis and Anthriscus sylvestris seed within arable field margins. Agriculture, Ecosystems and Environment, 59, 107-114.

Richards, A.J. (1986) Plant breeding systems. Chapman and Hall, New York, USA.

Ricklefs, R.E. (1987) Community diversity: relative roles of local and regional processes. Science, 235, 167-171.

Ricklefs, R.E. (1989) Speciation and diversity - the integration of local and regional processes. In: Speciation and its consequences. (ed by D. Otte, J.A. Endler. Sinauer Associates. Sunderland, MA., 599-624.

Robinson, R.A. \& Sutherland, W. (2002) Post-war changes in arable farming and biodiversity in Great Britain. Journal of Applied Ecology, 39, 157-176.

Roschewitz, I., Gabriel, D., Tscharntke, T. \& Thies, C. (2005a). The effects of landscape complexity on arable weed species diversity in organic and conventional farming. Journal of Applied Ecology, 42, 873-882.

Roschewitz, I., Thies, C., \& Tscharntke, T. (2005b) Are landscape complexity and farm specialisation related to land-use intensity of annual crop fields? Agriculture Ecosystems \& Environment, 105, 87-99.

Rosenzweig, M.L. (2003a) Reconciliation ecology and the future of species diversity. Oryx, 37, 194-205.

Rosenzweig, M.L. (2003b) Win-win ecology: how the earth's species can survive in the midst of human enterprise. Oxford University Press, New York.

Rothmaler, W. (2000) Exkursionsflora von Deutschland. Gefäßpflanzen: Atlasband. Jäger, E.J., Werner, K. (Eds.). Spektrum Akademischer Verlag, Heidelberg - Berlin - New York.

Rypstra, A.L., Carter, P.E., Balfour, R.A. \& Marshall, S.D. (1999) Architectural features of agricultural habitats and their impact on the spider inhabitants. Journal of Arachnology, 27, 371-377.

Salonen, J. (1993) Weed infestation and factors affecting weed incidence in spring cereals in Finland - a multivariate approach. Agricultural Science in Finland, 2, 525-536.

Schmidt, M.H., Roschewitz, I., Thies, C. \& Tscharntke T. (2005) The differential effects of landscape and management on diversity and density of ground-dwelling farmland spiders. Journal of Applied Ecology, 42, 281-287. 
Schneider, Ch., Sukopp, U. \& Sukopp, H. (1994) Biologisch-ökologische Grundlagen des Schutzes gefährdeter Segetalpflanzen. Bundesamt für Naturschutz, Bonn-Bad Godesberg.

Shmida, A. \& Wilson, M.V. (1985) Biological determinants of species diversity. Journal of Biogeography, 12, 1-20.

Silverton, J.W. \& Lovett Doust, J. (1993) Introduction to plant population biology. Blackwell Science, Oxford.

Simmering, D., Waldhardt, R. \& Otte, A. (2001) Zur vegetationsökologischen Bedeutung von scharfen Grenzlinien in Agrarlandschaften - Beispiele aus einer kleinstrukturierten Mittelgebirgslandschaft. Peckiana, 1, 79-87.

Sokal, R.R. \& Rohlf, F.J. (1995) Biometry, 3rd edn. Freeman \& Company, New York.

Sotherton, N.W. (1998) Land use changes and the decline of farmland wildlife: an appraisal of the set-aside approach. Biological Conservation, 83, 259-268.

Southwood, T.R.E. \& Henderson, P.A. (2000) Ecological Methods. Blackwell Science, Oxford.

Statistical Graphics Corp. (2001) Statgraphics Plus Version 5.1.

StatSoft, Inc., (2003) STATISTICA für Windows Version 6. www.statsoft.com.

Steffan-Dewenter, I., Münzenberg, U., Bürger, C., Thies C. \& Tscharntke, T. (2002) Scaledependent effects of landscape structure on three pollinator guilds. Ecology, 83, 14211432.

Steffan-Dewenter, I. \& Tscharntke, T. (1999) Effects of habitat isolation on pollinator communities and seed set. Oecologia, 121, 432-440.

Steffan-Dewenter, I. \& Tscharntke, T. (2001) Succession of bee communities on fallows. Ecography, 24, 83-93.

Stoate, C., Boatman, N.D., Borralho, R.J., Rio Carvalho, C., de Snoo, G.R., \& Eden, P. (2001) Ecological impacts of arable intensification in Europe. Journal of Environmental Management, 63, 337-365.

Summerville, K.S., Boulware, M.J., Veech, J.A. \& Crist, T.O. (2003) Spatial variation in species diversity and composition of forest Lepidoptera in eastern deciduous forests of North America. Conservation Biology, 17, 1045-1057.

Sutcliffe, O.L. \& Kay, Q.O.N. (2000) Changes in the arable flora of central southern England since the 1960s. Biological Conservation, 93, 1-8.

Swanton, C.J., Shrestha, A., Roy, R.C., Ball-Coelho, B.R. \& Knezevic, S.Z. (1999) Effect of tillage systems, $\mathrm{N}$, and cover crop on the composition of weed flora. Weed Science, 47, 454-461.

ter Braak, C.J.F. (1996) Canonical correspondence analysis: a new eigenvector technique for multivariate direct gradient analysis. Ecology, 67, 1167-1179.

Thies, C. \& Tscharntke, T. (1999) Landscape structure and biological control in agroecosystems. Science, 285, 893-895.

Thies, C., Steffan-Dewenter, I. \& Tscharntke, T., (2003) Effects of landscape context on herbivory and parasitism at different spatial scales. Oikos, 101, 18-25.

Thompson, H.M. (2001) Assessing the exposure and toxicity of pesticides to bumblebees. Apidologie, 32, 305-321. 
Thompson, H.M. (2003) Behavioural effects of pesticides in bees - their potential for use and risk assessment. Ecotoxicology, 12, 317-330.

Thompson, K. \& Ceriani, R.M. (2003) No relation between range size and germination niche width in the UK herbaceous flora. Functional Ecology, 17, 335-339.

Thompson, K., Gaston, K.J. \& Band, S.R. (1999) Range size, dispersal and niche breadth in the herbaceous flora of central England. Journal of Ecology, 87, 150-155.

Tilman, D. (1982) Resource competition and community structure. Princeton Univ. Press, Princeton.

Tilman, D., Cassman, K.G., Matson, P.A., Naylor, R., \& Polasky, S. (2002) Agricultural sustainability and intensive production practices. Nature, 418, 671-677.

Townsend, C. R., Harper, J. L., \& Begon, M. E. (2000) Essentials of Ecology. Blackwell Science, UK.

Tscharntke, T., Klein, A. M., Kruess, A., Steffan-Dewenter, I. \& Thies, C. (2005) Landscape perspectives on agricultural intensification and biodiversity - ecosystem service management. Ecology Letters, 8, 857-874.

Turner, M.G. (1989) Landscape ecology: the effect of pattern on process. Annual Review of Ecology and Systematics, 20, 171-197.

van Elsen, T. (2000) Species diversity as a task for organic agriculture in Europe. Agriculture, Ecosystems and Environment, 77, 101-109.

Valone, T.J. \& Hoffman C.D. (2002) Effects of regional pool size on local diversity in small-scale annual plant communities. Ecology Letters, 5, 477-480.

Vandermeer, J., Van Noordwijk, M., Anderson, J., Ong, C. \& Perfecto, I. (1998) Global change and multi-species agroecosystems: concepts and issues. Agriculture, Ecosystems and Environment, 67, 1-22.

Veech, J.A., Summerville, K.S., Crist, T.O. \& Gering, J.C. (2002) The additive partitioning of species diversity: recent revival of an old idea. Oikos, 99, 3-9.

Wagner, H.H., Wildi, O. \& Ewald, K.C. (2000) Additive partitioning of plant species diversity in an agricultural mosaic landscape. Landscape Ecology, 15, 219-227.

Wagner, H.H. \& Edwards, P.J. (2001) Quantifying habitat specificity to assess the contribution of a patch to species richness at a landscape scale. Landscape Ecology, 16, 121-131.

Walter, A. M., Christensen, S. \& Simmelsgaard, S.E. (2002) Spatial correlation between species densities and soil properties. Weed Research, 42, 26-38.

Weibull, A.C., Bengtsson, J. \& Nohlgren, E. (2000) Diversity of butterflies in the agricultural landscape: the role of farming system and landscape heterogeneity. Ecography, 23, 743-750.

Weibull, A.C., Östman, Ö. \& Granqvist, Å. (2003) Species richness in agroecosystems: the effect of landscape, habitat and farm management. Biodiversity and Conservation, 12, 1335-1355.

Whitehead, D.R. (1968) Wind pollination in the angiosperms: evolutionary and environmental considerations. Evolution, 23, 28-35. 
Wiegand, T., Moloney, K.A., Naves, J. \& Knauer, F. (1999) Finding the missing link between landscape structure and population dynamics: a spatially explicit perspective. The American Naturalist, 154, 605-627.

Wilson, P.J. \& Aebischer, N.J. (1995) The distribution of dicotyledonous weeds in relation to distance from the field edge. Journal of Applied Ecology, 32, 295-310.

Wisskirchen, R. \& Haeupler H. (1998) Standardliste der Farn- und Blütenpflanzen Deutschlands. Ulmer, Stuttgart.

Zobel, M. (1997) The relative role of species pools in determining plant species richness: an alternative explanation of species coexistence? Trends in Ecology and Evolution, 12, 266-269. 


\section{Summary}

During the last decades increasing agricultural intensification in Europe has led to a decrease in species richness and a change in species composition of arable weeds. The drivers of these diversity losses operate at various spatial scales. At the landscape and regional scale, farm enlargement and specialization on a narrow range of arable crops, abandonment of areas with marginal crop yields and land consolidation has led to simplified agricultural landscapes and a decrease in spatial heterogeneity over vast areas. At the local field and farm scale an intensification in crop management techniques has taken place involving the increased use of herbicides and fertilizers and a simplification of crop rotations.

The aim of this study was to examine the effects of landscape complexity (i.e. simple vs. complex landscapes) and local management (i.e. organic vs. conventional farming) on arable weed communities with particular focus on species richness, temporal and spatial species turnover (i.e. $\beta$-diversity), and community structure.

The study was conducted in three agricultural regions in Germany: Leine Bergland (Lower-Saxony), Soester Boerde (North-Rhine Westphalia), and Lahn-Dill Bergland (Hesse). To examine landscape effects, in each region circular landscape sectors were selected along a gradient of landscape complexity ranging from structurally simple landscapes, with a high percentage of arable land, to structurally complex landscapes with a high percentage of semi-natural habitats, such as grasslands, hedges, fallows, and field margins. In the centre of each landscape, arable weed species were recorded within either one focal conventional field or within a pair of one organic and one conventional field.

Both landscape complexity and local management influenced arable weed communities. Local species richness of arable weeds was strongly enhanced by landscape complexity in conventional fields, and to a lesser extent in organic fields. This landscape effect is likely due to a larger species pool in complex landscapes since they provide many disturbed habitats for arable weeds such as fallows, road verges and field margins, thereby enhancing the probability of propagule immigration into local fields. In a comparative analysis of landscape sectors of different diameter ranging from $1 \mathrm{~km}$ up to $5 \mathrm{~km}$, the predictive power of landscape complexity for local arable weed species richness was strongest at $2 \mathrm{~km}$. This indicated a scale-dependent relationship between landscape context and local species richness, suggesting a functional scale at which the existence of potential source habitats and processes like seed dispersal interact over time. A three-year study revealed that interannual variation in arable weed communities appeared to be mediated by landscape effects, as $\beta$-diversity (i.e. temporal species turnover) increased with increasing landscape complexity, and community similarity among years was high in simple but low in complex landscapes. The high temporal heterogeneity in arable weed communities appeared to be related to the plant's niche breadths in response to differing weather conditions since 
species occurring predominately in complex landscapes were generally less frequent than those in simple landscapes. Rarer species may have smaller niche breadths and increased sensitivity to changing conditions, which would explain the high inter-annual heterogeneity in plant communities observed in complex compared to simple landscapes.

Organic fields had a greater species richness and a higher spatial species turnover (i.e. $\beta$-diversity) than conventional fields. Differences in species numbers among farming systems were most strongly pronounced in simple landscapes. An evaluation of the relative contribution of $\beta$-diversity at three spatial scales (i.e. plot, field, region) to total observed species richness revealed that $\beta$-diversity at the field and regional scale explained most of the overall species richness, indicating considerable differences in community composition among fields and regions due to environmental heterogeneity. In addition to the general positive effect of organic farming on plant diversity, insect pollinated plants benefited disproportionately from organic farming, which appeared to be related to higher pollinator densities in organic fields, whereas in conventional fields non-insect pollinated plants dominate presumably due to a limitation of pollinators.

These results show that both complex landscapes and organic farming are of major importance for community patterns, enhancing species richness and temporal and spatial species turnover (i.e. $\beta$-diversity) of arable weeds. Hence, maintenance and enhancement of arable weed diversity requires a multi-scale perspective, incorporating both regional and local aspects. The landscape-wide agricultural intensification threatens the continuity of complex landscapes. High densities of field edges and semi-natural habitats in landscapes can act as refuges for many arable weed species and should therefore be preserved. At the same time, conservation strategies should aim to promote organic farming in simple landscapes due to the greater enrichment of diversity there compared to conventional farming. In addition, conservation areas should be selected with a maximum dissimilarity in abiotic and biotic site conditions to take advantage of the high spatial species turnover in arable weed communities among fields and regions. 


\section{Zusammenfassung}

In den letzten Jahrzehnten hat eine zunehmende Intensivierung der Landnutzung zu einem Artenrückgang und tiefgreifenden Veränderungen in der Zusammensetzung von Ackerwildpflanzengesellschaften geführt. Als Ursachen für diese Veränderungen sind landwirtschaftliche Rationalisierungs- und Intensivierungsmaßnahmen zu nennen, die auf verschieden räumlichen Skalen abliefen. Auf der regionalen Ebene haben Flurbereinigungsmaßnahmen, das Beseitigen von Hecken und Feldrändern und die Aufgabe von Grenzertragsstandorten zu einer Simplifizierung unserer Kulturlandschaft geführt. Auf lokaler Ebene hat eine Intensivierung der Bewirtschaftungsmaßnahmen stattgefunden, insbesondere durch Zunahme des Herbizid- und Düngemitteleinsatzes und Einengung der Fruchtfolgen.

In dieser Arbeit wurde die Bedeutung von Landschaftsstruktur (strukturreich vs. strukturarm) und lokaler Bewirtschaftungsweise (ökologisch vs. konventionell) für Ackerwildpflanzengemeinschaften mit besonderem Hinblick auf den lokalen Artenreichtum, den zeitlichen und räumlichen Artenwechsel ( $\beta$-Diversität) und die Zusammensetzung der Ackerwildpflanzengesellschaften analysiert.

Die Untersuchungen fanden in drei landwirtschaftlich geprägten Regionen statt: im Südniedersächsischen Berg- und Hügelland (Niedersachsen), in der Soester Börde (Nordrhein-Westfalen) und im Lahn-Dill-Bergland (Hessen). In jeder Region wurden Landschaften entlang eines Gradienten von einfach strukturierten Landschaften, die von annuellen Feldkulturen dominiert sind, bis hin zu strukturreichen Landschaften mit einem hohen Flächenanteil perennierender Lebensräume wie beispielsweise Brachen, Hecken, Feldrainen und Grünland ausgewählt. Im Zentrum jeder Landschaft wurden Ackerwildpflanzen entweder auf einer konventionell bewirtschafteten oder auf zwei nah zueinander liegenden ökologisch und konventionell bewirtschafteten Winterweizenflächen kartiert.

Sowohl die Landschaftsstruktur als auch die Bewirtschaftungsweise beeinflussten die Ackerwildpflanzengemeinschaften. Der lokale Artenreichtum stieg mit zunehmender Landschaftskomplexität besonders in konventionellen Feldern, und weniger steil in ökologischen Feldern an. Der Landschaftseffekt kann mit einem höheren Artenpool in strukturreichen Landschaften in Verbindung gebracht werden, da diese viele gestörte Habitate aufweisen, die Refugien für Ackerwildpflanzenpopulationen darstellen. Ferner zeigte sich in einer vergleichenden Analyse, bei der die Landschaftsstruktur auf größer werdenden Radien quantifiziert wurde, dass der lokale Artenreichtum am besten durch die Landschaft in $1 \mathrm{~km}$ Umgebung erklärt wird. Dies deutet auf eine ökologisch-funktionelle Skala hin, auf der Prozesse wie Samenverbreitung über einen langen Zeitraum stattfinden könnten. Eine Drei-Jahres-Studie zeigte darüber hinaus, dass die Heterogenität der Pflanzengemeinschaften ( $\beta$-Diversität) zwischen den Jahren in strukturreichen 
Landschaften größer war als in einfach strukturierten Landschaften. Der temporäre Artenwechsel in Ackerwildpflanzengesellschaften kann mit der artspezifischen ökologischen Nischenbreite als Reaktion auf unterschiedliche klimatische Bedingungen in Verbindung gebracht werden. Arten, die überwiegend in strukturreichen Landschaften vorkamen, waren im Mittel weniger häufig als Arten, die überwiegend in einfach strukturierten Landschaften vorkamen. Seltene Arten haben engere ökologische Nischen und reagieren damit sensibler auf von Jahr zu Jahr veränderte Umweltbedingungen.

Ökologisch bewirtschaftete Felder wiesen gegenüber konventionellen Feldern einen höheren lokalen Artenreichtum und einen höheren räumlichen Artenwechsel auf. Diese Unterschiede waren in einfach strukturierten Landschaften besonders deutlich. Eine Quantifizierung der $\beta$-Diversität auf verschiedenen räumlichen Skalenebenen (Plot, Feld, Region) zeigte, dass $\beta$-Diversität auf der Ebene von Feldern und Regionen den größten Beitrag zum Gesamtartenreichtum leistet, was auf eine hohe Bedeutung der unterschiedlichen abiotischen und biotischen Bedingungen zwischen den Feldern und Regionen hindeutet. Ökologisch bewirtschaftete Felder wiesen außerdem einen höheren Anteil an insektenbestäubten Ackerwildpflanzenarten auf, was mit einer höheren Bestäuberdichte in ökologisch bewirtschafteten Feldern in Verbindung gebracht werden kann, wohingegen in konventionellen Feldern selbstbestäubte Pflanzenarten dominierten.

Diese Ergebnisse zeigen, dass sowohl strukturreiche Landschaften also auch ökologischer Landbau von großer Bedeutung für Ackerwildpflanzengesellschaften sind und dabei insbesondere den lokalen Artenreichtum und den zeitlichen und räumlichen Artenwechsel fördern. Der Erhalt und die Förderung von Ackerwildpflanzen erfordert Maßnahmen auf verschieden räumlichen Skalen, bei denen lokale und regionale Aspekte berücksichtigt werden. Dem voranschreitenden Landschaftswandel sollte entgegengewirkt werden, da eine hohe Dichte an Feldrändern und naturnahen Habitaten in Landschaften als Refugium für viele Ackerwildpflanzen dienen kann. Gleichzeitig sollte der ökologische Landbau besonders in einfach strukturierten Landschaften gefördert werden, da dort der höchste Artenzuwachs gegenüber konventioneller Bewirtschaftung erzielt wird. Bei der Auswahl von geeigneten Gebieten sollte ferner auf eine große Unterschiedlichkeit hinsichtlich abiotischer und biotischer Eigenschaften der Flächen geachtet werden, um somit einen hohen Artenwechsel zwischen Feldern und Regionen auszuschöpfen. 


\section{Acknowledgements}

First, I want to express my grateful thanks to my supervisor Prof. Dr. Teja Tscharntke for being my advisor and mentor and providing ideas, constructive feedback, continual support and encouragement throughout the years. I wish to acknowledge Prof. Dr. Bärbel Gerowitt for co-reviewing my thesis.

My gratitude also goes to Dr. Carsten Thies, who supported and guided me during the planning and writing of proposals and manuscripts. I thank Dr. Tatyana Rand for her patient support in many English questions, discussing the manuscripts and providing a nice atmosphere in the office. With Dr. Indra Roschewitz I had a nice collaboration in the field and publication work. I thank Dr. David Kleijn and Yann Clough for involving me in their interesting overview papers on the EASY project.

This work was embedded in the BIOPLEX and EASY project. I thank all the people who were involved in the projects and made good collaborations possible, in particular Yann Clough, Dr. Jens Dauber, Andrea Holzschuh, Dr. Tobias Purtauf, Dr. Martin Schmidt and Dr. Carsten Thies. Many thanks to the farmers for their willingness to participate.

Special thanks also to my pre-reviewers Prof. Dr. Jan Bakker, Dr. Jens Dauber, Dr. Erica Fleishman, Dr. Terho Hyvönen, Dr. David Kleijn, Dr. Jochen Krauss, Dr. Ingolf Kühn, Dr. Jaan Liira, Dr. Jon Marshall, Dr. Tobias Purtauf, Dr. Tatyana Rand, Dr. Martin Schmidt, Jason Tylianakis, Prof. Dr. Thomas Valone, Dr. Helene Wagner, and Prof. Dr. Kerstin Wiegand, and many anonymous referees, who improved the manuscripts with their critical questions, feedback and helpful suggestions.

Prof. Dr. Joachim Saborowski, Dr. Katja Poveda, Dr. Sabine Eber and Yann Clough thank you very much for interesting discussions, advice, and courses in statistics and R-Project. Dr. Christof Bürger introduced me to Geographic Information Systems. Susanne Schiele helped in various ways and Friedrich Sundmacher with computer problems.

Financial support came from the „Niedersächsischen Graduierenförderung“ in the form of a PhD scholarship and from the Association of Applied Ecologists, the Unibund Göttingen and the German Research Foundation (DFG) in the form of travelling grants. 
I thank all my colleagues in the Agroecology group for the very nice and constructive atmosphere, which goes far beyond the scientific aspects. Special thanks to Dr. Katja Poveda, Dr. Indra Roschewitz, Dr. Catrin Westphal and Barbara Scheid.

Finally, I would like to say 'thank-you' to all my friends, for making me enjoy other aspects of life, my mother for her support and steady optimism, and Jens for encouragement and support in both personal and scientific regards.

Thank you all! 


\section{List of publications}

Gabriel D, Rand TA \& Tscharntke T. Landscape context mediates inter-annual variability in arable weed communities. Journal of Biogeography (submitted).

Gabriel D, Roschewitz I, Tscharntke T \& Thies C. Relative importance of beta diversity at different spatial scales - plant communities in organic and conventional agriculture. Ecological Applications (in review).

Gabriel D \& Tscharntke T. Insect pollinated plants profit from organic farming. Agriculture, Ecosystems and Evironment (in review).

Clough Y, Holzschuh A, Gabriel D, Purtauf T, Kleijn D, Kruess A, Steffan-Dewenter I, \& Tscharntke T. Alpha and beta diversity responses to crop management differ between species groups. (submitted).

Kleijn D, Baquero RA, Clough Y, Díaz M, De Esteban J, Fernández F, Gabriel D, Herzog F, Holzschuh A, Jöhl R, Knop E, Kruess A, Marshall EJP, Steffan-Dewenter I, Tscharntke T, Verhulst J, West TM \& Yela JL. Mixed biodiversity benefits of agrienvironment schemes implemented in contrasting European countries. Ecology Letters (in press).

Gabriel D, Thies C \& Tscharntke T (2005). Local diversity of arable weeds increases with landscape complexity. Perspectives in Plant Ecology, Evolution and Systematics 7: 8593.

Roschewitz I, Gabriel D, Tscharntke T \& Thies C (2005). The effects of landscape complexity on arable weed species diversity in organic and conventional farming. Journal of Applied Ecology 42: 873-882.

Gabriel D, I Roschewitz, Thies C \& Tscharntke T (2004). Diversity components of arable weeds in organic and conventional wheat fields - a multi-scale approach.

Verhandlungen der Gesellschaft für Ökologie 34: 183.

Gabriel D, Thies C \& Tscharntke T (2003). Variability of site and landscape metrics at different spatial scales. Verhandlungen der Gesellschaft für Ökologie 33: 84.

Gabriel D, Thies C \& Tscharntke T (2002). Scale-dependent effects of landscape structure on plant diversity in cereal fields. Verhandlungen der Gesellschaft für Ökologie 32: 358.

Gabriel D, Emmerich D, Brunsiek F, Tscharntke T \& Thies C (2001). Biodiversität bei verschiedenen Wirtschaftsweisen im Ackerbau. In: Formen der modernen Landwirtschaft im Vergleich. Universitätsdruckerei, Göttingen. Heft 10: 17-27. 


\section{Curriculum vitae}

Doreen Gabriel

born 30.07.1976 in Halle/Saale

2002 - 2006 PhD Study at the Department of Agroecology, Georg-AugustUniversity Göttingen, under the supervision of Prof. Dr. Teja Tscharntke

„Plant communities in organic and conventional agriculture comparing local, landscape and regional effects“"

Funded by a "Promotionsstipendium nach dem niedersächsischen

Graduiertenförderungsgesetz von 17.11.1984 - Nds. GVBI. S. 257“

1997 - 2002 Masters Study in Agricultural Sciences at the Georg-AugustUniversity Göttingen

Main focus: "Resource management"

Master thesis (2001 - 2002) at the Department of Agroecology, Georg-August-University Göttingen, under the supervision of Prof. Dr. Teja Tscharntke

„Species richness of arable weeds in landscapes of different complexity - GIS based analyses“

Erasmus Exchange Study (1998 - 1999) at the University of Nottingham, Great Britain

1995 - 1997 Undergraduate Studies at the Martin-Luther University HalleWittenberg

1991 - 1995 School, Novalis-Gymnasium Bad Dürrenberg, Graduation (Abitur)

1983 - 1991 School, Friedrich-Engels Oberschule Bad Dürrenberg 